\title{
A INOVAÇÃO FRUGAL E A CAPACIDADE DE CONHECIMENTO ABSORVIDO NAS UNIVERSIDADES
}

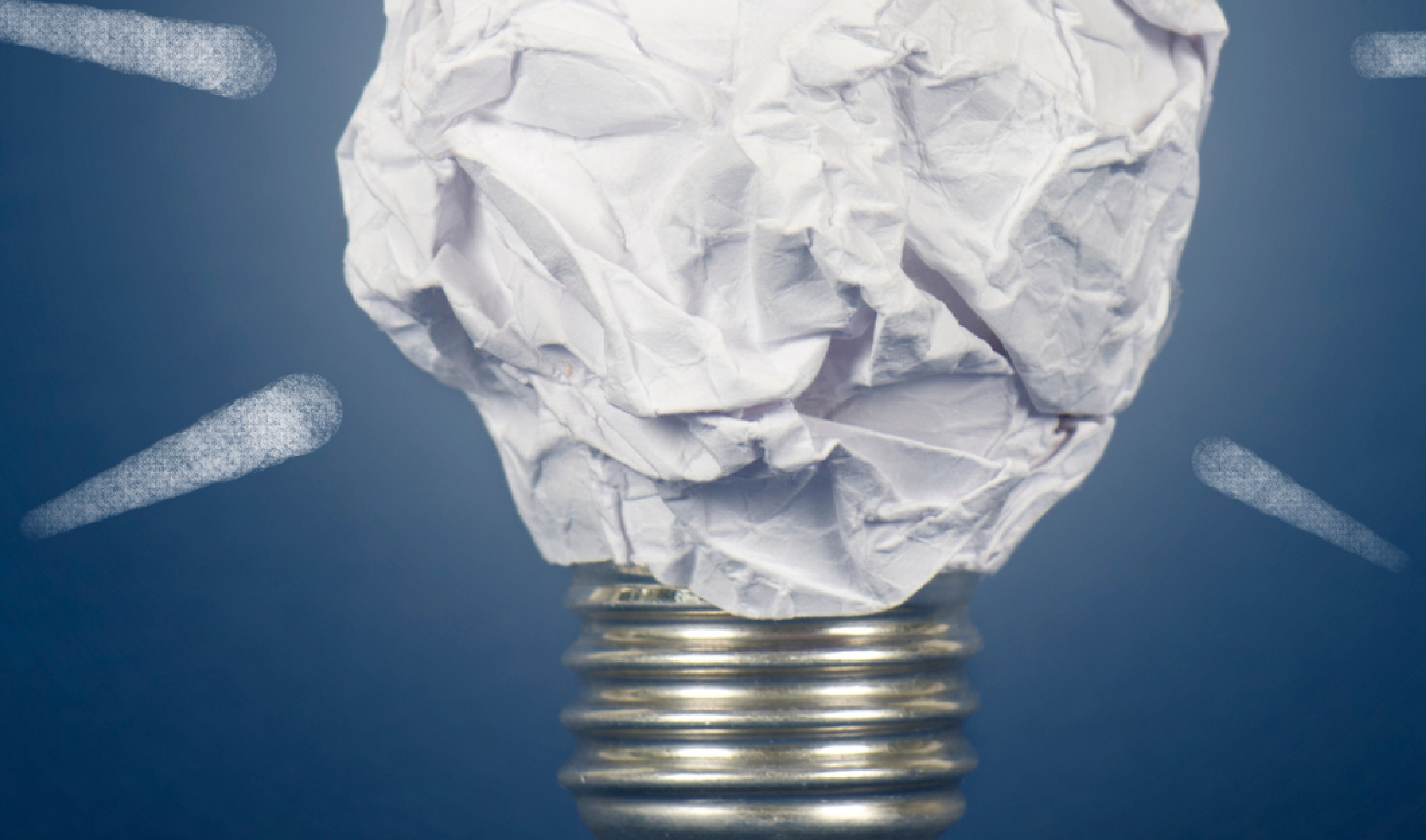

Denise Adriana Johann Luis Felipe Dias Lopes Claudete Correa Dos Santos Erick William Pereira
André Munzlinger Valéria Wisniewski Padilha Israel Braian da Silva Silva Ricardo Alberti 
DENISE ADRIANA JOHANN

Luis Felipe Dias Lopes

Claudete Correa Dos Santos

Erick William Pereira

André Munzlinger

Valéria Wisniewski Padilha

Israel Braian da Silva Silva

Ricardo Alberti

A INOVAÇÃO FRUGAL E A CAPACIDADE DE CONHECIMENTO ABSORVIDO NAS UNIVERSIDADES

$1^{\text {a }}$ ed.

Piracanjuba-GO

Editora Conhecimento Livre

Piracanjuba-GO 
$1^{\mathrm{a}} \mathrm{ed}$

\section{Dados Internacionais de Catalogação na Publicação (CIP)}

JOHANN, DENISE ADRIANA

J34A A INOVAÇÃO FRUGAL E A CAPACIDADE DE CONHECIMENTO ABSORVIDO

\section{NAS UNIVERSIDADES}

/ DENISE ADRIANA JOHANN. Luis Felipe Dias Lopes. Claudete Correa Dos Santos. Erick William Pereira. André Munzlinger. Valéria Wisniewski Padilha. Israel Braian da Silva Silva.

Ricardo Alberti. - Piracanjuba-GO

Editora Conhecimento Livre, 2021

80 f.: il

DOI: $10.37423 / 2021$.edcl337

ISBN: 978-65-89955-61-0

Modo de acesso: World Wide Web

Incluir Bibliografia

1. inovação-frugal 2. capacidade-de-conhecimento 3. universidade I. JOHANN, DENISE

ADRIANA II. Lopes, Luis Felipe Dias III. Santos, Claudete Correa Dos IV. Pereira, Erick William V. Munzlinger, André VI. Padilha, Valéria Wisniewski VII. Silva, Israel Braian da Silva VIII. Alberti, Ricardo IX. Título

CDU: 658

https://doi.org/10.37423/2021.edc1337

O conteúdo dos artigos e sua correção ortográfica são de responsabilidade exclusiva dos seus respectivos autores. 


\title{
EDITORA CONHECIMENTO LIVRE
}

\section{Corpo Editorial}

\author{
Dr. João Luís Ribeiro Ulhôa \\ Dra. Eyde Cristianne Saraiva-Bonatto \\ Dr. Anderson Reis de Sousa \\ MSc. Frederico Celestino Barbosa \\ MSc. Carlos Eduardo de Oliveira Gontijo
}

$\underline{\text { MSc. Plínio Ferreira Pires }}$

Editora Conhecimento Livre

Piracanjuba-GO 
A INOVAÇÃO FRUGAL E A CAPACIDADE DE CONHECIMENTO ABSORVIDO NAS UNIVERSIDADES
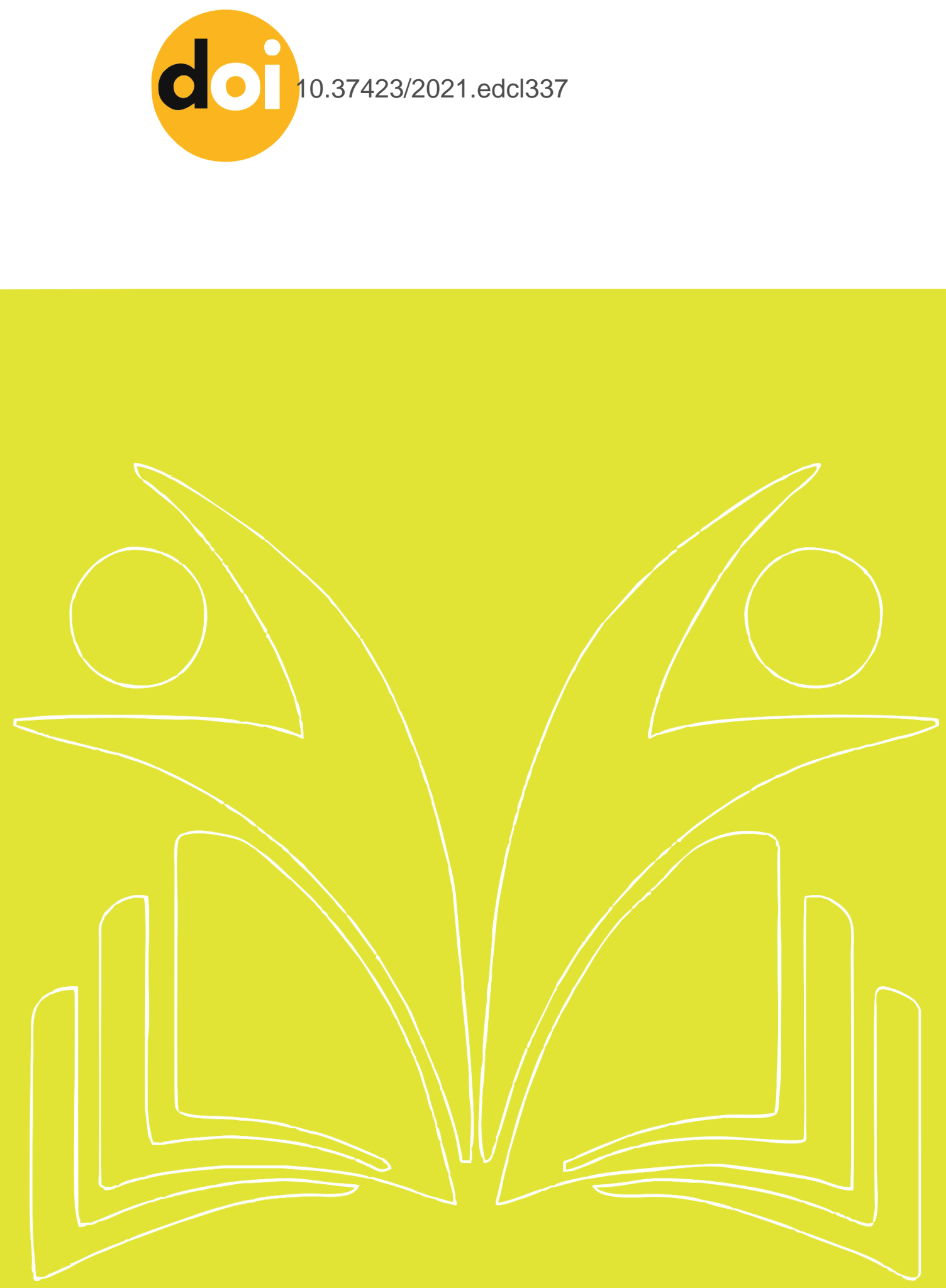
Resumo: 0 conhecimento tem sido força motriz desde os primórdios, da evolução do homem à civilização, e tem sido considerado propulsor da economia, além de acelerar o ritmo da inovação, que surge diante da exploração e renovação contínua de conhecimentos (JIMÉNEZ; COSTA; VALLE, 2014; MOUSTAGHFIR; SCHIUMA, 2013). Neste cenário, o conhecimento se tornou um valor, e as universidades são reconhecidas por sua promoção, aliada ao progresso científico (ATKINSON; BLANPIED, 2008).

A maior parte do conhecimento é produzida nas universidades, sendo que esta instituição ocupa lugar central no mundo do conhecimento, seu perfil decorre da expectativa da sociedade de que a universidade desempenhe seu papel no desenvolvimento e crescimento regional, sustentando a competitividade da economia (LEYDESDORFF; ETZKOWITZ, 1996; OLIVEIRA; MORAES, 2016).

Dadas constantes e dinâmicas transformações, a sociedade tem se tornado dependente cada vez mais da capacidade de capital intelectual para o crescimento e desenvolvimento econômico e social (QUANDT; BEZERRA; FERRARESI, 2015). Dessa forma, para a sobrevivência das economias modernas baseadas em conhecimento, é necessária a presença de atores inovadores em seu sistema, dentre eles, as universidades.

Aliado a esses fatores, o crescimento acelerado da população do planeta desperta preocupação e, alerta aos desafios encontrados em todas as cadeias de produção, nesse sentido, oferecer tecnologia de alta qualidade e custo baixo passou a ser estudada por diversas economias, uma vez que a tecnologia pode reduzir os custos (KUNAMANENI, 2018; RAO, 2017).

Conforme Prabhu (2017), a economia global enfrentará grandes desafios nas próximas décadas em termos de atender às necessidades de sete bilhões de pessoas, incluindo as necessidades básicas atuais não satisfeitas nos países em desenvolvimento. Atingir esse crescimento com recursos disponíveis pode ser um dos desafios para as economias emergentes. O setor empresarial, absorvido pela globalização e pela disputa por mercado, tem demonstrado expectativas em programas desenvolvidos pelas universidades por serem consideradas fontes de geração de inovação tecnológica. Desta forma, o setor empresarial espera que estas entreguem para a sociedade geração de conhecimento voltado à inovação em produtos, processos e gestão, tornando as empresas mais competitivas globalmente. Assim, pesquisadores poderão contribuir com o desenvolvimento tecnológico na atividade empresarial brasileira e, mais ainda, diminuir as barreiras nas interações entre as universidades e as empresas (BRASIL, 1996; LOUSADA; TEIXEIRA; MACCARI, 2014). 
Nesse sentido, Cohen e Levinthal (1990) explicam que a área Pesquisa e Desenvolvimento (P\&D) gera novos conhecimentos e contribui para o desenvolvimento da capacidade absortiva da empresa. Além disso, os autores estudaram a capacidade de absorção no que se refere à inovação no nível organizacional e identificaram que o conceito de capacidade de absorção é baseado em nível individual.

Nessa perspectiva, para que os programas de pós-graduação ampliem seus trabalhos, se faz necessário observar a forma como esse conhecimento, interno e externo, é utilizado como melhoria para a inovação e desempenho das pesquisas, assim, compreende-se que uma lente adequada para tal análise é a Teoria de Capacidades Dinâmicas de absorção (TEECE, 2007, 2014; TEECE; PISANO; SHUEN, 1990, 1997).

Compreendendo essa importância, estudos na literatura relatam casos de empreendedorismo e inovação considerados agentes de crescimento e desenvolvimento, por sua capacidade de fomentar mudanças econômicas e gerar emprego e renda (DRUCKER, 2016). Assim, na visão schumpeteriana a inovação é sugerida como uma atividade empreendedora que realiza novas combinações, onde indivíduos inovadores podem trazer mudanças sustentáveis, através da destruição criativa para determinados mercados, onde a exploração de uma ideia ou invenção é denominada inovação (ELIA et al., 2016; SCHUMPETER, 1934).

Para corroborar, pesquisas apontam duas importantes fontes de competitividade, a capacidade de absorção de conhecimento e a inovação. A capacidade de absorção desenvolve o capital humano, que é considerado um recurso valioso, raro, difícil de imitar e de substituir. Já, a inovação é primordial na construção da vantagem competitiva em resposta as rápidas e constantes mudanças ambientais ( DUH, 2013). Por outro lado, sabe-se que as inovações tem um papel importante na solução de problemas, levando ao resultado socioeconômico desejado, no entanto, a escassez de recursos implica os processos de inovação que trabalham em torno da complexidade e da frugalidade (PARWEZ, 2014).

Entre os diferentes tipos de inovação, tem-se a inovação frugal, que conforme Khan (2016) será chave central no futuro da gestão da inovação, com capacidade de proporcionar um novo caminho para as empresas. The Economist (2010) argumenta que a inovação frugal veio para quebrar todas as regras. Já, Tiwari e Herstatt (2012) acreditam que todas as soluções frugais são caracterizadas pela acessibilidade, robustez, facilidade de uso, escalabilidade adicionadas a uma proposta de valor competitiva. 
Corroborando, Agarwal e Brem (2017) pontuam que a perspectiva de frugalidade ultrapassa o foco no produto ou serviço, é elencada como uma mentalidade, ou um modo de vida. As economias desenvolvidas são desafiadas por certa frugalidade e não há dúvida de que a pesquisa acadêmica ocupa um papel importante, sendo que diversas pesquisas tem impulsionado setores da cadeia produtiva (WEISS; CATTANEO, 2017).

Diante disso, tem havido um aumento no interesse pela inovação frugal, o conceito de fazer mais com menos permitiu que mercados emergentes passassem a acessar segmentos de mercado inexplorados (RADJOU; PRAHBU, 2014; GOVINDARAJAN; TRIMBLE, 2012). 


\section{CAPÍTULO I-REVISÃO DE LITERATURA}

A revisão da literatura sugere uma relação de complementaridade entre a capacidade de absorção de conhecimentos e a inovação, mas que ainda é pouco explorada pelos pesquisadores (SPITHOVEN et al., 2010). Tsai (2001) pontua em sua pesquisa que a capacidade de absorção afeta de forma positiva e significativa a inovação de uma organização. Quanto maior a capacidade de absorção maior serão as chances de aplicação de novos conhecimentos e consequentemente a produção de produtos ou serviços inovadores (TSAI, 2001). Nesse mesmo sentido, Spithoven et al. (2010) afirmam que a capacidade de absorção é uma condição para o desenvolvimento de uma inovação.

Escribano et al. (2009) ressaltam que a inovação é oriunda de novos conhecimentos gerados através de um processo cíclico e cumulativo de conhecimento, onde o conhecimento é adicionado, excluído, modificado, transformado ou então reinterpretado. A partir de uma perspectiva de desenvolvimento e crescimento social, intelectual e econômico, pode-se ver a inovação como um ciclo em constante movimento, onde a produção, adoção, assimilação e exploração de conhecimento, são valores agregados ao processo (CROSSAN; APAYDIN, 2010).

Latouche (2010) aponta para a importância do surgimento de uma sociedade de abundância frugal, mais tarde Radjou e Prabhu (2014) buscam essa promoção utilizando a estratégia de inovação frugal.

Uma característica comum em processos de inovação bem-sucedidos é a ligação entre a empresa e as fontes de conhecimento fora da empresa, incluindo pesquisadores e universidades (LI et al., 2016). Sendo assim, a educação universitária é considerada ferramenta fundamental para a formação e desenvolvimento do capital intelectual, fator relevante de produção na economia moderna, onde as Instituições de Ensino Superior (IES) atuam nesse cenário como organizações orientadas para a criação, transmissão e disseminação do conhecimento (BHARDWAJ, 2015).

Portanto, o cenário descrito assinala para a necessidade de mais pesquisas, em diferentes contextos e com maiores perspectivas conceituais, a fim de se consolidar as descobertas no campo, e para isto, o instrumento utilizado nesta pesquisa é composto por quatro dimensões voltadas a inovação: a inovação aberta, inovação sustentável, inovação em custos e inovação de produtos.

Ainda foi constatada a importância da absorção do conhecimento para o desenvolvimento de pesquisas voltadas a inovação. A compreensão da dinâmica da absorção do conhecimento é necessária, pois a maneira como os pesquisadores dos grupos de pesquisas das universidades aprendem, combinam e aplicam o conhecimento gera ciência, tecnologia e consequentemente 
inovação. Dessa forma, conhecer esta relação com maior profundidade, principalmente a forma como o conhecimento é percebido e assimilado por pesquisadores, torna-se, neste estudo, aspecto fundamental para a compreensão de como ocorrem tais relações.

Dada a importância do conhecimento gerado e adquirido nas universidades é relevante compreender a forma como os estudantes absorvem, assimilam e aplicam esse conhecimento, já que estes atuam no mercado ou serão os profissionais do amanhã, um cenário que se apresenta carente de inovações que atendam lacunas de demandas ainda inexploradas. Conforme Oliveira e Moraes (2016), visando atender as mais diversas e complexas demandas as universidades, além do compromisso e responsabilidade social na formação de mestres e doutores, assumem também grandes desafios impostos missão de difundir conhecimento e contribuir com novas tecnologias provindas de pesquisas.

Para complementar, o Manual de Oslo (2018) destaca o pesquisador como peça fundamental nos trabalhos de Pesquisa e Desenvolvimento (P\&D). Nesse sentido, a universidade é a instituição que possui infraestrutura de pesquisa e também o conhecimento científico intrínseco à inovação, considerando ainda, que mais da metade da riqueza gerada nos países industrializados ocorre tendo como base a inovação (MAY, 2013; OECD, 2010).

Assim, ao coordenar as capacidades dinâmicas permite-se a criação de novos produtos e processos, respondendo as rápidas mudanças do mercado e suas constantes demandas (YILDIZ, 2019). Diversos estudos encontrados relacionam a frugalidade à inovação reversa e inovação sustentável, e ainda destaca apenas trabalhos com a temática inovação para a base da pirâmide, demonstrando um gap teórico para as demais demandas a serem abordadas, devido a relevância e crescente aumento no número de pesquisas existentes no contexto internacional.

Nas bases de dados Web of Science (WoS) e Scopus (CAPES, 2019; 2020; 2021), não foram encontradas publicações com as temáticas frugal innovation em alunos de pós-graduação no contexto brasileiro. Observa-se que mesmo com crescente aumento no meio acadêmico por busca na temática, a mesma ainda não é explorada no contexto acadêmico, visto a importância da disseminação de sua importância aos jovens, a futura mão de obra do país.

Esse estudo se dá por sua notável importância para o desenvolvimento da ciência e inovação impulsionando a economia nacional. Destaca-se ainda a representatividade deste universo repleto de amostras para pesquisas, aliado a relevância da economia do conhecimento estar atrelada aos cursos 
de pós-graduação, quanto a sua capacidade de gerar, disseminar e aplicar o conhecimento (O'SHEA et al., 2005).

A importância deste estudo vem também ao encontro da ideia de Cohen e Levinthal (1990), que consideram um fator crítico das capacidades inovadoras, a capacidade de explorar conhecimento externo, e acrescentam que além das habilidades básicas, a busca por novos conhecimentos através ciência e tecnologia são fundamentais para a inovação.

Para que o processo de inovação se consolide é necessário que haja criação de valor, já que inovação pode ser medida através de indicadores voltados aos níveis do esforço empregado através de recursos alocados para a inovação e da realização, ou seja, a introdução de produtos e processos novos ou melhorados (HOOKER; ACHUR, 2014). O que justifica analisar a teoria de capacidades dinâmicas de absorção, visto que, visam adquirir, assimilar, transformar e explorar conhecimento, com os objetivos de construir e manter o desempenho competitivo, de adaptar-se a ambientes turbulentos, e se possível, de modificar o meio ambiente organizacional (TEECE, 2007; 2014).

Salienta-se que o instrumento de inovação frugal validado por Silva, Itiel (2018) no contexto organizacional e por Bresciani et al. (2020) no contexto acadêmico, abrange de forma ampla quatro dimensões da inovação (inovação aberta; inovação sustentável; inovação em custo; inovação em produto), enquanto o instrumento de capacidade absortiva aborda quatro dimensões do construto conhecimento (capacidade de aquisição; capacidade de assimilação; capacidade de transformação e capacidade de exploração), validado na contexto acadêmico por Silva, Eduardo et al. (2016).

Sob esse enfoque, o cenário aqui descrito busca contribuir para minimizar esse compreender essa lacuna científica, buscando encontrar e oferecer esclarecimentos que envolvem os temas: capacidade absortiva individual e inovação frugal, buscando explicar se existe esta relação nos estudantes de pósgraduação.

\section{REVISÃO SISTEMÁTICA DE LITERATURA}

Foi realizado um estudo bibliométrico, para isso foram definidos o seguinte termos de busca: inovação frugal (Frugal Innovation). As buscas foram realizadas no mês de agosto de 2020 no Portal de Periódicos da Capes, nas bases de dados da Web of Science (WoS) e Scopus, com os termos no idioma inglês. Já, no segundo momento foi realizada a busca com termos em idioma português, na base de dados da Biblioteca Digital Brasileira de Teses e Dissertações (BDTD). Os objetivos foram, primeiramente, mapear o cenário mundial, localizando países, áreas de publicação, autores e a 
evolução das temáticas de IF. O resultado geral encontra- se na Tabela 1. Em segundo, as buscas das publicações foram importantes para a realização da revisão de literatura sobre as temáticas propostas neste estudo.

Tabela 1 - Resultado da pesquisa biblilométrica de IF

\begin{tabular}{l|c}
\multicolumn{1}{c|}{ Bases } & Inovação Frugal \\
\hline Biblioteca Digital Brasileira de Teses e Dissertações & 7 \\
Web of Science & 306 \\
Scopus & 396 \\
\hline Total & 709 \\
\hline
\end{tabular}

Fonte: Capes e BDTD (2020).

Na base Scopus foi utilizado o termo frugal innovation e foi encontrado o total de 396 publicações no período de 2010 a agosto de 2020 e não foram utilizados filtros para os demais resultados, ou seja, por se tratar de uma pequena quantidade encontrada, foram considerados todos os formatos de documentos. Já, na base WoS a busca foi da temática de frugal innovation, delimitada entre os anos de 2010 a agosto de 2020 foram encontrados o total de 306 publicações. Na BDTD a busca foi realizada com as palavras -inovação frugal de forma conjunta, logo encontrou-se 7 estudos, destes 3 teses de doutorado e 4 dissertações de mestrado, defendidas nos anos de 2018 e 2019. Para auxiliar na compreensão dos resultados após a avaliação, foram elaboradas tabelas e figuras e encontram-se nos subtítulos a seguir.

\section{INOVAÇÃO FRUGAL}

A inovação frugal remete voltar ao básico, ao simples. Assim, autores comungam do pensamento da frugalidade levar ao desenvolvimento de produtos com características inovadoras e disruptivas, com a utilização de tecnologias e materiais já existentes, e que sejam capazes de atender um grupo novo de consumidores (ZESCHKY et al., 2014). A expressão capacidade de fazer mais com menos\|também se refere a

Inovação Frugal (IF) (RADJOU; PRABHU, 2014).

Segundo Soni e Krishnan (2014) a inovação frugal é baseada na economia de escala, focada nos recursos e na inclusão de parte da população, criando dessa forma, não somente valor econômico, mas também valor social. Dessa forma, as inovações frugais ganharam popularidade, partem dos 
mercados emergentes e ganham as mais diversas economias (ECONOMIST, 2010; ZESCHKY et al., 2011). A busca de inovação em relação à limitação de recursos, as inovações frugais também ganham espaço quando se fala em inovação aberta ou inovação sustentável, onde pesquisadores lançam luz sobre a possibilidade da inovação frugal resgatar a chamada -tecnologia limpa (KHORASANIZADEH et al., 2016).

A IF se caracteriza pelas modificações sustentáveis e criação de valor para demandas e mercados com restrições de acesso. Nesse sentido, observadores econômicos e políticos também estão refletindo sobre como formalizar outra forma de crescimento com dimensões sustentáveis, para a economia volátil de hoje, com o enfrentamento do rápido esgotamento de recursos naturais (SIMULA; HOSSAIN; HALME, 2015).

Hossain, Simula e Halme (2016) consideram a IF um modelo de negócio voltado a melhoria de produtos, serviços ou processos com recurso financeiro e tecnológico limitado.

Assim, Weyracuch e Herstatt (2017) definem os três atributos de uma inovação frugal: reduzir de forma significativa os custos, concentrar as funcionalidades fundamentais e aperfeiçoar o desempenho. Esses critérios aliados ao fato do foco principal ser orientado ao usuário.

\section{INOVAÇÃO FRUGAL: PESQUISA BIBLIOMÉTRICA}

As buscas sobre a temática foram realizadas nas bases de dados Web of Science, Scopus (CAPES, 2020) e na BDTD. Destaca-se que na BDTD não foram realizadas delimitações e que o resultado se encontra integral, conforme se demonstra na Tabela 2.

Tabela 2 - Estudos de Inovação Frugal na BDTD

\begin{tabular}{l|c|c|c|c}
\hline \multicolumn{1}{c|}{ Título } & Tipo & Autor & Ano & Instituição \\
\hline $\begin{array}{l}\text { Intenção empreendedora em inovação } \\
\text { frugal: validação da escala EIF }\end{array}$ & Tese & BRESCIANI, S. A. T. & 2020 & UFSM \\
\hline $\begin{array}{l}\text { Modelo frugal à geração de ativos em } \\
\text { propriedade intelectual }\end{array}$ & Tese & TATUM, C. T. S. & 2020 & UFS \\
\hline $\begin{array}{l}\text { Capacidades Organizacionais para } \\
\text { inovação frugal }\end{array}$ & Tese & SLVA, I. M. & 2018 & USP \\
\hline $\begin{array}{l}\text { Frugal Innovation: a proposal of an } \\
\text { instrument to measurement }\end{array}$ & Tese & ROSSETTO, D. E. & 2018 & ESPM \\
\hline $\begin{array}{l}\text { Inovação Frugal à luz dos princípios da } \\
\text { Jugaad : estudo de múltiplos casos em } \\
\text { MPEs }\end{array}$ & Diss. & SILVA, S. B. S. & 2018 & UFS \\
\hline
\end{tabular}




\begin{tabular}{l|c|c|c|c}
\hline $\begin{array}{l}\text { Utilização de informações patentárias na } \\
\text { busca de soluções inovadoras para o setor } \\
\text { de atendimento hospitalar }\end{array}$ & Diss. & RAMÃO, G. B. & 2017 & UNINOVE \\
\hline $\begin{array}{l}\text { Patentes e inovação frugal em uma } \\
\text { perspectiva contributiva }\end{array}$ & Tese & MAZIERI, M. R. & 2016 & UNINOVE \\
\hline
\end{tabular}

Fonte: BDTD (2020)

A Tabela 2 apresenta os sete estudos encontrados na BDTD (Biblioteca Brasileira de Teses e Dissertações), onde se percebe que foram defendidos recentemente, entre 2016 e 2020 . Em sua tese intitulada - Intenção empreendedora em inovação frugal||: validação da Escala EIF, a autora Bresciani (2020) apresenta o objetivo de validar a Escala de Inovação Frugal - EIF (SILVA, 2018), aplicada com a Escala de Intenção Empreendedora - EIE (ALMEIDA, 2013; LIÑÁN; CHEN, 2009; THOMPSON, 2009), em estudantes do ensino superior.

Para isso, utilizou a metodologia de natureza quantitativa, com pesquisa survey, análise com Modelagem de Equações Estruturais (SEM) em uma amostra válida de 694 estudantes universitários, o estudo contribui para o progresso de estudos teóricos e empíricos sobre empreendedorismo, educação empreendedora nas IES e, inovação.

Tatum (2020) na metodologia da sua tese, para geração do modelo intitulado por FRUGAPI, realizou um estudo de casos múltiplos com abordagem mista, apoiada pelo método survey, utilizando fundamentos teóricos, principalmente por artigos indexados na base Capes com utilização da ferramenta SmartPls. Nos índices de inovações e conhecimentos, o autor verificou que os países apresentaram índices positivos de crescimento na era do conhecimento e da inovação e um crescente índice nos registros de proteção intelectual às patentes dos países emergentes.

Em sua tese de doutorado e Administração, Silva (2018) analisou a relação entre as capacidades organizacionais frente ao desenvolvimento da inovação frugal, dentre elas, as capacidades de produção, tecnológica, de marketing e de capital humano. Para isso, o autor, utilizou o método Survey, com amostra composta por 257 empresas brasileiras de diferentes tamanhos e setores. Os resultados empíricos de sua pesquisa demonstraram que a inovação frugal é uma estratégia que combina eficiência em custos e inovação.

A tese apresentada por Rosseto (2018) objetiva a construção de um instrumento de medida de inovação frugal. Foi utilizada a análise fatorial exploratória (AFE) e confirmatória (AFC)., baseado em dados de 1130 empresas, a partir de coletas realizadas no Brasil, Estados Unidos da América e Índia. 
Os resultados concluem que a IF é apropriada para utilização não somente em países emergentes, mas também em países em desenvolvimento e desenvolvidos.

Já, Silva (2018) em sua dissertação de mestrado tem como objetivo a descrição de do desenvolvimento de inovação frugal em pequenos negócios da região de Itabaiana/SE. A autora faz uma análise voltada as atividades de produção de bens e serviços à luz dos princípios da Jugaad. O estudo apresenta os seis princípios necessários para esse tipo de inovação: 1) buscar oportunidades na adversidade; 2) fazer mais com menos; 3) ser flexível; 4) simplificar; 5) dar chance aos excluídos e; 6) seguir o coração. A metodologia utilizada foi de natureza qualitativa com método de estudos de casos múltiplos, a partir disso, foram coletados dados em oito empresas. O estudo conclui que os princípios da Juggad estão presentes nas ações praticadas pelas empresas participantes.

Ramão (2018) em sua dissertação objetivou estudar patentes livres para reprodução no Brasil e com potencial de frugalidade, para isso utilizou um software livre de mineração de patentes para fazer a busca, a ferramenta computacional Patentnet. $O$ autor utilizou também a técnica bibliométrica. Após a avaliação dos problemas encontrados em um hospital público de grande porte o autor elencou os cinco temas, considerados relevantes. Seu estudo encontrou soluções para esses problemas a partir da análise e uso da base Espacenet, ou seja, encontrou quatro patentes inclusivas e que apresentam baixo custo de reprodução.

Por fim, a tese defendida por Mazieri (2016) teve como objetivo geral analisar as informações de patentes e as inovações frugais numa perspectiva contributiva. Para alcançar o objetivo, utilizou métodos qualitativos para a interpretação dos resultados. Foi realizada a análise de patentes de 10 diferentes áreas. $\mathrm{O}$ autor conclui que a IF não é um tipo de inovação e sim uma resposta dentro de um contexto e que, portanto, pode ser aliada a inovações incrementais, arquiteturais, modulares e radicais.

Para verificar a relevância acadêmica referente a capacidade inovação frugal realizou-se uma pesquisa bibliométrica na base dados Web of Science e Scopus (CAPES, 2020). Primeiramente digitou-se as palavras "frugal innovation" como tópico no campo de pesquisa da Web of Science, delimitando-se o período de 2010 a 2020. Dessa forma, foram levantadas as informações referentes ao: número total de publicações, áreas temáticas, tipo de documentos, ano das publicações, países e idiomas e quantidade de citações. Foram encontradas 306 publicações na base Web of Science e 396 publicações na base Scopus no período pesquisado.

A Figura 1 demonstra a evolução temporal das publicações realizadas nas duas bases. 
Figura 1 - Evolução temporal sobre Inovação Frugal

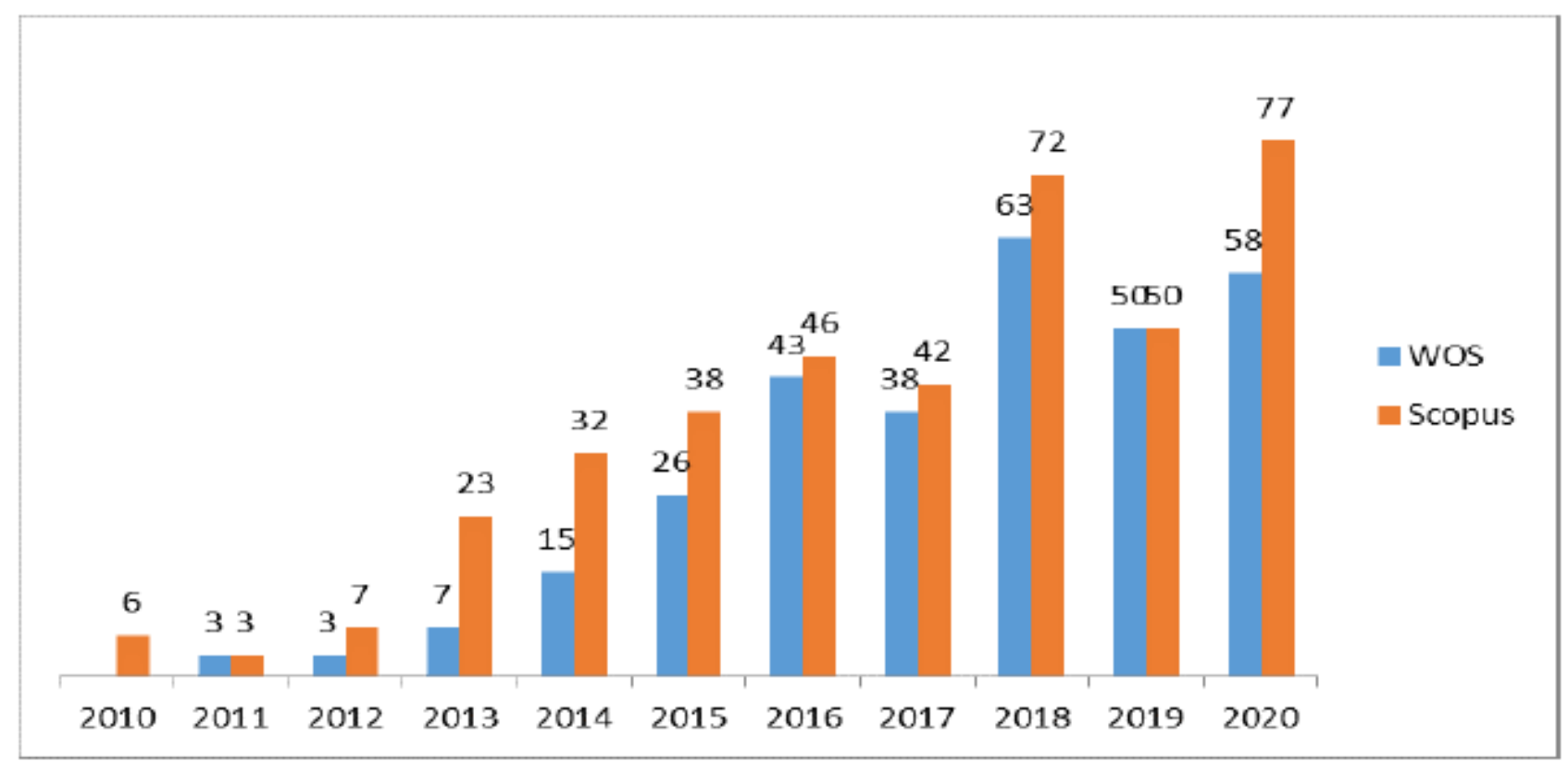

Fonte: WoS e Scopus (CAPES, 2020).

Sobre a evolução de publicações sobre IF, nota-se que a base Scopus apresenta maior quantidade durante o período pesquisado, sendo 396, enquanto na WoS foram encontradas 306 publicações. Considerando a última década, ressalta-se que em 2010 ainda não havia publicações na banca de dados WoS e na Scopus havia um pequeno número de publicações. Na Scopus e na WoS, no ano de 2018 ocorreu um elevado número de publicações nas respectivas bases, seguido por uma queda nas publicações em ambas as bases no ano de 2019. Já, em 2020 as publicações retomam e a base Scopus se destaca com 77 publicações.

A seguir, na Figura 2, apresenta-se o índice de áreas que mais publicam sobre a temática. 
Figura 2 - Áreas de publicação sobre Inovação Frugal

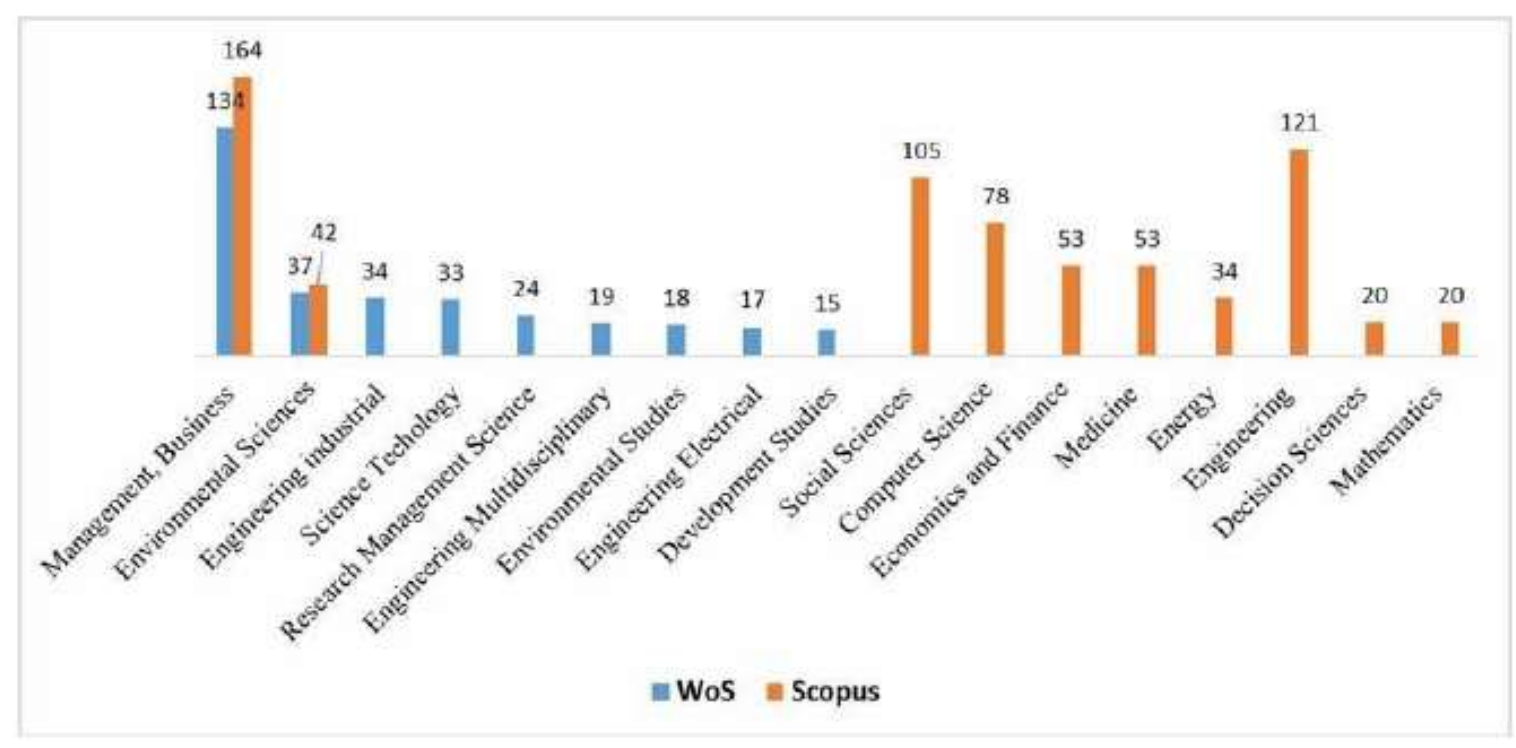

Fonte: WoS e Scopus (CAPES, 2020).

Nota-se que as bases, publicaram em áreas distintas, sendo que a única área de publicação entre as duas bases á a de gestão e negócios, onde na base Scopus a área negócio, gestão e contabilidade concentram 164 publicações, enquanto na WoS a área de gestão apresenta 134 publicações área de negócios. Percebe-se que a base da Scopus tem estudos direcionados a área médica e base WoS em contrapartida apresenta estudos voltados as engenharias.

A seguir, o próximo gráfico apresenta a quantidade publicada por países, demonstradas na Figura 3 e Figura 4.

Figura 3 - Índice de países que mais publicam sobre Inovação Frugal

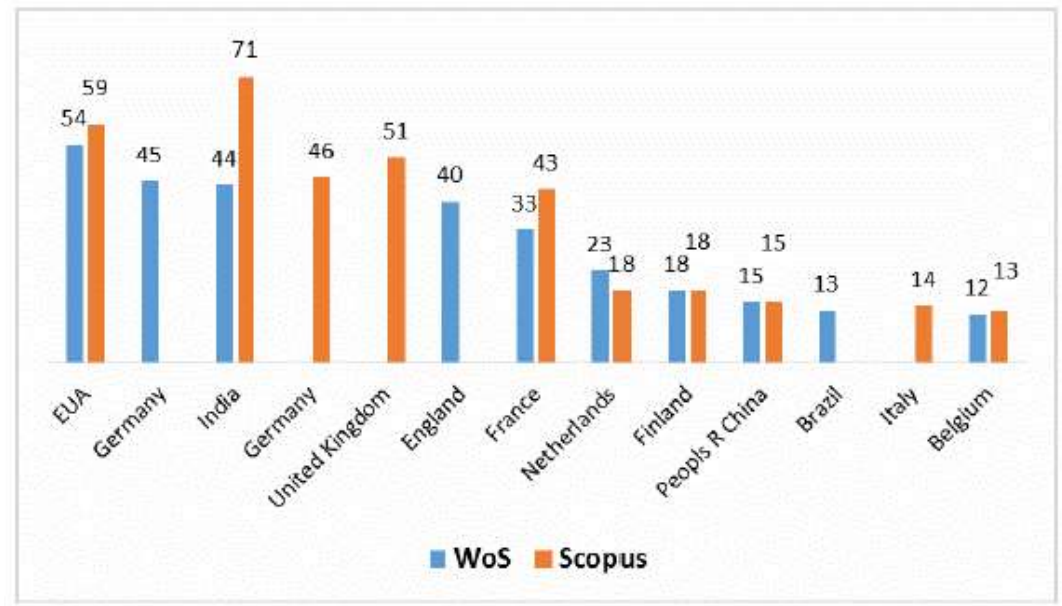

Fonte: WoS e Scopus (CAPES, 2020). 
Figura 4 - Países que mais publicam sobre Inovação Frugal

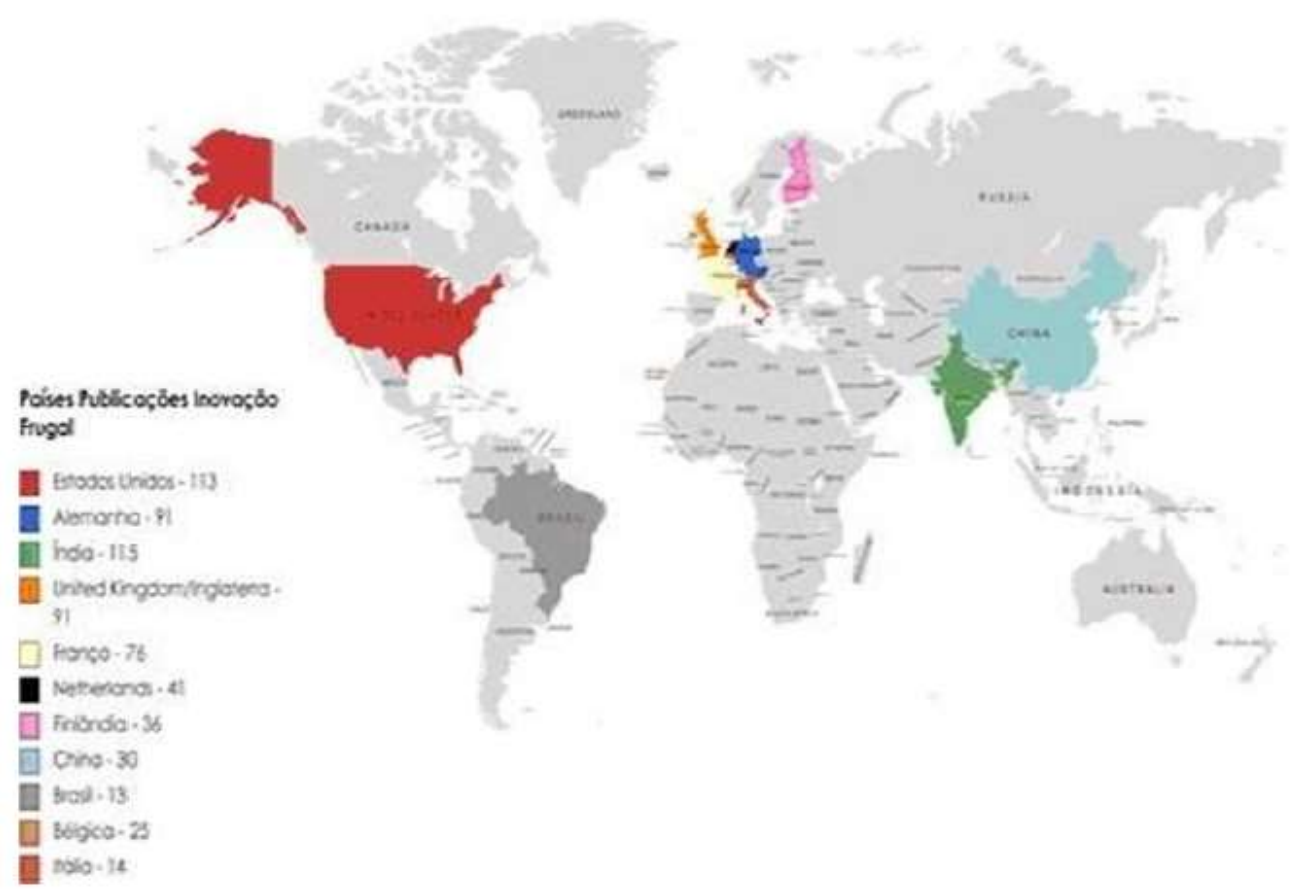

Fonte: os autores (mapchart.net)

Quanto ao número de publicações por países, a Índia lidera o ranking comum total de 115 publicações, em seguida aparece os Estados Unidos com um totao de 113 publicações. A Figura 5 representa o mapa dos trabalhos publicados e distribuídos pelo mundo sobre a temática Inovação Frugal.

Ressalta-se que na base Scopus, o Brasil se posiciona em 15a com 8 documentos publicados, enquanto, na base WoS são 13 documentos, ocupando a 9a posição. Assim, na Tabela 3, mostram-se os autores que mais publicaram sobre o tema.

Tabela 3 - Índice de autores sobre Inovação Frugal

\begin{tabular}{l|c|c||c|c}
\hline Posição & Autores & Freq. WoS & Autores & Freq. Scopus \\
\hline $1^{\mathrm{a}}$ & Hossain, M & 8 & Bream, A. & 10 \\
$1^{\mathrm{a}}$ & Belkadi, F. & 7 & Maussion, P. & 9 \\
$3^{\mathrm{a}}$ & Bernard, A. & 7 & Hossain, M. & 7 \\
$3^{\mathrm{a}}$ & Borini. F. M. & 7 & Mourtzis, D. & 7 \\
$3^{\mathrm{a}}$ & Maussion, P. & 7 & Belkadi, F. & 6 \\
$6^{\mathrm{a}}$ & Brem, A.. & 6 & Bernard, A. & 6 \\
$6^{\mathrm{a}}$ & Gassmann, O. & 6 & Harris, M. & 6 \\
$8^{\mathrm{a}}$ & Mourtzis, D. & 6 & Agarwal, N. & 5 \\
$9^{\mathrm{a}}$ & Noubactep, C. & 6 & Baekelandt, J. & 5 \\
$10^{\mathrm{a}}$ & Gupta, RK. & 5 & Bhatti, Y. & 5 \\
\hline
\end{tabular}

Fonte: WoS e Scopus (CAPES, 2020). 
Na primeira posição da base de dados WoS e na terceira posição na Scopus tem- se o autor e pesquisador Hossain que atua no departamento de Engenharia Industrial e Gestão na Aalto University, Espoo, Finlândia. Apresentados os resultados relevantes, ressalta-se que a partir da coleta dos dados encontrados em ambas as bases transportadas para o programa Excel. A partir das tabelas, foram realizadas as leituras dos resumos e analisados os estudos que se encontravam duplicados em ambas as bases. Logo após, foram selecionados para uma análise os trabalhos alinhados com o presente estudo.

\section{RELATÓRIO DE CITAÇÕES}

Conforme Araújo (2006) através dos dados da análise de citações descobre-se os itens relevantes ao estudo. Na Figura 5 consta o número de citações por ano.

Figura 5 - Total de citações de Inovação Frugal por ano

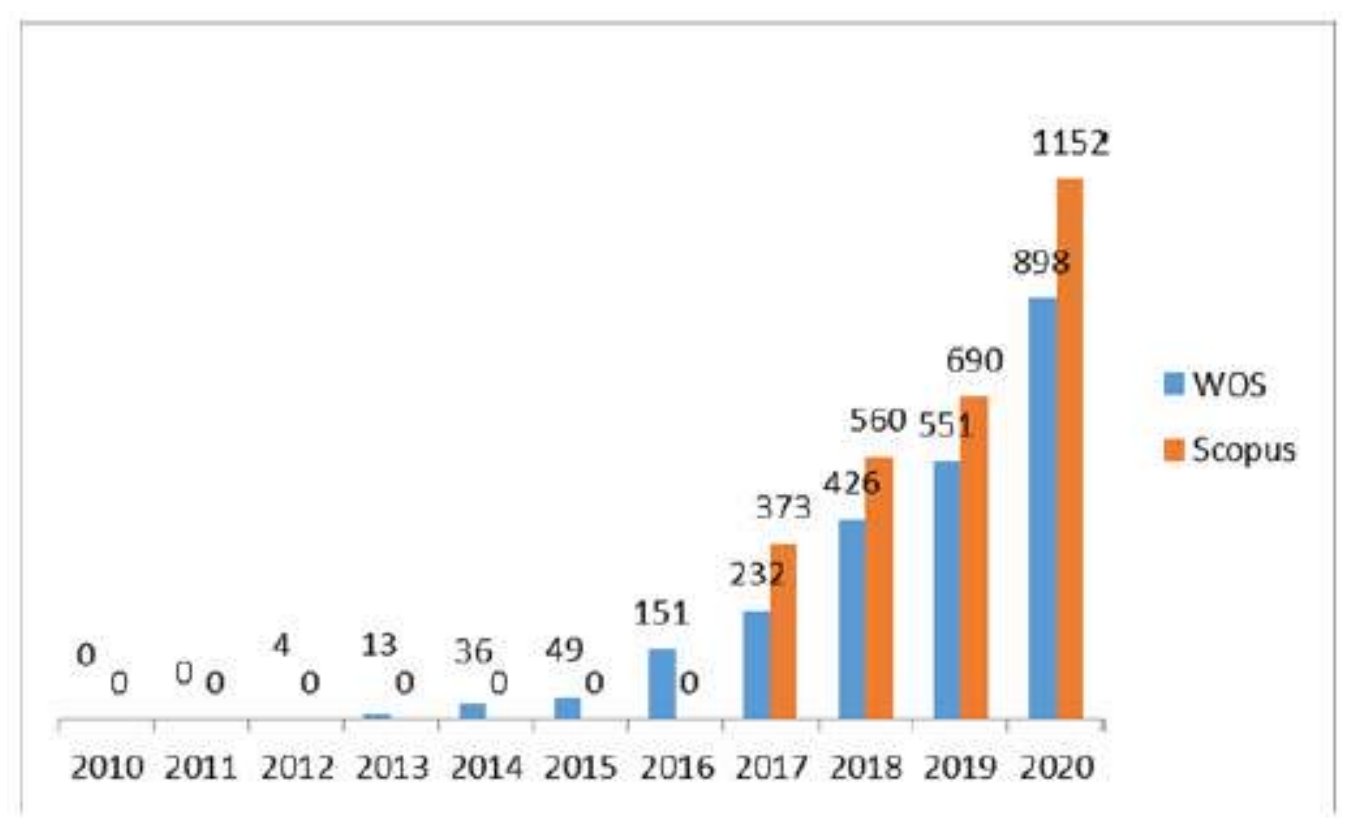

Fonte: WoS e Scopus (CAPES, 2021).

O período apurado totalizou 2.506 citações na base Web of Science, já na Scopus 2.775 foi o total de citações. Nos anos de 2010 e 2011 não houve publicações em nenhuma das bases, a partir de 2012 ocorre a primeira citação na base de dados WoS (com 4 citações), enquanto apenas no ano de 2017 ocorre a primeira citação na base de dados Scopus (373 citações).

Por meio da análise de citações identificaram-se os trabalhos mais citados sobre inovação frugal nas respectivas bases. Os trabalhos da base de dados da Web of Science são detalhados no Quadro 1. 
Quadro 1 - Os cinco estudos mais citados de Inovação Frugal na base de dados WoS

\begin{tabular}{|l|c|c|}
\hline \multicolumn{1}{|c|}{ DESCRIÇÃO } & $\begin{array}{c}\text { Ano de } \\
\text { publicação }\end{array}$ & Citações \\
\hline $\begin{array}{l}\text { Frugal innovation in emerging markets: the case of mettler toledo. Por: } \\
\text { Zeschky, Marco; Widenmayer, Bastian; Gassmann, Oliver. RESEARCH- } \\
\text { TECHNOLOGY MANAGEMENT; v. 54, e. 4, p: 38-45. }\end{array}$ & 2011 & 175 \\
\hline $\begin{array}{l}\text { Towards a sufficiency-driven business model: Experiences and } \\
\text { opportunities. Por: Bocken, N. M. P.; Short, S. W. ENVIRONMENTAL } \\
\text { INNOVATION AND SOCIETAL TRANSITIONS; v. 18, p. 41-61. }\end{array}$ & 2016 & 112 \\
\hline $\begin{array}{l}\text { From Cost to Frugal and Reverse Innovation: Mapping the Field and } \\
\text { Implications for Global Competitiveness. Por: Zeschky, Marco B.; }\end{array}$ & 2014 & 97 \\
$\begin{array}{l}\text { Winterhalter, Stephan; Gassmann, Oliver. } \\
\text { RESEARCH-TECHNOLOGY MANAGEMENT; v. 57; e. 4, p. 20-27. }\end{array}$ & \\
\hline $\begin{array}{l}\text { Resource-constrained product development: Implications for green } \\
\text { marketing and green supply chains. Por: Sharma, Arun; Iyer, } \\
\text { Gopalkrishnan R. INDUSTRILL MARKETING MANAGEMENT; v. 41, } \\
\text { e. 4, p. 599-608. }\end{array}$ & 2012 & 89 \\
\hline $\begin{array}{l}\text { Product innovation for the people's car in an emerging economy } \\
\text { Por: Ray, Sangeeta; Ray, Pradeep Kanta. TECHNOVATION; v. 31, e. 5-6, } \\
\text { p. 216-22.7 }\end{array}$ & 2011 & 81 \\
\hline
\end{tabular}

Fonte: Web of Science (CAPES, 2020).

Dentre as publicações mais citadas constam autores que mais publicam sobre a temática como, por exemplo, Zeschky e Gassmann. Seu artigo Inovação frugal em mercados emergentes: o caso da Mettler Toledo, os autores Zeschky, Widenmayer e Gassmann (2011), iniciam apresentando exemplos de inovações frugais como o veículo Nano, desenvolvido pela Tatá Motors na Índia, a máquina de ultrassom portátil desenvolvida pela General Eletric - GE na China, entre outros.

As análises apresentam as características dos produtos, motivação para o desenvolvimento dos produtos e, desenvolvimento e implementação dos produtos. Nas considerações finais, ressaltam que as subsidiarias ocidentais em países emergentes, necessitam dar autonomia e incentivar o setor de P\&D, com o objetivo de desenvolver produtos com características de inovações frugais. Para tanto, recomendam que seja dada atenção à promoção da mentalidade frugal nas equipes de P\&D.

No Quadro 2, são descritos os estudos com maior quantidade de citações, da base de dados Scopus (CAPES, 2020). 
Quadro 2 - Os cinco estudos mais citados de inovação frugal da base de dados Scopus

\begin{tabular}{|l|c|c|}
\hline \multicolumn{1}{|c|}{ DESCRIÇÃO } & $\begin{array}{c}\text { Ano da } \\
\text { publicação }\end{array}$ & Citações \\
\hline $\begin{array}{l}\text { Towards a sufficiency-driven business model: Experiences and } \\
\text { opportunities. Por: Bocken, N.M.P., Short, S.W. ENVIRONMENTAL } \\
\text { INNOVATION AND SOCIETAL TRANSITIONS; v. 18, p. 41-61 }\end{array}$ & 2016 & 125 \\
\hline $\begin{array}{l}\text { From cost to frugal and reverse innovation: Mapping the field and } \\
\text { implications for global competitiveness. Por: Zeschky, M.B., } \\
\begin{array}{l}\text { Winterhalter, S., Gassmann, O.RESEARCH TECHNOLOGY } \\
\text { MANAGEMENT; v. 57, e. 4, p. 20-27. }\end{array}\end{array}$ & 2014 \\
\hline $\begin{array}{l}\text { Resource-constrained product development: Implications for green } \\
\text { marketing and green supply chains. Por: Sharma, A., Iyer, G.R. Industrial } \\
\text { Marketing Management,; v. 41, e. 4, p. 599-608. }\end{array}$ & 2012 & 95 \\
\hline $\begin{array}{l}\text { Product innovation for the people's car in an emerging economy Por: } \\
\text { Ray, Sangeeta; Ray, Pradeep Kanta TECHNOVATION; v. 31; e. 5-6, p. } \\
216-227\end{array}$ & 2011 & 90 \\
\hline $\begin{array}{l}\text { How disruptive is frugal? Por: Rao, B.C. TECHNOLOGY IN SOCIETY; } \\
\text { v. 35, e. 1, p. 65-73. }\end{array}$ & 2013 & 86 \\
\hline
\end{tabular}

Fonte: Scopus (CAPES, 2020).

Já na base Scopus, dentre as publicações mais citadas constam autores que mais publicam sobre a temática como, por exemplo, Bocken \& Short. Seu artigo - Towards a sufficiency-driven business model: Experiences and opportunities\|. Igualmente, o estudo de Bocken e Short (2016) iniciam-se com o apontamento sobre a necessidade das organizações se capacitarem para o desafio de pensar de forma disruptiva, com o objetivo de projetar e difundir inovações voltadas para as necessidades locais. Assim, o estudo tem como objetivo entender como as escolhas da Tatá Motors em relação ao uso de tecnologia, design de produto e práticas organizacionais para o desenvolvimento de novos produtos, permitiram enfrentar o desafio de inovação para o mercado de baixa renda da Índia.

Para tanto, a metodologia é de natureza qualitativa com estudo de caso único, com triangulação de dados de artigos científicos, documentos de entrevistas com profissionais em cargos técnicos e gerenciais da Tatá Motors e de fornecedores e, ainda, entrevista in loco com gerentes sêniores de duas principais fornecedoras de componentes automotivos e com o diretor da Sociedade de Fabricantes de Automóveis, na Índia. A análise de dados demonstrou que a organização utilizou recursos de forma econômica, ou seja, fez uso de uma nova combinação de tecnologias de componentes existentes, assim, foi possível criar um novo produto modular para alcançar os requisitos exclusivos de preçodesempenho.

Seguindo as análises, na Figura 5 é demonstrado o mapa de co-citações dos autores. A partir de cocitação é possível analisar a estrutura intelectual entre os autores, ou seja, quanto mais dois autores 
são citados juntos, mais próxima é a relação entre eles, Dessa forma, a análise de co-citação permite analisar os clusters existentes e os autores que pertencem a eles (RUIZ-NAVARRO; RAMOSRODRÍGUEZ, 2004).

Nessa análise, foram selecionados autores citados pelo menos 20 vezes, verificando os possíveis grupos ou pares de artigos que são citados em conjunto com outro artigo. Para isso, utilizou-se o software VOSviewer com o objetivo de identificar os possíveis clusters de autores e suas relações, bem como criação de mapas de relacionamentos e clusters e mapa de palavras chaves que aparecem com frequência no texto. A Figura 6 representa o Mapa de co-citações da base de dados Web of Science.

Figura 6 - Mapa de co-citação de inovação frugal base de dados WoS

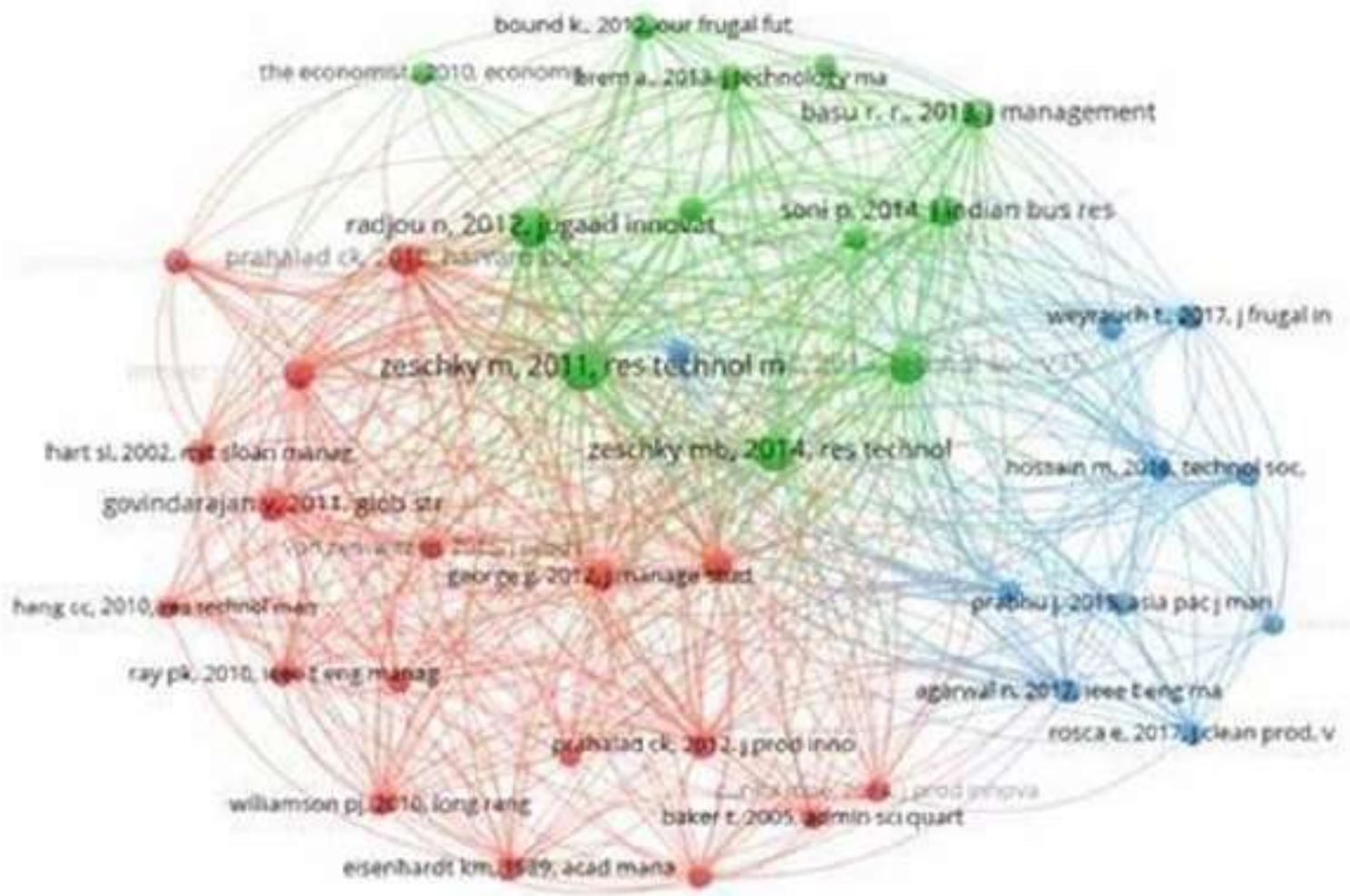

Fonte: elaborado pela autora por meio do VOSviewer.

Das 25.239 referências citada na base de dados Web of Science 55 foram citados mais de 20 vezes. Como se pode observar na Figura 6, os autores Zeschky (2011) e Zechky (2014) aparecem com aparecem com 94 e 69 citações respectivamente. Rao (2013) aparece com 62 citações e em seguida Radjou (2012) aparece entre os 3 autores mais citados com 72 citações. O maior é o cluster é o vermelho, composto por 18 autores, entre eles, Zeschky, Govindarajan e Prahalad. O cluster de cor 
verde aparece com 12 autores, com destaque para Radjou e Tiwari e por o cluster de azul com um total de 10 citações, entre elas dos autores Weyrauch com 31 citações.

\section{MAPA TEXTUAL BASE DE DADOS WOS E SCOPUS}

Por meio da análise das palavras-chaves das 306 publicações encontradas na base de dados WoS e 396 na base de dados Scopus, de 10.327 palavras chaves 340 foram utilizadas com maior frequência, mais de 10 vezes, destas, 204 são relevantes para o presente estudo. As análises de palavras mais citadas nos artigos foram realizadas utilizando o software VOSviewer, nos campos de título e resumo. A partir de então, o software utilizou o total de 204 palavras chaves relevantes, selecionadas e agrupadas em 6 clusters que quanto mais importante um item, tanto maior será a sua escrita e o seu círculo representativo (VAN ECK; WALTMAN, 2010), A Figura 7 apresenta 204 palavras chaves com mais de 10 ocorrências de um total de 7.987 links.

Figura 7- Rede de palavras de inovação frugal

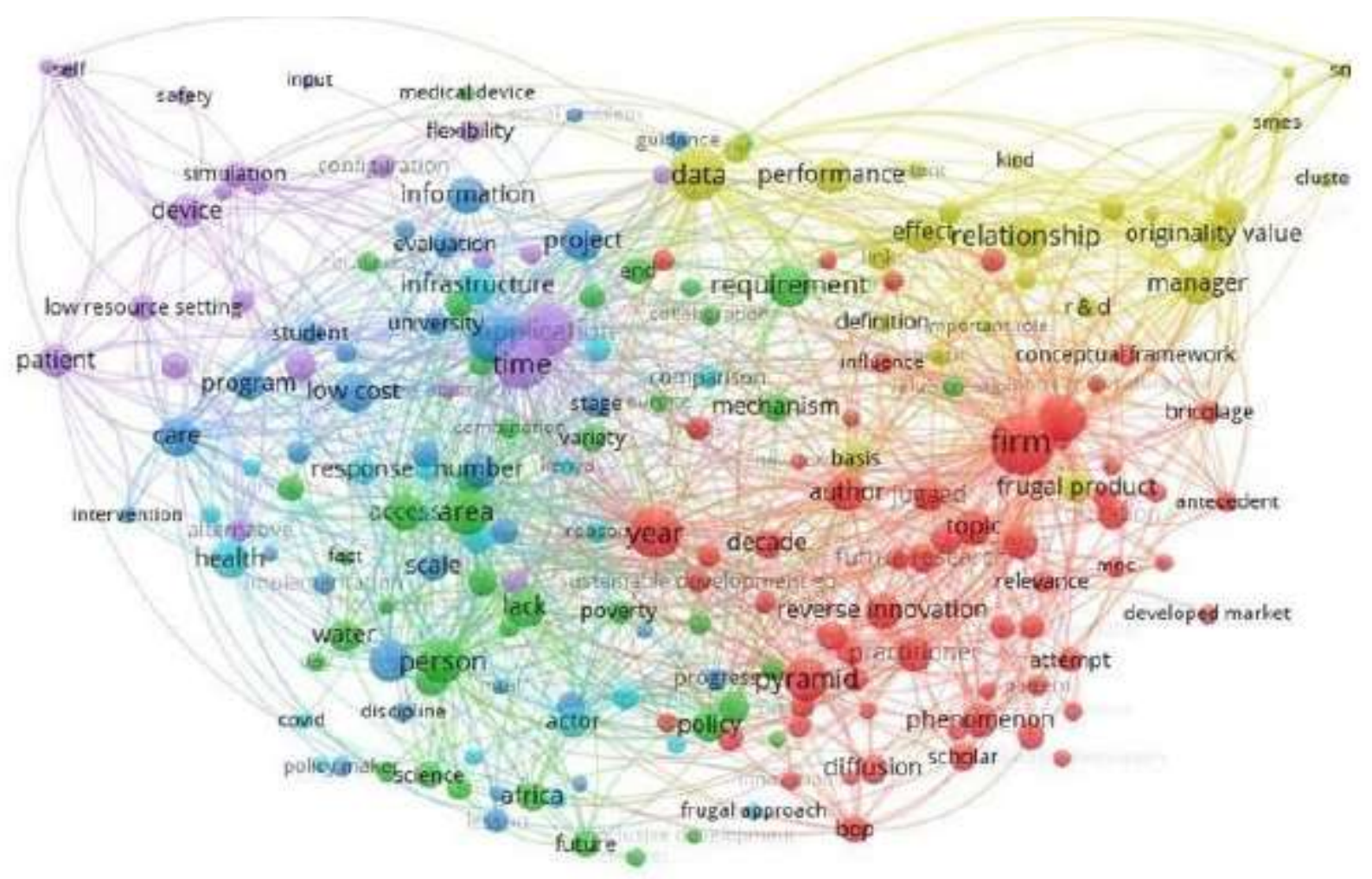

Fonte: Elaborado pela autora por meio do Vosviewer

$\mathrm{Na}$ rede de palavras verificam-se seis clusters predominantes, o principal corresponde às palavras elencadas no grupo firm em vermelho com 61 itens. Observa-se o cluster com vermelho tem como o principal expoente com o termo firm e termos como bricolagem, capability, frugal, innovation process, 
jugaad, pyramid, e sustainble innovation compõem o cluster. O segundo cluster, de cor verde com 41 termos como Africa, Europe, education, frugal innovator, new business model e Science. Já o terceiro cluster de cor azul escuro e formado por 33 itens como information e Project, e o quarto cluster de cor amarela, formado por 26 palavras chaves com destaque para Brazil e frugal product.

O quinto cluster de cor roxa é composto por 23 itens e palavras chaves como investment, limitation e flexibility e por fim o sexto e último cluster de cor azul clara composto por 20 palavras chaves, entre elas, government e frugal approach. A palavra inovação frugal apresentou 144 ocorrências e 963 links com os itens dos demais clusters. Já, a palavra inovação apresentou 76 ocorrências e 68 links com os demais clusters.

\section{INSTRUMENTOS DE MEDIÇÃO DE INOVAÇÃO FRUGAL}

Para o estudo do próximo capítulo foi utilizado o instrumento de Silva (2018). O autor aponta quatro dimensões de inovação, no modelo proposto, fundamentadas a partir das dimensões estudadas pelos autores Alburub e Lee (2012) - Open Innovation (Inovação Aberta); Chen, Lai e Wen (2006) Sustainable Innovation (Inovação Sustentável), Afonso et al., (2008) - Cost Innovation (Inovação em Custos) e, Product Innovation (Inovação em Produtos) com os autores Gunday et al., (2011). Os autores defendem que a inovação é a chave para uma organização manter a vantagem competitiva e assim, alcançar a liderança desse mercado. Passa-se a discussão de cada tipo de inovação, que compõem o instrumento de Silva (2018) utilizado na presente pesquisa.

\section{INOVAÇÃO SUSTENTÁVEL}

O estudo de Chen, Lai e Wen (2006) apresenta como objetivo explorar os desempenhos da inovação verde em produto e inovação verde em processo. Alguns conceitos foram criados na tentativa de minimizar o impacto de atividades industriais, buscando minimizar a degradação do meio ambiente, classificando a inovação verde em três categorias: inovação de produtos verdes; inovação de processos verdes; e inovação gerencial verde (CHEN; LAI; WEN, 2006; CHEN et al, 2009; CHIOU et al. 2011).

Chen (2008) introduziu então o conceito de competências essenciais. O conceito de Inovação verde proposto por Chen; Lai; Wen (2006) está relacionado a produtos e processos, incluindo a inovação em tecnologias que estão envolvidas na economia de energia, prevenção de poluição, reciclagem de resíduos, projetos de produtos verdes ou gestão ambiental corporativa. 
Os construtos teóricos utilizados na elaboração do Instrumento de Inovação Verde de Chen, Lai e Wen (2006) foram: desempenho da Inovação de Produtos Verdes, desempenho da Inovação de Processo Verde e vantagem Competitiva Corporativa. No contexto metodológico da construção da escala o objetivo geral dos autores foi investigar se o desempenho da inovação verde trouxe efeito positivo para a vantagem competitiva. O estudo contou com 16 variáveis. Já a amostra contou com 300 empresas da indústria de informação e eletrônica de Taiwan.

A dimensão Inovação Sustentável do instrumento de Silva, Itiel (2018), utilizado na presente pesquisa considerou apenas 4 itens da dimensão, ou seja, não serão consideradas as definições defendidas por Chen, Lai e Wen (2006) e sua escala com itens sobre a IS.

\section{INOVAÇÃO ABERTA}

O estudo de Alburub e Lee (2012) intitulado Gestão da inovação aberta: desafios e perspectivas' apresentam como objetivo analisar o estado da inovação aberta na Coréia do Sul, com destaque para os desafios atuais e possíveis mecanismos para superar as limitações da teoria da inovação aberta, como a ambiguidade do conceito e da modalidade. Os autores realizaram um estudo de caso com 85 empresas sulcoreanas. Alburub e Lee (2012) ressaltam que o tamanho da empresa e o tipo de indústria tem um efeito na inovação aberta. Dessa forma, as indústrias transformadoras, grandes empresas, indústria de alta tecnologia e empresas com mercados estrangeiros têm mais experiência em atividades de inovação aberta.

Os autores elencam o tipo de mercado (nacionais e estrangeiros) e experiência com parceiros estrangeiros como fatores que afetam o grau de atividade de inovação aberta, assim, o interesse pela inovação aberta aumentou tanto no ambiente organizacional quanto no acadêmico.

\section{INOVAÇÃO EM CUSTO}

O estudo de Afonso et al. (2008) defende que a redução do tempo e o custo de Desenvolvimento de Novos Produtos (NPD), pode criar vantagens relativas em participação de mercado, lucro e competitividade a longo prazo, principalmente durante o primeiro estágio, ou seja, na fase de produção, antes de disponibilizar o produto no mercado. Nesse sentido, o estudo busca a criação de uma escala de inovação em custo, para isso, os autores coletaram através de um questionário eletrônico enviado para 500 empresas industriais, consideradas entre as 1.500 maiores Pequena e Média empresas (PMEs) portuguesas, nos anos de 2005 e 2006. 
O instrumento foi elaborado para realçar a forma como a NPD foi realizada nas empresas, com a extensão do uso de técnicas de Inovação Custeio Alvo (TC), sendo medidas pela escala de Likert de cinco pontos.

\section{INOVAÇÃO EM PRODUTOS}

Em seu estudo, Gunday et al. (2011) consideram o Manual de Oslo da OCDE (2005) como fonte principal para descrever, identificar e classificar inovações em organizações, a partir dos quatro diferentes tipos, isto é, inovação em produtos, inovação de processos, inovação de marketing e inovação organizacional.

O objetivo dos autores foi explorar as inovações e seus efeitos sobre o desempenho da empresa, examinando inovações em produto, processo, marketing e organizacional, bem como o desempenho de produção, desempenho de mercado e desempenho financeiro. $O$ estudo foi realizado na Turquia com 184 empresas de manufatura, com até 50 funcionários, considerada pequena; entre 50 e 250 funcionários, considerada média e, acima de 250, considerada grande. Dessa forma, para a construção de escala de inovação em produtos, foram utilizadas dez questões, no primeiro bloco da pesquisa e em seguida, foram apresentados sete constructos (GUNDAY et al., 2011).

Os construtos elaborados para a escala de inovação em produtos de Gunday et al. (2011) possuem oito dimensões para medir inovações em produtos, inovações em processos, inovações em marketing, inovações organizacionais, inovação em desempenho, desempenho de produção, desempenho de mercado e desempenho financeiro.

\section{METODOLOGIA DE PESQUISA}

Para responder os objetivos propostos, a pesquisa caracteriza- se como de abordagem quantitativa, com objetivo exploratório descritivo e causal (HAIR Jr. et al., 2009). A pesquisa quantitativa caracterizase por utilizar a quantificação na coleta e no tratamento dos dados levantados, com o uso de técnicas estatísticas, com isso é possível obter uma maior margem de segurança nos resultados.

Esta pesquisa quanto ao caráter quantitativo desenvolveu suas hipóteses a partir da revisão de literatura feita com base em publicações indexadas na BDTD, Web of Science e Scopus (CAPES, 2020). Os instrumentos escolhidos para mensurar Capacidade Absortiva Individual, Silva et al. (2016) e Inovação Frugal, Silva (2018) compõem o instrumento desta pesquisa. 
As pesquisas exploratórias são realizadas quando se busca examinar um tema ou um problema de pesquisa pouco explorado, sobre o qual existem dúvidas ou que ainda não foram abordados no meio científico (GIL, 1999). A estratégia de pesquisa utilizada é do tipo Survey, conforme Freitas et al., (2000) é uma técnica descritora dos dados da amostra de forma quantitativa, utilizando um instrumento de coleta de dados prefixado, com o intuito de compreender o que está acontecendo com aquela população.

\section{OBJETO DE PESQUISA, POPULAÇÃO E AMOSTRA}

O objeto de estudo da presente pesquisa é composto por estudantes dos cursos de pós-graduação da Universidade Federal de Santa Maria (UFSM), que é uma Instituição Federal de Ensino Superior, sediada em Santa Maria (Rio Grande do Sul, Brasil), na Cidade Universitária Prof. José Mariano da Rocha Filho. No ensino presencial, oferece 132 cursos/habilitações de graduação e 108 cursos de pósgraduação, sendo 33 de doutorado, 56 de mestrado, 19 de especialização e um programa de pósdoutorado conforme mostra a Tabela 6.

Tabela 6 - Estudantes de Pós-graduação da UFSM

\begin{tabular}{|c|c|c|}
\hline Programa de Pós-Graduação & Número de Cursos & Número de Alunos \\
\hline Mestrado & 56 & 2.112 \\
\hline Doutorado & 33 & 1.689 \\
\hline Total & 89 & 3.801 \\
\hline
\end{tabular}

Fonte: Elaboração própria com dados do Sistema de Informação para o Ensino - SIE/UFSM (2019).

Foram identificados os centros e seus referidos programas de pós-graduação com diferentes conceitos em relação a avaliação do conceito CAPES. Além dos campi, a atual estrutura é composta por doze unidades universitárias. A Tabela 7 apresenta os centros e seus respectivos cursos de mestrado e doutorado. 
Tabela 7- Classificação dos Programas de Pós-Graduação da UFSM

\begin{tabular}{l|c|c}
\multicolumn{1}{c|}{ Centro de Pós-Graduação } & Mestrado & Doutorado \\
\hline Centro de Artes e Letras (CAL) & 2 & 2 \\
Centro de Ciências Naturais e Exatas (CCNE) & 11 & 7 \\
Centro de Ciências Rurais (CCR) & 9 & 8 \\
Centro de Ciências da Saúde (CCS) & 7 & 4 \\
Centro de Ciências Sociais e Humanas (CCSH) & 4 & 6 \\
Centro de Educação (CE) & 2 & 1 \\
Centro de Educação Física e Desportos (CEFD) & 8 & 0 \\
Centro de Tecnolodia (CT) & 1 & 5 \\
Centro Técnico Industrial de Santa Maria (CTISM) & 56 & 0 \\
\hline \multicolumn{1}{c|}{ Total } & & 33 \\
\hline
\end{tabular}

Fonte: Elaboração própria com dados do Sistema de Informação para o Ensino - SIE/UFSM (2019).

Sendo assim, a pesquisa foi realizada nos nove Centros da Universidade Federal de Santa Maria.

Os Programas de Pós-graduação (PPGs) se distribuem em notas 3 (regular), 4 (bom) e 5 (muito bom), e destes últimos se destacam programas excelentes, com notas 6 e 7, que constituem referências para as Áreas. Sendo que um programa de pós-graduação está apto a oferecer curso de doutorado se tiver conceito 4 ou mais.

\section{VARIÁVEIS E MEDIDAS}

Conforme Hair Jr. et al. (2009) é necessário que seja realizada a operacionalização da quantificação das variáveis. Portanto, estas precisam ser transformadas passíveis de observação empírica e mensuração (GIL, 1999). Em decorrência disso, as dimensões de Capacidade de Absorção Individual e Inovação Frugal serão mensuradas com base em instrumentos de pesquisa já validados no Brasil.

\section{TRATAMENTO E ANÁLISE DOS DADOS}

A etapa de análise dos dados trabalhou com os dados e informações coletadas a partir da aplicação do questionário de CAI e IF e dos dados sócio demográficos dos estudantes de pós-graduação. Os dados coletados por meio de questionário do tipo survey foram organizados, codificados e processados com auxílio de planilha Excel $^{\circledR}$ e dos softwares STATISTICA ${ }^{\circledR}$ versão 6, do SPSS $^{\circledR}$ (Statistical Package for the Social Science) versão 26, SAS ${ }^{\circledR}$ (Statistical Analisys System) versão 9.0 e do SmarthPLS ${ }^{\circledR}$ versão 3.3.3. 
Os dados sociodemográficos e os indicadores das escalas foram analisados por meio de medidas descritivas, tais como, freqüência, média e desvio padrão. Logo após foram aplicadas técnicas de análise multivariada, mais especificamente Análise Fatorial Confirmatória (AFC) pela técnica Partial Least Squares Structural Equation Modeling (PLS-SEM).

Primeiramente, foi realizada a análise fatorial confirmatória para os modelos de mensuração dos construtos e pôr fim a análise do modelo de equações estruturais, para análise do modelo estrutural e análise das hipóteses. A análise fatorial é uma técnica que verifica as inter-relações entre os indicadores, resultando em um conjunto menor e selecionado de variáveis (HAIR Jr. et al., 2009). Conforme Hair Jr. et al. (2009) a análise fatorial é dividida em análise fatorial exploratória e confirmatória, sendo a análise fatorial exploratória utilizada quando se sabe pouco ou nada das variáveis que constituem o modelo e nem da relação entre os dados, enquanto a análise fatorial confirmatória é utilizada para testar como determinadas variáveis se adaptam ao construto, quando existe já um modelo teórico.

A AFC objetiva principalmente comprovar os conceitos analisados, detalhando quais as variáveis medidas se correlacionarão com quais fatores ou variáveis latentes e quais destas últimas se relacionam entre si. Ainda, Hair Jr. et al. (2014) pontuam que a análise fatorial confirmatória além de medir os construtos analisados, fornece um teste de confirmação da teoria mensurada. Conforme Hair Jr. et al. (2014), a Modelagem de

Equações Estruturais (MEE) é utilizada para testar a validade de um construto e as suas relações teóricas, assim, as equações elaboradas descrevem todas as relações de entre os construtos da análise em questão.

\section{RESULTADO DA PESQUISA}

\section{PERFIL DOS ESTUDANTES DE PÓS-GRADUAÇÃO}

A Tabela 8 apresenta os resultados dos dados acadêmicos, ou seja, modalidade ao qual pertencem, e contato com disciplinas ou outras modalidades de inovação. 
Tabela 8 - Dados acadêmicos dos participantes $(n=462)$

\begin{tabular}{lcc}
\hline \multicolumn{1}{c}{ Variáveis } & Frequência & $\%$ \\
\hline Modalidade & & \\
Doutorado & $\mathbf{2 2 5}$ & $\mathbf{4 8 , 7 0}$ \\
Mestrado Acadêmico & 199 & 43,07 \\
Mestrado Profissional & 38 & 8,23 \\
\hline Disciplina Inovação & & \\
Não & $\mathbf{3 1 1}$ & $\mathbf{6 7 , 3 2}$ \\
Sim & 151 & 32,68 \\
& & \\
Outras Modalidades Inovação & & $\mathbf{6 3 , 8 5}$ \\
Não & $\mathbf{2 9 5}$ & 36,15 \\
Sim & 167 & \\
\hline
\end{tabular}

Fonte: Dados da pesquisa

Considerando que o tamanho da amostra foi de 462 participantes, destes alunos da modalidade doutorado representam $48.70 \%$ da amostra, seguidos por $43,07 \%$ de alunos do mestrado e acadêmico e 8,23\% do mestrado profissional. Quanto a participação 67,32\% não cursaram nenhuma disciplina de inovação. O contato com outras modalidades de inovação é representando 36,15\% da amostra, enquanto $63,85 \%$ da amostra jamais participaram de outras modalidades de inovação como palestras, simpósios, projetos de extensão, visita orientada a habitats de inovação, entre outros. A Tabela 9 demonstra a distribuição sociodemográfica dos estudantes de pós-graduação.

Tabela 9 - Dados sociedemográficos dos participantes $(n=462)$

\begin{tabular}{lcc}
\hline \multicolumn{1}{c}{ Variáveis } & Frequência & $\%$ \\
\hline Sexo & & \\
Homem & $\mathbf{2 3 9}$ & $\mathbf{5 1 , 7 3}$ \\
Mulher & 223 & 48,27 \\
& & \\
\hline Faixa de idade & & 19,48 \\
De 17 a 25 anos & 90 & $\mathbf{5 3 , 9 0}$ \\
De 26 a 35 anos & $\mathbf{2 4 9}$ & 11,69 \\
De 36 a 40 anos & 54 & 14,94 \\
Acima de 41 anos & 69 & \\
& & \\
\hline Estado Civil & 129 & 27,92 \\
Casado & 7 & 1,52 \\
Separado & $\mathbf{3 0 0}$ & $\mathbf{6 4 , 9 4}$ \\
Solteiro & 26 & 5,63 \\
\hline Outros & &
\end{tabular}

Fonte: Dados da pesquisa. 
Analisando os dados dos participantes, identifica-se que mais da metade são homens, representando $51,73 \%$ da amostra. Dessa forma, 48,27\% são mulheres. Desses, 53,90\% tem entre 26 e 35 anos. Quanto ao estado civil uma parte significativa da amostra é solteira, representando $64,94 \%$ do total de 462 alunos de pós-graduação.

Apresentado os resultados da primeira parte do instrumento de pesquisa, passase para a próxima etapa, ou seja, a análise do modelo estrutural da Capacidade de Absorção Individual (Silva et al., 2016) e escala de Inovação Frugal (Silva, 2018) com a utilização do modelo de equações estruturais.

\section{ANÁLISE E VALIDAÇÃO DO MODELO ESTRUTURAL}

Em relação a fundamentação dos estudos, destacando autores que mais contribuíram para o norteamento e desenho da pesquisa, em capacidade de absorção e capacidade absortiva individual tem-se: Cohen e Levinthal (1989) e Zara e George (2002). Os autores Cohen e Levinthal (1989) com apontamentos da relevância de P\&D para que de fato ocorra a capacidade de absorção organizacional, que conforme os autores é necessária e fundamental para a capacidade das organizações identificar, assimilar e explorar informações existentes no ambiente através de um modelo tridimensional, resultando em competitividade organizacional e crescimento econômico.

Ainda, Zara e George (2002) aprimoram o modelo de Cohen e Levinthal (1989) e o abordam como um construto multidimensional, com quatro dimensões, divididas em 2 subconjuntos de capacidade de absorção: a capacidade de absorção potencial e a capacidade de absorção realizada.

Nesse sentido, enquanto instrumento, foi utilizada a Escala de Capacidade Absortiva Individual de Silva e Eduardo et al., (2016) adaptada ao contexto universitário do instrumento validado por Machado (2014) no Brasil, com as seguintes variáveis: Aquisição com itens de AQ1 a AQ3; Assimilação, com itens de AS1 a AS4;

Transformação com itens de TR1 a TR3 e; Exploração com itens de EX1 a EX3.

Na temática Inovação Frugal destaca-se Silva, Itiel (2018) e Bresciani et al., (2020), com o instrumento validado no contexto brasileiro, a partir da a concepção de autores estrangeiros, com Abulrub e Lee (2012), Chen (2008), Afonso et al. (2008) e, Gunday et al. (2011), proponentes das dimensões que compõe a escala de inovação frugal. 


\section{CAPÍTULO II - INOVAÇÃO FRUGAL E SUAS DIMENSÕES: EVIDÊNCIAS NO CONTEXTO ACADÊMICO}

Resumo: O presente estudo teve como objetivo analisar a inovação frugal e suas dimensões - inovação aberta (OI), inovação sustentável (SI), inovação de custos (CI) e inovação de produtos (PI) - no contexto universitário sob a percepção de estudantes de pósgraduação. Utilizou-se a abordagem quantitativa e modelagem de equações estruturais (MEE) para uma amostra de 462 estudantes de pós-graduação em uma universidade brasileira. As análises confirmaram e validaram todas as hipóteses propostas como aceitas com uma relação direta e positiva entre todas as dimensões do modelo, a inovação aberta e inovação sustentável (H1), inovação aberta e inovação de produto (H2), inovação aberta e inovação em custo (H3), inovação sustentável e inovação em produto (H4), inovação sustentável e inovação em custo (H5) e inovação em custo e inovação de produto (H6). Constatou-se que o modelo é útil para demonstrar a ligação da inovação aberta para com as demais inovações preditoras da inovação frugal, podendo desta forma direcionar os processos no momento da criação do produto ou serviço. A percepção dos estudantes no contexto da inovação frugal teve destaque na relação da inovação aberta (OI) com a inovação sustentável (OS) com o grau mais significativo $(0,680)$, visto que, diversos estudos associam práticas de gestão de Inovação aberta ao desempenho inovador e sustentável das organizações.

Palavras-chave: Inovação; inovação frugal; estudantes de pós-graduação; modelagem de equação estrutural. 


\section{INTRODUÇÃO}

A inovação é desejada por organizações de todos os países, e começou ser debatida cientificamente pelos economistas Richard Cantillon (1755), Jean Baptiste Say (1803) e Joseph Schumpeter (1949), McClelland (1965), pois além de estar associada a vantagem competitiva, pode garantir a diminuição nos custos e o acréscimo nos lucros.

Outros autores corroboram que a inovação é responsável pelo desempenho das organizações, comprovado através da correlação positiva inovação X desempenho (SULISTYO; SIYAMTINAH, 2016). A Organização para a Cooperação e Desenvolvimento Econômico (OECD, 2018) alinhada em estimular o progresso econômico e o comércio mundial, acredita que a inovação não necessariamente seja a criação de um produto ou serviço novo, assim, expande o conceito para um novo método de marketing, ou um novo processo organizacional, nas práticas de negócios e/ou na organização do local de trabalho significativamente melhorado. Miocevic e Morgan (2018) em seu estudo ressaltaram que as capacidades de detecção do mercado são essenciais para promover a capacidade das organizações em reconhecer e explorar oportunidades, aumentando dessa forma o crescimento dos negócios. 0 valor da inovação observado nas organizações analisadas aponta níveis mais elevados de crescimento em comparação com empresas que tinham menor capacidade de inovação (MIOCEVIC; MORGAN, 2018).

Aliado a esses fatores descritos sobre o valor da inovação, Kunamaneni (2018) destaca a preocupação com o crescimento acelerado da população do planeta e, alerta aos desafios encontrados em todas as cadeias de produção. Com isso, a inovação através da oferta de tecnologia de alta qualidade e custo baixo, levando a disrupção em setores, passou a ser estudada por diversas economias, uma vez que a tecnologia pode reduzir os custos (RAO, 2017).

Diante deste cenário, na era de avanço tecnológico, dentre os diferentes tipos de inovações, encontram-se as inovações frugais em pauta nos debates entre indústrias, gerentes de operações e acadêmicos de negócios (TIWARI et al., 2017). Conforme Soni e Krishnan (2014), o conceito originouse nas economias emergentes em busca do desenvolvimento de produtos ou serviços que atendam às necessidades do mercado e garantam acesso a consumidores ainda não atendidos, preenchendo esta lacuna. Desta maneira, Khan (2016) sinaliza em seus estudos que as inovações frugais se tornarão a chave central para o futuro da gestão da inovação e terão a capacidade de proporcionar novos caminhos para as organizações. 
Agarwal e Brem (2017) apontam que a visão frugal vai além do foco em produtos ou serviços e a classifica como um estado de espírito ou até um modo de vida.

Diversos pesquisadores reconhecem esta inovação emergente, como economia reversa, e destacam atributos, como custos significativamente mais baixos, facilidade de uso, recursos limitados e baixos impacto no meio ambiente\| (WEYRAUCH; HERSTATT, 2017).

Conforme o Journal The Economist (2010) as economias em desenvolvimento ou desenvolvidas, enriquecidas com conhecimento, passaram a prestar atenção na Inovação Frugal (FI) visto que, são desafiadas por algum tipo de frugalidade (GOVINDARAJAN; TRIMBLE, 2012). De um lado algumas economias ainda analisam a inovação frugal, e por outro, estudos destacam que os produtos frugais têm a participação em diversos outros mercados e, sinalizam que não há dúvida de que a pesquisa acadêmica desempenha um papel importante na construção de arcabouço teórico e empírico relacionado a temática, já que importantes estudos tem acelerado múltiplos setores da cadeia produtiva (BOUCHERY, 2012; WEISS; CATTANEO, 2017).

Ainda conforme AlMulhim (2021) na última década aumentaram estudos que explicam o papel das fontes internas e externas de conhecimento sobre Inovação Frugal, mas esses estudos se limitam apenas na identificação do papel das fontes de conhecimento nas práticas organizacionais. Dessa forma, para analisar e compreender a inovação frugal pode dar luz a produtos e serviços capazes de preencher lacunas no mercado, além de atender a base da pirâmide, promover vantagem competitiva produzindo mais com menos, além de contribuir com o progresso no entendimento de inovação sustentável.

Considerando-se que a inovação frugal alavanca esforços para criação de novos negócios, produtos, serviços e processos, neste estudo tem-se a seguinte questão: em estudantes de cursos de pósgraduação, a inovação aberta se relaciona de forma direta e positiva com as três dimensões de inovações, de custo, de sustentabilidade, e de produto, sendo preditoras da Inovação Frugal?

Dessa forma, o objetivo desse estudo foi testar a relação entre as dimensões que compõem a inovação frugal (SILVA, 2018; BRESCIANI et al., 2020), sendo elas, a inovação aberta (ALBURUB; LEE, 2012), inovação sustentável (CHEN; LAl; WEN, 2006), inovação em custo (AFONSO et al., 2008) e, a inovação de produto proposta por Gunday et al (2011), utilizando o modelo de equações estruturais para medir essas relações. O conjunto desses quatro tipos de inovações, conceitualmente direcionou o estudo de Silva (2018) e Bresciani et al. (2020), construindo a nomenclatura de Inovação Frugal. 


\section{REVISÃO TEÓRICA}

\section{INOVAÇÃO FRUGAL}

Segundo AlMulhim (2021) as organizações que se concentram no conhecimento de inovação frugal, de fontes internas e externas, encontram-se melhores preparadas no enfrentamento de desafios de sustentabilidade, bem como, desenvolvem suas capacidades e mantem a eficiência para produtividade máxima, utilizando menos recursos.

A expansão dos mercados emergentes, a ampla difusão do consumismo e ao mesmo tempo, a necessidade de desenvolvimento suportável, são fatores que sinalizam a necessidade para que ocorram mudanças e implementação de inovações nos processos de produção, em produtos e serviços. Com base nisso, tem-se a inovação frugal, termo discutido inicialmente para atender as necessidades dos consumidores com limitação financeira, ou seja, para oferecer oportunidade a clientes não afluentes, mas que ao longo de seu desenvolvimento, tem-se expandido para mercados desenvolvidos, como estratégia de melhoria competitiva (HOSSAIN, 2018; WEYRAUCH; HERSTATT, 2017).

Conforme Silva (2018), o objetivo da inovação frugal é criar o novo com menos recursos, utilizando tecnologias apropriadas para o desenvolvimento de produtos e serviços, com qualidade, baixo custo e que atendam às necessidades e expectativas dos consumidores, além disso, essas inovações precisam ser guiadas pela sustentabilidade.

Nesse sentido, é possível afirmar que esse tipo de inovação recomenda - fazer mais com menos, para mais pessoas\| (WEYRAUCH; HERSTATT, 2017), ou seja, o objetivo é tornar o produto ou serviço acessível aos consumidores que tem poucos recursos financeiros.

Hossain (2018, p. 927) define a inovação frugal como uma solução de recurso escasso (produto, serviço, processo ou modelo de negócio) que é concebido e implementado, apesar de limitaç̃̃es financeiras, tecnológicas, materiais ou outros recursos. Ainda, continua explicando que o resultado final é significativamente mais barato do que as ofertas da concorrência (se disponível) e é bom o suficiente para atender as necessidades básicas dos clientes que de outra forma permaneceriam desatendidos $\|$.

É consenso entre autores que a inovação frugal ainda é inexplorada e necessita de muitas pesquisas de análise prática (ALMULHIM, 2021; BRESCIANI et al., 2020). 
Nesse sentido, Hossain (2018) afirma que a inovação frugal é considerada um tópico relevante no discurso social e acadêmico, portanto, sinalizam a importância de desenvolvimento de instrumentos de pesquisa, bem como sua aplicação em estudos empíricos.

\section{INSTRUMENTOS DE INOVAÇÃO FRUGAL}

Enquanto instrumentos validados, a revisão bibliográfica demonstrou a validação de três Escalas de Inovação Frugal, por Rosseto et al. (2017), Silva (2018) e Bresciani et al. (2020). A primeira, com o objetivo de medir o nível de frugalidade alcançado pela organização, o instrumento proposto por Rosseto et al. (2017) é aplicado com uso da escala Likert com cinco a sete pontos.

A métrica proposta por Silva et al. (2018), conceituada como meta-construção de inovação aberta, de custos, de sustentabilidade e de produto, onde cada dimensão contribui para a compreensão da IF, sendo elas: Open Innovation - Inovação Aberta (OI) de Abulrub e Lee (2012); Sustainable Innovation Inovação Sustentável (SI) de Chen (2008); Cost Innovation - Inovação em Custos (CI) de Afonso et al. (2008) e, Product Innovation - Inovação de Produtos (PI) de Gunday et al. (2011).

O questionário foi aplicado com escala Likert com cinco pontos de verificação.

Nesse estudo, os autores aplicaram no contexto organizacional, juntamente com um instrumento de capacidades organizacionais com as seguintes dimensões: capacidade de produção; capacidade tecnológica; capacidade de capital humano e; capacidade de marketing.

A métrica de inovação frugal validada no contexto organizacional brasileiro,pelos autores Silva et al. (2020), foi validada no contexto universitário, sob a percepção de estudantes de graduação, pelos autores Bresciani et al. (2020). A partir da revisão de literatura foram elaboradas as hipóteses do modelo porposto.

\section{INOVAÇÃO ABERTA}

Pode-se inferir que a inovação aberta é uma estratégia competitiva importante em alguns setores, resulta da geração e utilização de ideias dentro e fora das organizações com o uso de entradas e saídas de conhecimento com o propósito de acelerar a inovação interna e expandir os mercados de inovação externa (CHESBROUGH, 2007).

Assim, pode-se considerar que inovação aberta é um determinante do sucesso na realização do processo de produção para alcançar uma produção sustentável. Os resultados de estudos mostram 
que a inovação aberta tem um forte efeito na obtenção de uma produção mais limpa (RUMANTI et al., 2020). Com esse olhar apresentam-se as seguintes hipóteses:

H1: A Inovação Aberta está relacionada à Inovação de Produto;

H2: A Inovação Aberta está relacionada à Inovação em Custo;

H3: A Inovação Aberta está relacionada à Inovação Sustentável.

\section{INOVAÇÃO SUSTENTÁVEL}

O estudo de Chen, Lai e Wen (2006, p. 232) apresenta como objetivo explorar se o desempenho da inovação verde em produto e inovação verde em processo trouxe efeitos positivos para a vantagem competitiva das empresas pesquisadas.

Desta maneira, ressaltam que a adoção de estratégias proativas na gestão ambiental corporativa pode, para além de prevenir a empresa de enfrentar protestos ambientalistas ou penalidades, mas também ajudar as empresas a desenvolver novas oportunidades de mercado e aumentar a vantagem competitiva.

A coleta de dados realizada pelos autores envolveu o envio de 600 questionários para gestores de produção, marketing, P\&D e, departamentos de proteção ambiental, de diferentes empresas de Taiwan. O instrumento utilizado continha 4 itens relacionados a inovação verde e 8 itens para medição do desempenho da vantagem competitiva das empresas (CHEN, LAI; WEN, 2006) .

Considerando que a inovação sustentável contribui com inovações que trazem principalmente soluções para questões ambientais, ainda, sendo reconhecida como uma estratégia de diferenciação no uso correto e racional de insumos, com menor custo e menor risco ambiental e para consumidores, alinhando-se com as expectativas dos stackholders, apresentam-se as seguintes hipóteses:

H4: A Inovação Sustentável está relacionada à Inovação de Produto;

H5: A Inovação Sustentável está relacionada de à Inovação em Custo.

\section{INOVAÇÃO EM CUSTO E INOVAÇÃO DE PRODUTO}

Afonso et al. (2008) defendem que a redução do tempo e o custo de Desenvolvimento de Novos Produtos (NPD), pode criar vantagens relativas em participação de mercado, lucro e competitividade a longo prazo, principalmente durante o primeiro estágio, ou seja, na fase de produção, antes de disponibilizar o produto no mercado. Diante disso, o estudo desses autores segue pesquisas que 
abordam Custo do NPD, Custeio Alvo (TC) e a Redução do lead time para o desenvolvimento de produtos - TtM (time-to-market), com o objetivo de testar fatores e variáveis que estão associados com as habilidades organizacionais de minimização de tempo e custo.

$\mathrm{Na}$ inovação de produto e serviço incluem-se melhoramentos significativos em especificações técnicas, componentes e materiais, softwares incorporados, facilidades de uso ou outras características funcionais (OECD, 2018, p. 56). Seguindo esse conceito, o objetivo do estudo de Gunday et al. (2011) foi explorar as inovações e seus efeitos sobre o desempenho da empresa, examinando inovações em produto, processo, marketing e organizacional, bem como o desempenho de produção, desempenho de mercado e desempenho financeiro.

A inovação de produto é um processo difícil, impulsionado pelos avanços das tecnologias, mudança nas necessidades dos clientes, encurtamento dos ciclos de vida dos produtos e aumento da concorrência global|l (GUNDAY et al., 2011, p. 672).

Considerando os estudos de inovação em custos e inovação de produto, apresenta-se a seguinte hipótese:

H6: A Inovação em Custo está relacionada à Inovação de Produto.

\section{METODOLOGIA}

Conforme Hair Jr. et al. (2009) é necessário que seja realizada a operacionalização da quantificação das variáveis. Portanto, estas precisam ser transformadas passíveis de observação empírica e mensuração (GIL, 1999). Em decorrência disso, as dimensões inovação aberta, inovação sustentável, inovação em custos e inovação de produtos foram mensuradas com base em instrumentos de pesquisa já validados no Brasil.

O instrumento utilizado foi de Silva (2018) e validado no contexto universitário por Bresciani et al. (2020), ou seja, foram utilizadas 18 afirmativas, composto por um construto exógeno (OI) e três construtos endógenos (OS, OP e OC), respondido com escala Likert de 5 pontos, indo desde - discordo totalmente\| (1) até - concordo totalmente\| (5).

A inovação aberta (ALBURUB e LEE, 2012) é o construto exógeno proposto no modelo, já a inovação sustentável (CHEN; LAl; WEN, 2006), inovação em custo (AFONSO et al., 2008) e inovação de produto (GUNDAY et al., 2011) são construtos endógenos de inovação frugal, instrumento validado por Silva (2018). 
No instrumento validado por Bresciani et al. (2020) juntamente com a Intenção Empreendedora, os autores afirmam que a intenção empreendedora contribui para o entendimento da construção da inovação frugal através da inovação aberta, sustentável, de custos e de produtos. Neste sentido, o modelo estudado, reflete como os estudantes de graduação com intenção empreendedora reconhecem a inovação frugal (BRESCIANI et al., 2020).

No presente estudo o instrumento utilizado é composto por 18 afirmativas, adaptadas para o contexto de estudantes universitários e respondido com uma escala Likert de cinco pontos, indo desde discordo totalmente\| (1) até concordo totalmente\| (5).

A amostra é definida como não probabilística por conveniência, com a população de 3.801 estudantes de pós-graduação da Universidade Federal de Santa Maria-UFSM. Foram disparados os questionários de forma on line para todos os estudantes matriculados nos cursos de pós-graduação, 462 questionários foram respondidos e utilizados para esse estudo.

Seguidamente, optou-se pelas técnicas de modelagem de equações estruturais baseada em variâncias (Partial Least Squares Structural Equation Modeling - PLS- SEM). A abordagem PLS-SEM se concentra na maximização da variância explicada das dimensões endógenas, assim, a modelagem de equação estrutural é considerada uma poderosa ferramenta por sua versatilidade em facilitar a confirmação de relações existente entre múltiplas variáveis (HAIR Jr.; GABRIEL; PATEL, 2014).

\section{MEDIDAS E VALIDAÇÃO}

A Inovação aberta (OI) foi usada como variável independente. Esta variável causa flutuações em outras variáveis no modelo. A literatura de inovação considera a inovação aberta um das mais importantes construtos e consequências das demais inovações, bem como do desenvolvimento sustentável, através da iniciação, acessibilidade, construção de pontes e encontrando soluções únicas para os problemas através do diálogo mútuo e reciprocidade (SEXANA, 2015).

Assim, esta interação de interação deve facilitar a formação de um desenvolvimento sustentável e inclusivo por meio de inovações abertas, portanto, este critério é de relevância teórica. A análise preditiva inclui a inovação aberta neste modelo como preditora das demais inovações que compõem a inovação frugal através da análise dos mínimos quadrados parciais (PLS) para a construção de um modelo estrutural (CHIN, 1998). Os valores da variável exógena não são explicados pelo modelo, são assumidos como resultado. 
Portanto, a Inovação Sustentável (SI), Inovação de Custos (CI) e Inovação em Produtos (PI), são chamadas de endógenas e dependentes, porque são influenciadas pelas variáveis exógenas do modelo, de forma direta ou indireta. Os valores das variáveis endógenas são explicados por uma ou mais variáveis exógenas do modelo.

\section{RESULTADO DA PESQUISA}

A análise do diagrama de mensuração e suas relações entre variáveis latentes e suas respectivas variáveis observadas são apresentadas na Figura 1.

Figura 1 - Modelo de mensuração Inovação Frugal

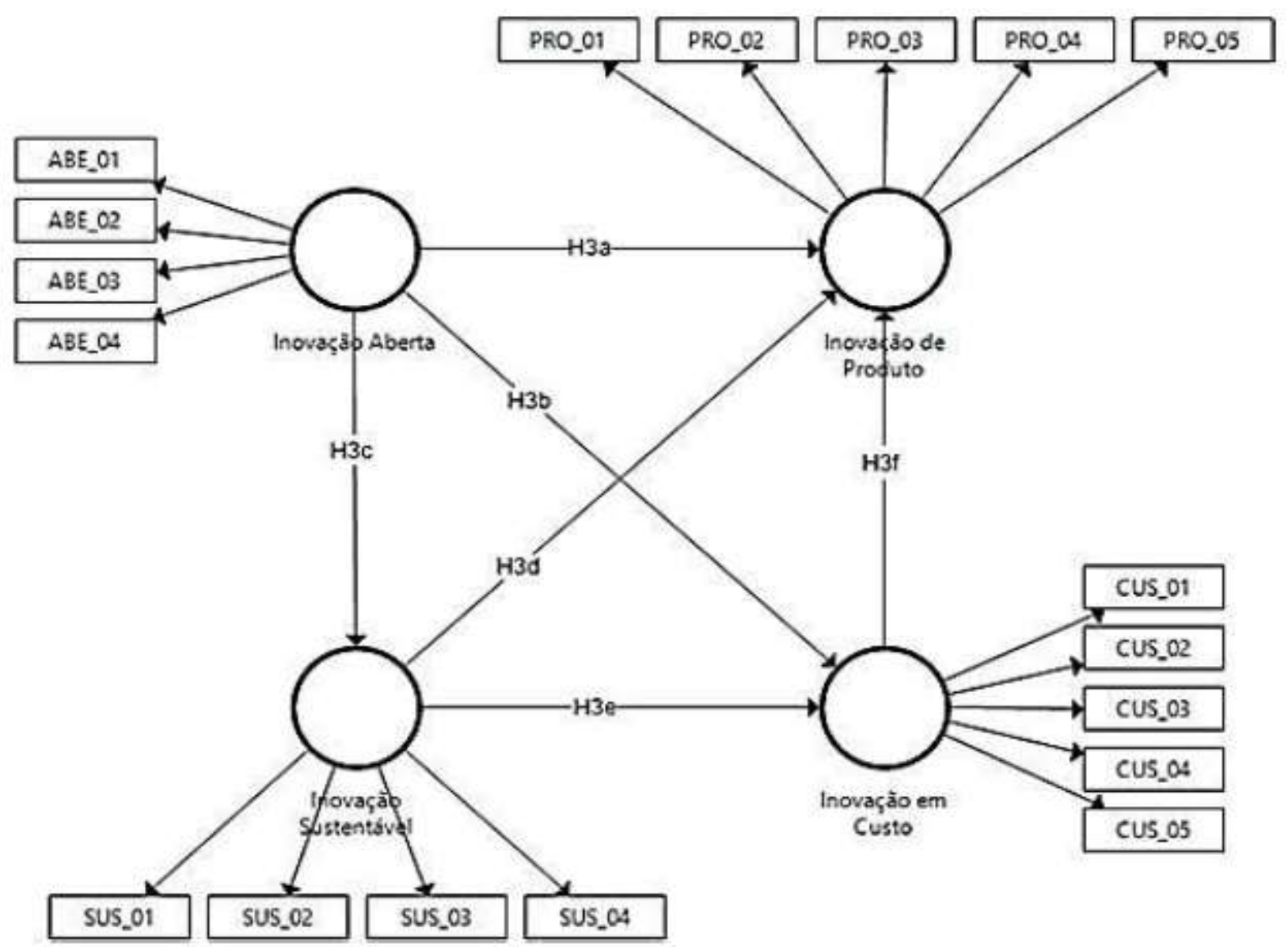

Fonte: Software Smart PLS ${ }^{\circledR}$ v. 3.3.3 (RINGLE; WENDE; BECKER, 2015).

Conforme a Figura 1 observa-se que o modelo de mensuração apresenta quatro hipóteses que conectam as cinco variáveis latentes as 14 variáveis observadas e 4 varáveis latentes (OI), sendo a variável independente. Já a inovação sustentável, de produtos e em custos, são as variáveis 
dependentes do modelo proposto no presente estudo. As escalas utilizadas são de estudos anteriores válidos e confiáveis. O construto de inovação aberta foi medido com uma escala de quatro itens, adotados a partir dos estudos de Alburub e Lee (2012). Uma escala de cinco itens foi adotada de Gunday et al. (2011) para medir a variável inovação de produto. Para inovação sustentável a escala de quatro itens de Chen, Lai e Wen (2006). E, por fim uma escala de cinco itens foi adotada de Afonso et al., (2008) para medir a variável inovação em custo.

Foram utilizadas três etapas para análise dos dados coletados. Na primeira estrutura de análise, com os dados processados no SmartPLS 3.3.2 foram verificadas as cargas fatoriais de todas as variáveis, para avaliar a consistência interna e a validade de construto (validade convergente e validade discriminante). O resultado demonstrou a validade das cargas referentes aos construtos próximas de 0,70, dessa maneira, não sendo necessário excluir nenhuma variável do presente estudo. Hair Jr et al. (2009) afirmam que as cargas fatoriais entre as variáveis latentes e as manifestas, são considerados valores aceitáveis maiores que 0,70 .

O estudo retratou validade convergente aceitável, uma vez que a variância média extraída (AVE) de todos os seus construtos reflexivos de primeira ordem (inovação aberta, inovação sustentável, inovação de produto e inovação em custo), com valores excedentes a 0,50, enquanto as cargas fatoriais de todos os itens ficaram acima de 0,70 (HAIR et al., 2017 ). Corroborando com Chin (1998) que considera cargas fatoriais que variam de 0,50 a 0,70 aceitáveis como os valores para AVE e carga fatorial de todos os construtos reflexivo excederam seus valores aceitáveis padrão, a validade convergente é considerada adequada.

Na Tabela 1, pode-se observar a consistência interna e validade convergente, resultados que atendem aos requisitos de obtenção de valores superiores a 0,50 para VME, valores superiores a 0,70 para a consistência interna ( $\alpha$ de Cronbach) e a confiabilidade composta, conforme pontuam Hair Jr. et al. (2009).

Tabela 1 - Alfa de Cronbach, Confiabilidade Composta e AVE para o modelo

\begin{tabular}{lccc}
\hline \multicolumn{1}{c}{ Dimensões } & $\begin{array}{c}\text { Alfa de } \\
\text { Cronbach }\end{array}$ & $\begin{array}{c}\text { Confiabilidade } \\
\text { Composta }\end{array}$ & $\begin{array}{c}\text { Variância Média } \\
\text { Extraída (VME) }\end{array}$ \\
\hline Inovação Aberta & 0,844 & 0,895 & 0,681 \\
Inovação Sustentável & 0,939 & 0,956 & 0,846 \\
Inovação de Produto & 0,951 & 0,963 & 0,837 \\
Inovação em Custo & 0,925 & 0,944 & 0,770 \\
\hline
\end{tabular}

Fonte: Software SmartPLS ${ }^{\circledR}$, v. 3.3.3 (RINGLE; WENDE; BECKER, 2015). 
A Tabela 1 demonstra que os resultados iniciais foram satisfatórios. Já, a segunda etapa, após se garantir a validade convergente (VC), foi a de observação dos valores da consistência interna alfa de Cronbach (AC) e confiabilidade composta (CC) (RINGLE et al., 2014).

Valores de alfa e confiabilidade composta de 0,60 a 0,70 são considerados adequados em pesquisas exploratórias e valores de 0,70 a 0,90 são considerados satisfatórios (HAIR Jr et al., 2015). Assim, ao analisar a Tabela 1, observou-se que o ajuste do modelo de forma compatível com os parâmetros sugeridos por Chin (1998) respectivamente para: validade convergente (VME >0,50); confiabilidade composta (Valores $>0,70$ ) e $\alpha$ de Cronbach (valores $>0,70$ ). O resultado da validade discriminante, também, mostrou-se satisfatório após o ajuste do modelo.

Depois de reconhecidas as inter-relações provenientes das variáveis e estruturado o modelo de mensuração de caminhos (Figura 2), com os resultados referentes aos quatro construtos, o modelo de caminhos fornece os resultados das cargas fatoriais entre indicadores e construtos.

Figura 2 - Modelo de caminhos da dimensão Inovação Frugal

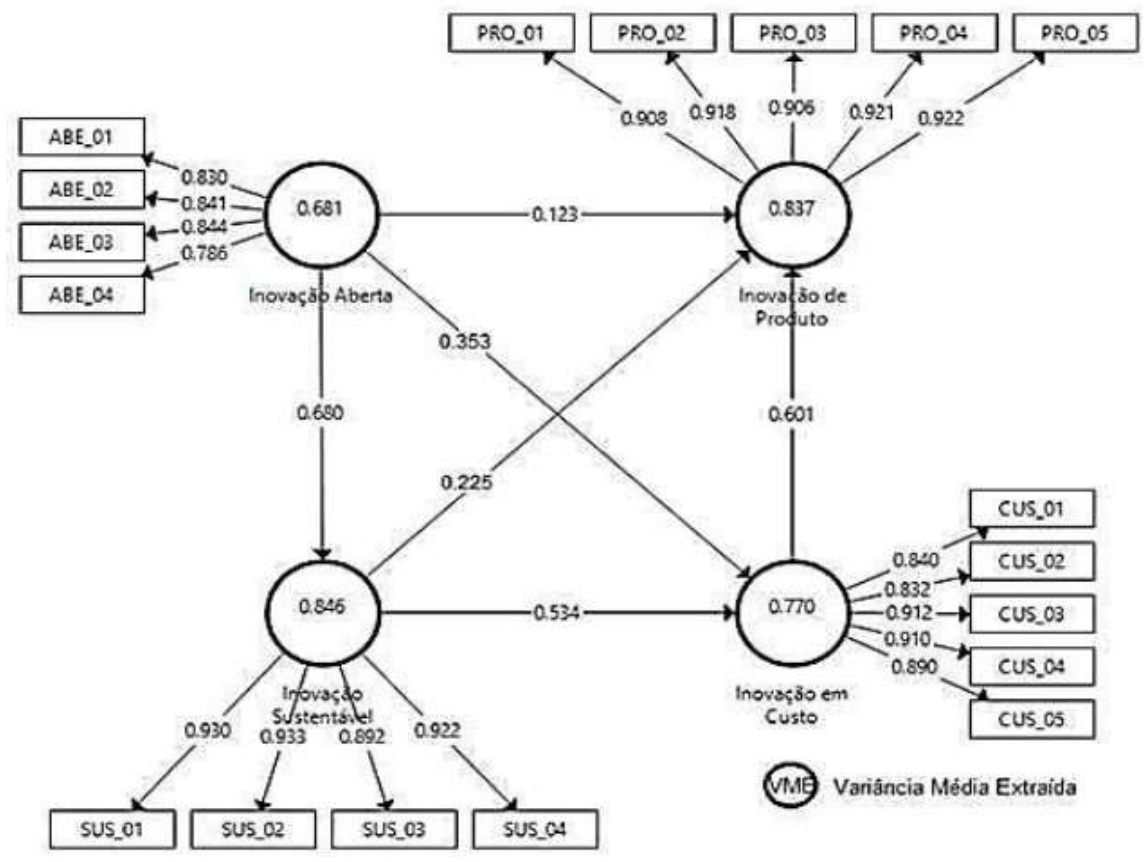

Fonte: SmartPLS ${ }^{\circledR}$ software, v. 3.3.3 (RINGLE; WENDE; BECKER, 2015).

Através do diagrama de caminhos, é possível descrever as equações estruturais, conforme a Tabela 2. 
Tabela 2 - Diagrama de caminhos inicial para o modelo

\begin{tabular}{ccccc}
\hline Dimensões Endógenas & $=$ & Dimensões Exógenas & + & Erro \\
\hline PRO & $=$ & $\beta_{1} \mathrm{ABE}+\beta_{2} \mathrm{SUS}+\beta_{3} \mathrm{CUS}$ & + & $\varepsilon_{\mathrm{PRO}}$ \\
SUS & $=$ & $\beta_{4} \mathrm{ABE}$ & + & $\varepsilon_{\mathrm{SUS}}$ \\
CUS & $=$ & $\beta_{5} \mathrm{ABE}+\beta_{6} \mathrm{SUS}$ & + & $\varepsilon_{\mathrm{CUS}}$ \\
\hline
\end{tabular}

Fonte: Dados da pesquisa com base em Hair Jr., Gabriel e Patel (2014).

Na segunda etapa foi utilizada a avaliação da Validade Discriminante (VD) do MEE. Conforme Hair Jr. et al. (2014) a VD é um indicador de que as dimensões ou variáveis latentes são independentes uma das outras. Nesse sentido, foi utilizado o critério de Fornell e Larcker (1981) onde se compara as raízes quadradas dos valores das VME's de cada dimensão com as correlações Pearson entre os construtos (ou variáveis latentes). O resultado encontrado das raízes quadradas das VME's deve ser maiores que as correlações entre as dimensões.

Os resultados apresentados na Tabela 3 confirmam a validade discriminante, visto que todos os valores estão bem abaixo dos limites recomendados. De acordo com Fornell e Larcker (1981) os valores de correlação menores que a AVE (valores superiores a 0,50 confirma a validade discriminante. Ainda conforme Ringle, Silva e Bido (2014), a dimensão é única variável que carrega características que não são representativas de outras. Conforme os resultados apresentados na Tabela 3 verifica-se que as cargas fatoriais das VO's nos constructos (VL's) originais são sempre maiores que em outro, constatando dessa forma, que o modelo tem validade discriminante pelo critério de Chin (1998). 
Tabela 3 - Análise da validade discriminante pelo método de Fornell-Larker

\begin{tabular}{|c|c|c|c|c|}
\hline \multirow{2}{*}{ Indicadores } & \multicolumn{3}{|c|}{ Dimensões (Inovacão) } & \multirow[b]{2}{*}{ Sustentável } \\
\hline & Aberta & Custo & Produto & \\
\hline ABE_01 & 0,830 & 0,513 & 0,532 & 0,556 \\
\hline ABE_02 & 0,841 & 0,638 & 0,617 & 0,574 \\
\hline $\mathrm{ABE} 03$ & 0,844 & 0,640 & 0,626 & 0,539 \\
\hline $\mathrm{ABE}^{-} 04$ & 0,786 & 0,564 & 0,550 & 0,576 \\
\hline CUS_01 & 0,581 & 0,840 & 0,678 & 0,714 \\
\hline CUS_02 & 0,585 & 0,832 & 0,644 & 0,617 \\
\hline CUS_03 & 0,670 & 0,912 & 0,778 & 0,690 \\
\hline CUS 04 & 0,653 & 0,910 & 0,825 & 0,698 \\
\hline CUS_05 & 0,648 & 0,890 & 0,842 & 0,678 \\
\hline PRO_01 & 0,648 & 0,819 & 0,908 & 0,698 \\
\hline PRO_02 & 0,655 & 0,817 & 0,918 & 0,709 \\
\hline PRO_03 & 0,631 & 0,763 & 0,906 & 0,740 \\
\hline PRO 04 & 0,655 & 0,781 & 0,921 & 0,697 \\
\hline PRO_05 & 0,642 & 0,767 & 0,922 & 0,697 \\
\hline SUS_01 & 0,645 & 0,698 & 0,698 & 0,930 \\
\hline SUS_02 & 0,634 & 0,702 & 0,696 & 0,933 \\
\hline SUS_03 & 0,638 & 0,714 & 0,748 & 0,892 \\
\hline SUS_-04 & 0,581 & 0,734 & 0,702 & 0,922 \\
\hline
\end{tabular}

Fonte: Software SmartPLS ${ }^{\circledR}$, v. 3.3.3 (RINGLE; WENDE; BECKER, 2015).

A validade discriminante pode ser entendida como a constatação de que as cargas fatoriais de cada variável observada (indicador) agrupam-se em seus respectivas dimensões ou variáveis latentes (RINGLE; SILVA; BIDO, 2014). A Tabela 4 apresenta os resultados encontrados conforme critérios Critérios de Fornell-Larker e HTMT do modelo.Tabela 4 - Critérios de Fornell-Larker e HTMT

Matriz de Correlação de Pearson

\begin{tabular}{lccccc}
\cline { 2 - 3 } Dimensoes & V M & Aberta & Sustentável & Produto & Custo \\
\hline ABE & 0,825 & 1,000 & & & \\
SUS & 0,920 & 0,680 & 1,000 & & \\
PRO & 0,915 & 0,706 & 0,774 & 1,000 & \\
CUS & 0,877 & 0,716 & 0,774 & 0,863 & 1,000 \\
\hline
\end{tabular}

LS (HTMT) ${ }_{97,5 \%}$

\begin{tabular}{lccc} 
Inovação Aberta & & \\
Inovação Sustentável & 0,820 & & \\
& 0,836 & 0,862 & \\
Inovação de Produto & 0,874 & 0,940 \\
\hline
\end{tabular}

Fonte: Software SmartPLS ${ }^{\circledR}$, v. 3.3.3(RINGLE; WENDE; BECKER, 2015). 
Os resultados encontrados indicam o quanto as variáveis latentes são independentes uma das outras, confirmando a validade discriminante de cada dimensão (HAIR Jr. et al., 2017). Na Tabela 4 observouse a confirmação do Critério de Fornell- Larker, onde na diagonal apresentam as raízes quadradas das VME's e nas demais células as correlações entre as dimensões, onde para confirmar o critério a $\sqrt{V M E^{\prime} s}>r_{i j}$, para $i \neq \mathrm{j}$. Já o critério de HTMT (Heterotrait-Monotrait Ratio) os resultados atendem a exigência do critério, ou seja, os LS (HTMT)97,5\% < 1,00.

Conforme apontamentos de Chin (1998) utilizou-se a observação das cargas cruzadas (cross loading), observando os indicadores com cargas fatoriais mais altas nas suas respectivas variáveis latentes (VL ou dimensão) do que em outras, confirmando a validade discriminante de cada dimensão (Tabela 4). $\mathrm{Na}$ terceira etapa, após a confirmação da validade discriminante de cada dimensão parte-se para a análise do modelo estrutural. Nesse sentido, Hair Jr. et al.

(2017) pontuam que a avaliação do modelo estrutural pode ser medida pela análise de colinearidade (Variance Inflation Factor - VIF); pela avaliação da relevância preditiva Q2; nível de significância do R2; tamanho do efeito f2; e por fim, avaliação da significância e relevância dos betas do modelo estrutural (teste $\mathrm{t}$ de Student). A Variance Inflation Factor - VIF indica se há um potencial problema de colinearidade no modelo (Tabela 5).

Tabela 5 - Valores de VIF - Análise de multicolineariedade para as dimensões do modelo

\begin{tabular}{|c|c|c|c|}
\hline \multirow{2}{*}{ Dimensões Exógenas } & \multicolumn{3}{|c|}{ Dimensões Endógenas (Inovação) } \\
\hline & Sustentável & Produto & Custo \\
\hline Inovação Aberta & 1,000 & 2,233 & 1,858 \\
\hline Inovação Sustentável & & 2,716 & 1,858 \\
\hline Inovação em Custo & & 3,003 & \\
\hline
\end{tabular}

Fonte: Software SmartPLS ${ }^{\circledR}$, v. 3.3.3(RINGLE; WENDE; BECKER, 2015).

Observa-se no modelo que todos os valores de $\mathrm{VIF}<5$, atendendo a não existência de fortes correlações entre as dimensões, portanto não há problemas de colinearidade. O VIF é uma medida do grau em que cada variável independente é explicada pelas demais variáveis independentes. Quanto maior for o fator de inflacionamento da variância, mais severa será a multicolinearidade. Conforme Hair et al. (2010), além dos efeitos na explicação, a multicolinearidade pode ter sérios efeitos nas estimativas dos coeficientes de regressão e na aplicabilidade geral do modelo estimado. 
Os resultados mostraram que o VIF dos construtos variou de 1.000 a 3.003 , o que indica que a multicolinearidade não foi um problema nesse estudo. Além disso, as cargas principais de cada construto foram significativamente maiores do que as outras cargas, o que novamente indicou que a multicolinearidade não foi um problema.

Conforme Kutner et al. (2004) a regra geral aceita para a existência de multicolinearidade que os fatores de inflação da variância (VIFs) sejam maiores que dez, ou o valor de tolerância menor que 0,10. Ainda, seguindo os preceitos de Ringle, Silva e Bido (2014), avaliou-se o poder de predição do modelo e a utilidade de cada variável latente, por intermédio dos indicadores de validade preditiva $\left(Q^{2}\right)$ demonstrado na Tabela 6.

Tabela 6 - Relevância preditiva do modelo

\begin{tabular}{lccc}
\multicolumn{1}{c}{ Dimensões Preditivas } & SQO & SQE & $\mathrm{Q}^{2}=1-{ }^{-\mathrm{SQE}}$ \\
& & & $\mathrm{SQO}$ \\
\hline Inovação Sustentável & $1.852,00$ & $1.135,70$ & 0,387 \\
Inovação de Produto & $2.315,00$ & 817,28 & 0,647 \\
Inovação em Custo & $2.315,00$ & $1.135,59$ & 0,509 \\
\hline
\end{tabular}

SQO = Soma dos Quadrados Observados; SQEE = Soma dos Quadrados dos Erros Fonte: Software SmartPLS ${ }^{\circledR}$, v. 3.3.3(RINGLE; WENDE; BECKER, 2015).

Os resultados mostraram que o modelo apresentou propriedade preditiva ao processar valores $\mathrm{Q}^{2}$ maiores do que zero $(I C=0,509, I S=0,387$ e IP =0,647), destacando a inovação em produto com o maior grau de propriedade preditiva.

Em seguida na Tabela 7 foram analisados o tamanho do efeito $\left(\mathrm{f}^{2}\right)$, obtidos pelo módulo Blindfolding, a qualidade do modelo ajustado e busca a variância das dimensões endógenas explicadas pelo modelo estrutural (RINGLE; SILVA; BIDO, 2014) e os coeficientes de explicação de Pearson ( ${ }^{2}$ ).

Conforme os autores, os valores referenciais para análise do $\mathrm{R}^{2}$ seguem os parâmetros sugeridos por Cohen: $2 \%$ efeito pequeno, $13 \%$ efeito médio e $26 \%$ efeito grande. A inovação aberta consegue explicar a inovação de produto é explicada em $78 \%$ pela inovação aberta, a inovação em custo é explicada em $67 \%$ pela inovação aberta, e por fim a inovação sustentável é explicada em $46 \%$ pela inovação aberta, ou seja, R2 representa em uma escala de $0 \%$ a $100 \%$ o quanto os construtos independentes explicam os dependentes. 
Tabela 7 - Efeitos entre as dimensões $\left(f^{2}\right)$ e coeficiente de explicação $\left(R^{2}\right)$

\begin{tabular}{cccc}
\hline \multirow{2}{*}{ Dimensões Exógenas } & & \multicolumn{3}{c}{ Dimensões Endógenas (Inovacão) } \\
\cline { 3 - 4 } & Sustentável & Produto & Custo \\
\hline Inovação Aberta & $0,858(0,000)$ & $0,031(0,132)$ & $0,202(0,000)$ \\
\hline $\mathrm{R}^{2}$ & $0,462(0,000)$ & $0,780(0,000)$ & $0,667(0,000)$ \\
\hline
\end{tabular}

Fonte: Software SmartPLS ${ }^{\circledR}$, v. 3.3.3 (RINGLE; WENDE; BECKER, 2015).

O tamanho do efeito ( $f 2$ ) ou indicador de Cohen (Tabela 7) avalia quanto a dimensão é útil para o ajuste do modelo. O valor é obtido pela inclusão e exclusão de dimensões no modelo (um a um). Hair Jr et al. (2017) consideram respectivamente valores de 0,02, 0,15 e 0,35 pequenos, médios e grandes, onde apenas a inovação de produto possui um efeito médio sobre o modelo, as demais inovações apresentam um

A variável latente exógena Inovação aberta (OI) em relação a variável dependentes endógenas inovação sustentável (SI), admitiu-se um poder de grande de explicação, de 86\% na variável dependente endógena. Em relação a variável dependente endógena inovação de produto (PI), admitiu-se um pequeno poder de explicação de 0,3\% e por fim, a variável endógena inovação em custos foi considerada com um médio efeito de $20 \%$. Constatadas as validades convergente e discriminante, bem como a confiabilidade dos modelos de mensuração reflexivos e o poder de explicação das variáveis latentes endógenas pela variável exógena $\left(13<R^{2}<27 \%\right)$, foi iniciada a análise do modelo de mensuração.

Após os ajustes relacionados ao valor preditivo e o tamanho do efeito do modelo foi calculado o coeficiente de caminhos do modelo proposto que são: entre IA e IS $(0,858)$, entre IA e IP $(0,031)$, entre IA e IC $(0,202)$. Dessa maneira, a Figura 3 demonstra o modelo de caminhos final das relações entre as dimensões. 
Figura 3 - Modelo de caminhos final da dimensão Inovação Frugal

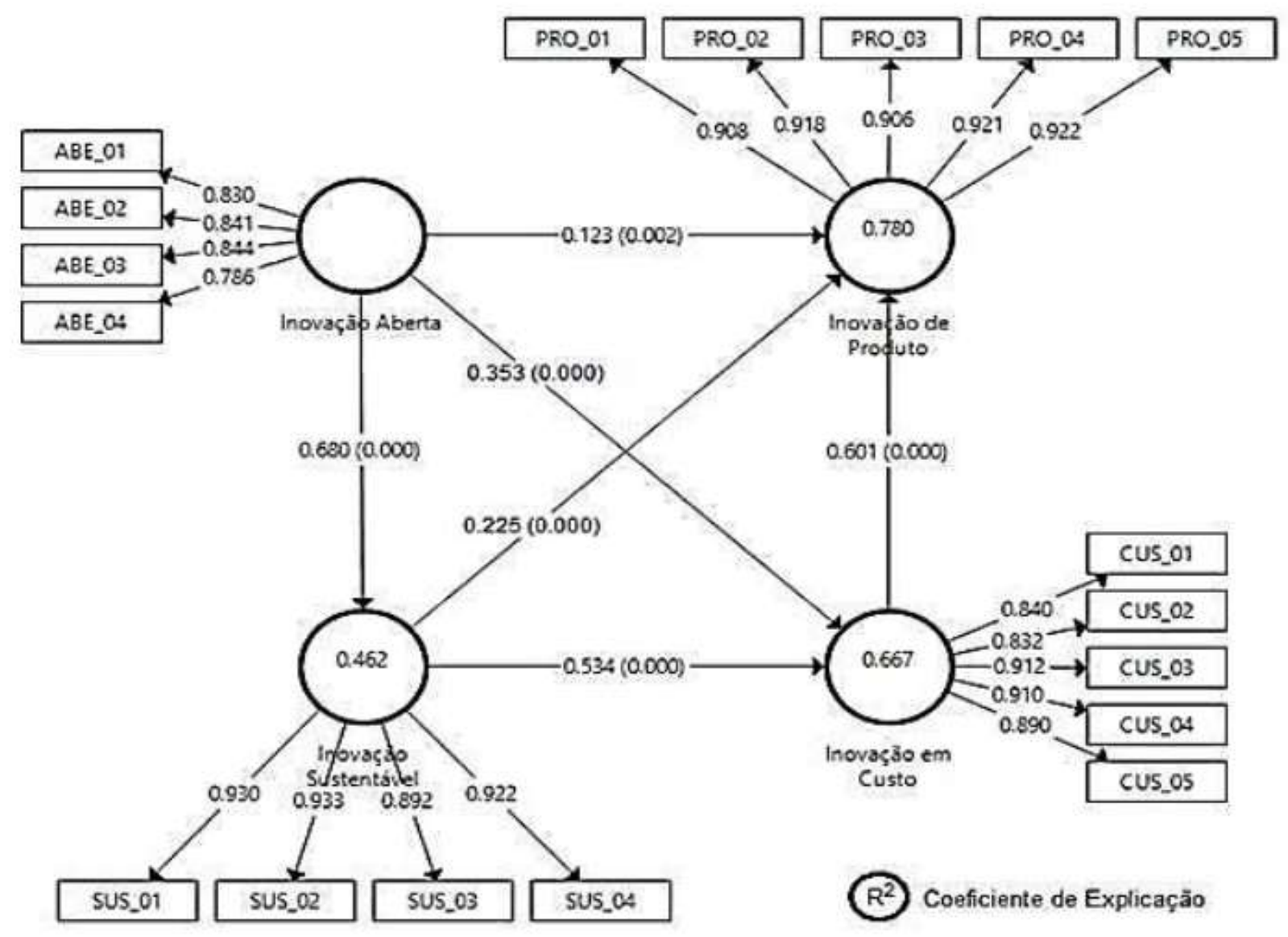

Fonte: SmartPLS ${ }^{\circledR}$ software, v. 3.3.3 (RINGLE; WENDE; BECKER, 2015).

A Figura 3 do modelo final apresenta os itens referentes a cada dimensão após as etapas de validação do modelo, desta forma, o presente estudo conclui que o modelo é sustentado empiricamente e suas dimensões possuem relações significativas. Os valores de todos os índices de ajustes confirmam o excelente ajuste do modelo estrutural. Na Tabela 8 é apresentado o diagrama de caminhos final para o modelo.

Tabela 8 - Diagrama de caminhos final para o modelo

\begin{tabular}{clccc}
\hline Dimensões Endógenas & $=$ & Dimensões Exógenas & + & Erro \\
PRO & $=$ & $0,123 \mathrm{ABE}+0,225 \mathrm{SUS}+0,601 \mathrm{CUS}$ & + & $\varepsilon_{\mathrm{PRO}}$ \\
SUS & $=$ & $0,680 \mathrm{ABE}$ & + & $\varepsilon_{\mathrm{SUS}}$ \\
CUS & $=$ & $0,353 \mathrm{ABE}+0,534 \mathrm{SUS}$ & + & $\varepsilon_{\mathrm{CUS}}$ \\
\hline
\end{tabular}

Fonte: Dados da pesquisa com base em Hair Jr., Gabriel e Patel (2014). 
Na sequência, foram calculados também os valores do teste $t$, que conforme Hair Jr. et al. (2009), deve-se testar a relação causal entre duas dimensões, através do teste $t$ de Student para verificar se ela é significante ou não para que o coeficiente Beta seja significativo ou não. A Tabela 9 demonstra as relações entre as dimensões.

Tabela 9 - Validação dos coeficientes estruturais e suas respectivas hipóteses

\begin{tabular}{cccccccc}
\hline Dim. Exógenas & $\rightarrow$ & Dim. Endógenas & $\beta$ 's & D.P. & $\begin{array}{c}\text { Estat. T } \\
(\mid \beta / \mathbf{D} \text {. P. })\end{array}$ & p-valor & Situação \\
\hline Aberta & $\rightarrow$ & Sustentável & 0,680 & 0,029 & 23,299 & 0,000 & Aceita \\
Aberta & $\rightarrow$ & Produto & 0,123 & 0,039 & 3,147 & 0,002 & Aceita \\
Aberta & $\rightarrow$ & Custo & 0,353 & 0,041 & 8,528 & 0,000 & Aceita \\
Sustentável & $\rightarrow$ & Produto & 0,225 & 0,042 & 5,294 & 0,000 & Aceita \\
Sustentável & $\rightarrow$ & Custo & 0,534 & 0,040 & 13,502 & 0,000 & Aceita \\
Custo & $\rightarrow$ & Produto & 0,601 & 0,046 & 13,193 & 0,000 & Aceita \\
\hline
\end{tabular}

Fonte: Software SmartPLS ${ }^{\circledR}$, v. 3.3.3(RINGLE; WENDE; BECKER, 2015).

De acordo com os dados apresentados na Tabela 9, os valores das relações entre as VL estão acima do valor de referência 1,96, considerando o nível de significância adotado de 5\%, ou seja, as dimensões se relacionam de forma significativa (HAIR Jr, et al., 2017; RINGLE, SILVA, BIDO; 2014). Os valores encontrados foram: $\mathrm{OI} \rightarrow \mathrm{SI}$ (tcal = 23,299), $\mathrm{OI} \rightarrow \mathrm{PI}(\mathrm{tcal}=3,147), \mathrm{OI} \rightarrow \mathrm{Cl}$ (tcal = 8,528), $\mathrm{SI} \rightarrow \mathrm{PI}(\mathrm{tcal}=$ 5,294), $\mathrm{SI} \rightarrow \mathrm{Cl}$ (tcal = 13,502), $\mathrm{Cl} \rightarrow \mathrm{PI}(\mathrm{tcal}=13,193)$,. Sendo assim, todas as hipóteses propostas no modelo foram aceitas.

Finalizada a avaliação da qualidade de ajuste do modelo, por intermédio das análises de coeficientes de caminho do modelo ajustado, interpretados como os betas ( $\beta$ 's) da regressão, conclui-se que as relações da Inovação Frugal: Inovação Aberta (OI), Inovação Sustentável (SI), Inovação de Custos (CI) e Inovação de Produtos (PI) são significativas $(t>1,96$ e $p<0,05)$ o que levou a aceitação de todas as hipóteses ( $\mathrm{H} 1, \mathrm{H} 2, \mathrm{H} 3, \mathrm{H} 4, \mathrm{H} 5$ e H6). Os coeficientes de caminho (B), explicam quão forte é o efeito de um construto sobre os demais, dessa forma, a inovação aberta exerce o maior efeito do modelo sobre a inovação sustentável, com 0,680 graus.

As análises confirmaram a relação positiva entre a inovação aberta e inovação sustentável (H1), inovação aberta e inovação de produto $(\mathrm{H} 2)$, inovação aberta e inovação em custo $(\mathrm{H} 3)$, inovação sustentável e inovação em produto (H4), inovação sustentável e inovação em custo, (H5) e inovação em custo e inovação de produto (H6). 
Assim, a primeira hipótese propõe que a Inovação aberta influência direta e positivamente a inovação sustentável. Conforme os dados descritos o coeficiente de caminho da relação entre Ol e SI é o mais significativo, com um beta de 0,680 e $p$ no valor de 0,000 . Os resultados confirmam que a inovação aberta favorece a inovação sustentável em $68 \%$ e a inovação em custo favorece a inovação do produto em $60 \%$.

Podemos destacar ainda que a inovação sustentável favorece a inovação em custo em 53\%.

A seis hipóteses influenciam direta e positivamente as relações propostas entre os construtos. A primeira hipótese é suportada com um $\beta=0,680(p=0,000)$. A segunda hipótese apresentada no estudo (H2) a qual analisa a influência direta e positiva da inovação aberta e da inovação de produto é suportada com um valor de $\beta=0,123(p=0,002)$. A terceira hipótese apresenta um valor de beta= $0,353(p=0,000)$. Enquanto a quarta hipótese $\beta=0,225(p=0,000)$, já a quinta hipótese $\beta=0,534(p=$ $0,000)$. E por fim, a sexta hipótese $]=0,601(p=0,000)$. De fato, a inovação sustentável é a dimensão mais impactada pela inovação aberta, seguida pela inovação em produto fortemente impactada pela inovação de custo.

\section{CONSIDERAÇÕES FINAIS}

O objetivo desse estudo foi testar a relação entre as dimensões da Inovação Frugal, composta pelas dimensões de inovação aberta (ALBURUB; LEE, 2012), inovação sustentável (CHEN; LAI; WEN, 2006), inovação em custo (AFONSO et al., 2008) e, inovação de produto (GUNDAY et al., 2011), utilizando o modelo de equações estruturais. A dimensão exógena de inovação aberta e as três dimensões endógenas de inovação, formam o modelo de inovação frugal proposto por Silva (2018) no contexto organizacional, validados e adaptados por Bresciani et al. (2020) para o contexto de estudantes do ensino superior.

Para o modelo proposto, a inovação aberta (OI) se relaciona de forma direta e positiva com as demais inovações, com isso, corrobora com o apontamento realizado no estudo de Bogers et al. (2018), que indicam a abertura das empresas a fontes externas de conhecimento como um importante impulsionador do desempenho da inovação.

Os resultados indicam que o modelo atendeu os critérios de validade convergente e discriminante para todas as pressuposições. Além disso, os resultados mostraram a confiabilidade das dimensões variando de 0,80 a 0,93, indicando que todos os valores foram dentro da escala aceitável. As análises 
confirmaram todas as relações são positivas entre e dimensão exógena (IO) as dimensões endógenas (OS, OP e OC).

Constatou-se, também, que a maior significância estatística foi entre Inovação aberta (OI) e inovação sustentável (IS) a qual o valor de $t$ da relação $(\mathrm{OI} \rightarrow \mathrm{OS}$; $\mathrm{tc}=23,299)$ foi superior a 1,96 (valor de $t$ tabulado), o que indicou um nível de significância menor do que 0,05. O coeficiente de caminho ou coeficiente de regressão padronizado $(\beta)$ desta relação (OI $\rightarrow$ OS) indicou que a variação de uma unidade em inovação aberta (OI) é capaz de influenciar uma variação de 0,680 na inovação sustentável (IS).

Constatadas a validade convergente, a validade discriminante e a qualidade do modelo ajustado, aceitando todas as hipóteses, confirmando o poder de explicação do modelo, onde se pode afirmar que o modelo proposto é confiável e apresenta validade preditiva.

Nesse sentido, a modelagem se mostrou eficiente e confirmatória para identificar a percepção dos estudantes de pós-graduação em inovação aberta, inovação sustentável, inovação de produto ou inovação em custo, ou seja, nas inovações formadoras da inovação frugais. Assim, o modelo proposto é explicado em $78 \%$ pela inovação de produto, em $67 \%$ pela inovação em custo e em $46 \%$ pela inovação sustentável. Conclui se que a inovação frugal neste modelo proposto é explicada em maior parte pela inovação do produto com um percentual de quase $80 \%$, destacando dessa forma o quanto a inovação de produto pode explicar a inovação frugal.

Sendo assim, o modelo estudado, reflete como os estudantes de pós-graduação reconhecem a inovação frugal, e conclui que primeiramente eles percebem a relação da inovação aberta com a inovação sustentável, seguido pela relação da inovação em custo com a inovação em produto, e por fim, a relação sustentável com a inovação em custos.

A estimação e avaliação do modelo em estudo permitiram concluir que o modelo teórico proposto é satisfatório. A qualidade do modelo é boa, constatando-se que os índices de fiabilidade, validade e de ajustamento para o construto latente (inovação aberta) em relação aos construtos dependentes (inovação sustentável, inovação de produtos e inovação em custos) apresentam valores superiores aos recomendados (HAIR et al., 2009).

Como possível limitação da pesquisa, pontua-se a escassez de instrumentos que compõem a inovação frugal, bem como o desenvolvimento de estudos teóricos e empíricos que possam contribuir para a 
disseminação desse tipo de inovação, dada a urgência de se repensar as formas de produção e uso de recursos naturais. 


\section{CAPÍTULO III- MODELAGEM DA CAPACIDADE ABSORTIVA INDIVIDUAL COMO ANTECEDENTE DA}

\section{INOVAÇÃO FRUGAL EM ESTUDANTES DE PÓS GRADUAÇÃO}

Resumo: O objetivo desse estudo é avaliar as dimensões da capacidade de absorção individual em inovações frugais de estudantes de pós-graduação de uma universidade brasileira. Para a coleta de dados, o método utilizado foi Survey e nas análises, uso de técnica de modelagem de equações estruturais (SEM), com Software Smart $\mathrm{PLS}^{\circledR}{ }^{\circledR}$ v. 3.3.3, utilizando dados coletados de 462 estudantes de diferentes cursos de pós-graduação. 0 instrumento de pesquisa foi composto por três blocos, 0 primeiro buscou conhecer o perfil sociodemográfico dos estudantes, no segundo, as escala de Capacidade de Absorção Individual (CAI) e de Inovação Frugal (IF). Os resultados demonstram que a as dimensões da Capacidade de Absorção Individual impactam as dimensões da Inovação Frugal, apontando que os estudantes analisados tem capacidade de exploração em inovação aberta, inovação sustentável, inovação de produtos e inovação em custos.

Confirmou-se confiabilidade nas escalas CAI-IF para medição das dimensões da capacidade absortiva individual em inovação frugal. Assim, esse estudo representa uma importante contribuição para o avanço nas discussões de CAI e IF no contexto acadêmico.

Palavras-chave: Dimensões de capacidade absortiva individual. Dimensões da inovação frugal. Estudantes de pós-graduação. Modelagem de equação estrutural. 


\section{INTRODUÇÃO}

As empresas buscam firmar parcerias com instituições geradoras e difusoras de conhecimento científico e tecnológico, neste sentido, a universidade tem muito a contribuir, fomentando com pesquisas acessos a novas fontes de conhecimento para a inovação (MURTIC et al., 2018), pois sabese que a transferência de conhecimento reduz significativamente custos de Pesquisa e Desenvolvimento (P\&D), contribuindo com novas estratégias e vantagem competitiva.

A absorção do conhecimento (CA) foi introduzida por Cohen e Leninthal (1990) como um modelo tridimensional, mais tarde Zahra e George (2002) reconceituaram a capacidade de absorção e introduziram a dimensão da transformação e distinguiram o potencial de capacidade de absorção (PAC) que compreende as dimensões aquisição e assimilação de novos conhecimentos e a (RAC) que compreende as dimensões de transformação e exploração dos novos conhecimentos.

Nesse sentido a capacidade de absorção de conhecimento é um processo interativo entre conhecimento e aprendizagem. Flatten et al. (2011) citam que poucos estudos de CA foram aplicados ao contexto individual, das relações dos indivíduos com as dimensões da CA. Prexl et al. (2020), em sua pesquisa concluíram que o indivíduo tem papel central na inovação e absorção de novos conhecimentos, influenciando de forma direta e positiva os processos e estrutura de uma organização. Conforme Prexl et al. (2020), a exploração individual é considerada importante na combinação com os conhecimentos para criar novos bens, serviços, processos ou formas organizacionais, assim, os estudantes de pós-graduação são ativos na dimensão exploração da capacidade de absorção individual.

A inovação tem papel relevante no desenvolvimento de novos produtos e processos, seja através do conhecimento científico, tecnológico ou diante de suas relações de P\&D (ALMULHIM, 2021). Diante disso, a inovação do tipo frugal tem sido pauta de inúmeros estudos em diferentes contextos (HOSSAIN, 2018; ZESCHKY et al., 2014) mas ainda faltam pesquisas que busquem compreender e investiguem a inovação frugal no contexto da gestão do conhecimento, seu compartilhamento e sua transferência (ALMULHIM, AF (2021). Nesse contexto, encontrou-se somente um estudo, dos autores Dost et al. (2019), que examinou o impacto das fontes de conhecimento na inovação frugal através de um estudo com PMEs da Arábia Saudita.

Para Mortazavi et al. (2020) diversas fontes de conhecimento podem facilitar ou introduzir a Inovação Frugal, desta maneira, os autores destacam as universidades empreendedoras como fontes de 
conhecimento, capazes de contribuir com o desenvolvimento de produtos econômicos, com aumento da produtividade da organização.

Por conseguinte, esta pesquisa oferece a possibilidade de compreensão da dinâmica da absorção de conhecimento nas suas quatro dimensões pautadas na teoria (ZAHRA; GEORGE, 2002) no ambiente acadêmico. Já que a capacidade de aquisição, assimilação, transformação e exploração em estudantes de pós-graduação envolvidos no desenvolvimento de pesquisa e ciência alinhadas ao desenvolvimento de produtos, serviços ou processo frugais.

Conforme já relatado pela Organização para a Cooperação e Desenvolvimento Econômico (OCDE, 2018) o conhecimento científico e o tecnológico, impulsionados pelos fluxos de investimentos em indústrias de tecnologia, em P\&D (Pesquisa e Desenvolvimento) e capital humano, vêm projetando um novo significado ao conceito contemporâneo de produtividade. Assim, esta pesquisa contribui com as teorias existentes, ainda que embrionárias, a respeito da capacidade de absorção do conhecimento a nível individual em inovação frugal.

Nesse sentido, o objetivo principal do presente estudo é examinar os efeitos das capacidades absortivas individuais do conhecimento na Inovação Frugal, e por fim, compreender se a capacidade de absorção dos indivíduos afeta de alguma forma a Inovação Frugal.

\section{REFERENCIAL TEÓRICO}

\section{CAPACIDADE ABSORTIVA INDIVIDUAL (CAI) E SUAS DIMENSÕES}

Muitos estudos abordam capacidade de absorção em diferentes níveis: individual (COHEN; LEVINTHAN, 1990), organizacional (COHEN; LEVINTHAN, 1990; SCHMIDT, 2010), díade de aprendizagem (LANE; LUBATKIN; 1998), intra distrito (CAMISÓN; FORÉS, 2011) e inter aliança (LEE; LIANG; LIU, 2010;).

A capacidade absortiva pode ser abordada em nível organizacional, mas também em nível individual, onde autores denominam de caráter cumulativo, onde a memória dos conhecimentos do indivíduo é associada ao processo de aprendizagem (COHEN; LEVINTHAL, 1990; VERGA-JURADO; GUTIERREZGRACIA, 2008). Nesse sentido, a capacidade absortiva das organizações interliga as habilidades e conhecimentos dos indivíduos nela inseridos. Dessa forma, para que os indivíduos possam desenvolver sua capacidade absortiva individual (CAI), é necessário investimento no desenvolvimento de capital humano, aumentando assim sua capacidade absortiva (COHEN; LEVINTHAL, 1990; KIM; 
MAUBOURGNE, 1998). Sob essa perspectiva os autores Wang, Feng e Liu (2015) desenvolveram a capacidade absortiva individual para identificação, assimilação e transformação do conhecimento, e também do comportamento dos indivíduos possibilitando dessa forma um melhor entendimento desempenho dos indivíduos.

O nível individual de capacidade de absorção está na capacidade de reconhecer, assimilar, explorar e transformar o conhecimento externo. As capacidades absortivas individuais são fundamentais para gestão do conhecimento, bem como o papel que os indivíduos desempenham em absorver conhecimento externo (VOLBERBA; FOSS; LYLES, 2010).

Outros estudos que defendem ser a capacidade absortiva em nível individual relacionada ao âmbito organizacional foram realizados pelos autores Da Silva, Eduardo et al. (2016) e Fuchs, Rosseto e Carvalho (2016). Esses, corroboram com Cohen e Levinthal (1990) em relação a compreensão e interpretação do conhecimento adquirido do ambiente externo ser dependente da assimilação de cada indivíduo inserido na organização.

Estudos realizados na última década têm sido realizados com foco na capacidade absortiva individual, contribuindo dessa forma para que a temática se desenvolva rapidamente. Autores corroboram que as características individuais tem relação direta com a capacidade absortiva organizacional e pontuam que a qualificação dos indivíduos afeta o processo de adquirir, assimilar, explorar e aplicar o conhecimento. Diante disso, concluem que o conhecimento adquirido do ambiente externo dependente da assimilação de cada indivíduo inserido na organização (COHEN; LEVINTHAL 1990; DA SILVA, EDUARDO et al. 2016; FUCHS, ROSSETO; CARVALHO, 2016).

\section{INOVAÇÃO FRUGAL (IF) E SUAS DIMENSÕES}

Para Silva, Etiel (2018) ainda é direcionada pouca atenção para examinar os esforços de inovação das empresas locais de países em desenvolvimento. Dessa maneira, em seu estudo, apresenta como objetivo averiguar a associação entre determinadas capacidades organizacionais que auxiliam no desenvolvimento de inovação frugal. Assim, defende que proposição de valor da inovação frugal manifeste o novo por menos, baseado na interação dos seguintes conceitos: inovação em custo, inovação sustentável, inovação aberta e inovação em produto.

No modelo proposto por Silva e Etiel (2018), validado no contexto organizacional, as capacidades organizacionais (produção; tecnológica; capital humano e; marketing) são construtos exógenos, enquanto a inovação frugal é um construto endógeno. Desta maneira, a escala de IF é composta com 
itens mensurados pelos autores Abulrub e Lee (2012) - Open Innovation; Chen, Lai e Wen (2006) e Chen (2008) - Sustainable Innovation, Afonso et al. (2008) - Cost Innovation e, Product Innovation com os autores Gunday et al. (2011).

\section{ELABORAÇÃO DAS HIPÓTESES DA PESQUISA}

Conforme Barros (2008, p. 306), [...] uma hipótese bem construída oferece uma ponte, mesmo que provisória, entre a Teoria e o Método e procedimentos de pesquisa, para além de ajudar a delimitar o próprio tema em questão, trazendo-Ihe uma feição problematizadora. Desta forma, apresentados os estudos que fundamentam essa pesquisa, foram elaboradas as seguintes hipóteses:

H1: Existe relação estatisticamente significativa entre Capacidade Absortiva e Inovação Frugal.

Com base no exposto, a hipótese 1 pode ser desdobrada em outras dezesseis hipóteses, relacionandose com cada dimensão da Inovação Frugal (Inovação aberta, inovação sustentável, inovação em custos e inovação em produtos) com a Capacidade Absortiva (Aquisição, Assimilação, Transformação e Exploração).

H1a: A Capacidade de Aquisição do Conhecimento está relacionada com a Inovação em Custo;

H1b: A Capacidade de Aquisição do Conhecimento está relacionada com a Inovação Sustentável;

H1c: A Capacidade de Aquisição do Conhecimento está relacionada com a Inovação de Produto;

H1d: A Capacidade de Aquisição do Conhecimento está relacionada com a Inovação Aberta;

H1e: A Capacidade de Assimilação do Conhecimento está relacionada com a Inovação em Custo;

H1f: A Capacidade de Assimilação do Conhecimento está relacionada com a Inovação Sustentável;

H1g: A Capacidade de Assimilação do Conhecimento está relacionada com a Inovação de Produto;

H1h: A Capacidade de Assimilação do Conhecimento está relacionada com a Inovação Aberta;

H1i: A Capacidade de Transformação do Conhecimento está relacionada com a Inovação em Custo;

H1j: A Capacidade de Transformação do Conhecimento está relacionada com a Inovação Sustentável;

H1k: A Capacidade de Transformação do Conhecimento está relacionada com a Inovação de Produto;

H1l: A Capacidade de Transformação do Conhecimento está relacionada com a Inovação Aberta;

H1m: A Capacidade de Exploração do Conhecimento está relacionada com a Inovação em Custo;

H1n: A Capacidade de Exploração do Conhecimento está relacionada com a Inovação Sustentável; 
H1o: A Capacidade de Exploração do Conhecimento está relacionada com a Inovação de Produto. H1p: A Capacidade de Exploração do Conhecimento está relacionada com a Inovação Aberta.

\section{PERCURSO METODOLÓGICO}

Para a pesquisa, optou-se pela abordagem quantitativa, com objetivo descritivo.

Diante disso, Gil (1999, p. 46) explica que as pesquisas descritivas têm como objetivo primordial a descrição das características de determinada população ou fenômeno ou, então, o estabelecimento de relações entre variáveis\|.

Quanto ao método, utilizou-se levantamento Survey. Conforme Freitas et al. (2000), esse tipo de levantamento é útil para identificar e descrever características de uma determinada população-alvo, informações e conclusões, a partir da coleta de dados com um instrumento pré-definido, normalmente um questionário. Esse método serve de base para as análises estatísticas das variáveis estudadas. Assim, nesse estudo, para a análise descritiva dos dados utilizou-se inicialmente o software SPSS versão 26, onde se buscou compreender o perfil dos estudantes que participaram da pesquisa.

Essa pesquisa constitui- se na aplicação de um questionário com três seções, sendo a primeira, questões objetivas sobre dados sociodemográficos dos participantes.

A segunda seção, uma dimensão da Escala de Capacidade Absortiva Individual (CAI) e a terceira, quatro dimensões da Escala de Inovação Frugal, ambos com Escala Likert de cinco pontos, com opções de discordo totalmente a concordo totalmente.

A amostra foi composta por 462 estudantes de pós-graduação. Para o questionário de Capacidade absortiva de individual foi utilizada o instrumento de Silva, Eduardo et al. (2016) e na terceira parte a escala de Inovação Frugal validada no contexto brasileiro por Silva, Etiel (2018) e Bresciani et al., (2020), composta por quatro dimensões reflexivas, com itens mensurados pelos autores Alburub e Lee (2012) - Open Innovation (OI), composta por quatro itens; Chen, Lai e Wen (2006) - Sustainable Innovation (SI), composta por quatro itens; Afonso et al., (2008) - Cost Innovation (CI), composta por cinco itens e, Product Innovation (PI) com os autores Gunday et al., (2011), composta por cinco itens.Para análise das hipóteses foi utilizada a técnica de modelagem de equações estruturais (SEM), conforme Hair Jr. et al. (2014) a técnica de Modelagem de Equações se conceitua por combinar elementos de regressão múltipla (examinando relações de dependência) e da análise fatorial 
(representando construtos não diretamente observados), estimando assim relações de dependência simultânea.

A análise do diagrama de caminho e suas relações entre variáveis latentes e suas respectivas variáveis observadas, e hipóteses propostas na pesquisa são mostradas na Figura 1 e no diagrama 1.

Figura 1 - Modelo de caminho das dimensões CAI- IF

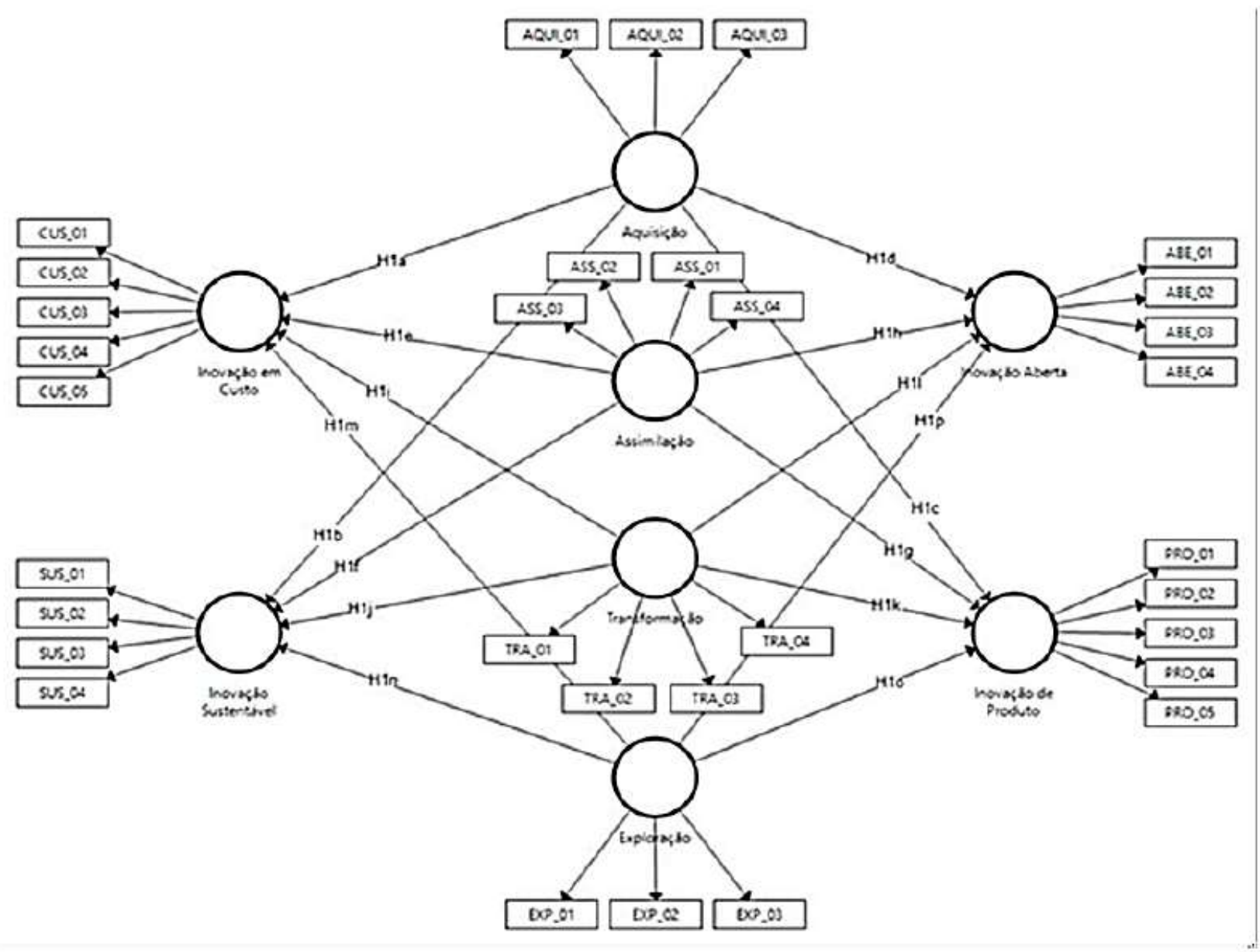

Fonte: Software Smart PLS ${ }^{\circledR}$ v. 3.3.3 (Ringle et al., 2015).

Na Figura 1, observa-se que o modelo de mensuração formado por 4 variáveis exógenas e independentes (capacidade de aquisição, capacidade de assimilação, capacidade de transformação e capacidade de exploração) que conectam 4 variáveis endógenas e dependentes (inovação aberta, inovação sustentável inovação de produto e inovação em custo), com um total de 16 hipóteses e 32 questões (indicadores).

Nesse sentido na Tabela 1, apresenta-se o diagrama de caminhos que tem por finalidade descrever as equações estruturais. 
Tabela 1 - Diagrama de caminhos inicial para o modelo

\begin{tabular}{clccc}
\hline $\begin{array}{c}\text { Dimensões } \\
\text { Endógenas }\end{array}$ & $=$ & $\begin{array}{c}\text { Dimensões } \\
\text { Exógenas }\end{array}$ & + & Erro \\
\hline $\mathrm{CUS}$ & $=$ & $\beta_{1} \mathrm{AQUI}+\beta_{2} \mathrm{ASS}+\beta_{3} \mathrm{TRA}+\beta_{4} \mathrm{EXP}$ & + & $\varepsilon_{\mathrm{CUS}}$ \\
$\mathrm{SUS}$ & $=$ & $\beta_{5} \mathrm{AQUI}+\beta_{6} \mathrm{ASS}+\beta_{7} \mathrm{TRA}+\beta_{8} \mathrm{EXP}$ & + & $\varepsilon_{\mathrm{SUS}}$ \\
$\mathrm{PRO}$ & $=$ & $\beta_{9} \mathrm{AQUI}+\beta_{10} \mathrm{ASS}+\beta_{11} \mathrm{TRA}+\beta_{12} \mathrm{EXP}$ & + & $\varepsilon_{\mathrm{PRO}}$ \\
$\mathrm{ABE}$ & $=$ & $\beta_{13} \mathrm{AQUI}+\beta_{14} \mathrm{ASS}+\beta_{15} \mathrm{TRA}+\beta_{16} \mathrm{EXP}$ & + & $\varepsilon_{\mathrm{ABE}}$ \\
\hline
\end{tabular}

Fonte: Dados da pesquisa com base em Hair Jr., Gabriel e Patel (2014).

\section{APRESENTAÇÃO E DISCUSSÃO DOS RESULTADOS}

A primeira etapa para validação, conhecida como Avaliação do Modelo de Mensuração busca assegurar a confiabilidade do modelo, através da avaliação do Alfa de Cronbach ( $\alpha$ ); Confiabilidade Composta $\left(\mathrm{P}_{\mathrm{c}}\right)$; Variância Média Extraída - AVE (Average Variance Extracted); Cargas Fatoriais Cruzadas; Critério Fornell-Larcker e

Critério Heterotrait-Monotrait Ratio (HTMT) confirmado pelo método Boostrapping.Na segunda etapa, conhecida como Avaliação do Modelo Estrutural através da Avaliação da Colinearidade (VIF); Coeficiente de determinação (R2) confirmado pelo método Boostrapping; tamanho do efeito (f2) confirmado pelo método Boostrapping; confirmação das hipóteses pelo teste $t$ de Student determinado pelo método Boostrapping e por fim, relevância preditiva (Q2) confirmado pelo método Blindfolding.

A análise confiabilidade composta se refere à quantidade de questões sobre cada variável, as questões devem ter a capacidade de explicar a variável. Para alcançar essa resposta é necessário se elas são suficientes para calcular o Alfa de Cronbach, a confiabilidade composta e a Variância Média Extraída (VME).

Já o teste de validade convergente (variância média extraída ou AVE) buscando os valores das cargas fatoriais, a validade convergente, a confiabilidade e a validade discriminante dos modelos de mensuração reflexivos (Ringle et al., 2014).

Conforme apontamentos de Ringle et al. (2014), a partir dos dados da amostra e a alocação das variáveis observadas nas suas respectivas variáveis latentes, nesse estudo a análise foi satisfatória, os valores de todas as cargas fatoriais, de acordo com o parâmetro (valores $>0,70$ ). Em seguida, foram realizados os testes de validade convergente (variância média extraída ou AVE) e confiabilidade (consistência interna e confiabilidade composta). 
Os resultados atenderam aos requisitos de obtenção de valores superiores a 0,50 para AVE e valores superiores a 0,70 para a consistência interna ( $\alpha$ de Cronbach) e a confiabilidade composta (Hair Jr. et al., 2005). Inicia-seentão a análise do modelo de mensuração. A Tabela 2 demonstra os resultados encontrados.

Tabela 2 - Consistência interna e validade convergente

\begin{tabular}{lccc|}
\hline \multicolumn{1}{|c}{ Dimensões } & $\begin{array}{c}\text { Alfa de } \\
\text { Cronbach }\end{array}$ & $\begin{array}{c}\text { Confiabilidade } \\
\text { composta }\end{array}$ & $\begin{array}{c}\text { Variância Média } \\
\text { Extraída (VME) }\end{array}$ \\
\hline Aquisição (AQU) & 0,696 & 0,821 & 0,605 \\
Assimilação(ASS) & 0,851 & 0,877 & 0,642 \\
Exploração (EXP) & 0,840 & 0,903 & 0,757 \\
Transformação (TRA) & 0,868 & 0,910 & 0,716 \\
\hline Inovação Aberta (ABE) & 0,844 & 0,895 & 0,681 \\
Inovação Sustentável (SUS) & 0,939 & 0,956 & 0,846 \\
Inovação de Produto (PRO) & 0,951 & 0,962 & 0,837 \\
Inovação em Custo (CUS) & 0,925 & 0,943 & 0,769 \\
\hline
\end{tabular}

Fonte: Software SmartPLS ${ }^{\circledR}$, v. 3.3.3 (RINGLE; WENDE; BECKER, 2015).

Para Chin (1998) e Hair Jr. et al. (2009) a análise de confiabilidade de item está relacionada a qualidade de itens (perguntas), confirmando a correlação dos itens, sendo assim, o valor maior ou igual a 0,70. Nesse sentido, Chin (1998) pontua que, caso a pergunta não alcance a confiabilidade de item, deve-se retirá-la do questionário, que chama de depuração. Dessa forma, pode-se observar na Tabela 3 a validade descriminante, que todas as variáveis observadas (VO's) atenderam ao critério das cargas fatoriais cruzadas, ou seja, as cargas fatoriais das VO's com a variável latente (VL) original são maiores do que as cargas fatoriais com as demais variáveis latentes (VL's) das escalas EIE-EIF. 
Tabela 3 - Cargas fatoriais cruzadas

\begin{tabular}{|c|c|c|c|c|c|c|c|c|}
\hline \multirow{2}{*}{ Indicadores } & \multicolumn{8}{|c|}{ Dimensões } \\
\hline & $\mathbf{A Q U}$ & ASS & EXP & TRA & ABE & SUS & PRO & CUS \\
\hline AQUI_01 & 0,764 & 0,283 & 0,343 & 0,367 & 0,156 & 0,142 & 0,084 & 0,095 \\
\hline AQUI_02 & 0,751 & 0,550 & 0,216 & 0,275 & 0,057 & 0,076 & 0,028 & 0,033 \\
\hline AQUI_03 & 0,817 & 0,553 & 0,215 & 0,299 & 0,103 & 0,128 & 0,121 & 0,095 \\
\hline ASS_01 & 0,448 & 0,854 & 0,363 & 0,512 & 0,055 & 0,040 & 0,072 & 0,040 \\
\hline ASS_02 & 0,502 & 0,869 & 0,281 & 0,364 & 0,064 & 0,048 & 0,037 & 0,023 \\
\hline ASS_03 & 0,404 & 0,731 & 0,228 & 0,359 & 0,040 & $-0,020$ & 0,013 & $-0,028$ \\
\hline ASS_04 & 0,474 & 0,741 & 0,260 & 0,380 & 0,058 & $-0,010$ & $-0,022$ & $-0,008$ \\
\hline EXP_01 & 0,329 & 0,341 & 0,869 & 0,574 & 0,230 & 0,188 & 0,180 & 0,167 \\
\hline EXP_02 & 0,299 & 0,341 & 0,891 & 0,567 & 0,252 & 0,164 & 0,169 & 0,153 \\
\hline EXP_03 & 0,275 & 0,288 & 0,851 & 0,520 & 0,239 & 0,179 & 0,176 & 0,214 \\
\hline TRA_01 & 0,351 & 0,421 & 0,467 & 0,817 & 0,188 & 0,153 & 0,163 & 0,152 \\
\hline TRA_02 & 0,397 & 0,489 & 0,512 & 0,867 & 0,181 & 0,167 & 0,158 & 0,159 \\
\hline TRA_03 & 0,280 & 0,343 & 0,548 & 0,855 & 0,215 & 0,155 & 0,149 & 0,145 \\
\hline TRA_04 & 0,375 & 0,485 & 0,621 & 0,846 & 0,223 & 0,152 & 0,155 & 0,143 \\
\hline$\overline{\mathrm{ABE}} 01$ & 0,164 & 0,073 & 0,233 & 0,187 & 0,842 & 0,555 & 0,532 & 0,512 \\
\hline $\mathrm{ABE}-02$ & 0,121 & 0,078 & 0,242 & 0,226 & 0,843 & 0,573 & 0,615 & 0,636 \\
\hline $\mathrm{ABE} \_03$ & 0,127 & 0,026 & 0,228 & 0,218 & 0,851 & 0,537 & 0,623 & 0,639 \\
\hline ABE_04 & 0,078 & 0,051 & 0,208 & 0,150 & 0,763 & 0,577 & 0,551 & 0,561 \\
\hline SUS_01 & 0,150 & 0,025 & 0,195 & 0,158 & 0,641 & 0,934 & 0,699 & 0,698 \\
\hline SUS_02 & 0,169 & 0,048 & 0,191 & 0,178 & 0,630 & 0,937 & 0,698 & 0,703 \\
\hline SUS_03 & 0,134 & 0,049 & 0,172 & 0,187 & 0,637 & 0,885 & 0,749 & 0,710 \\
\hline SUS_04 & 0,133 & 0,025 & 0,190 & 0,159 & 0,577 & 0,921 & 0,703 & 0,735 \\
\hline PRO_02 & 0,092 & 0,038 & 0,140 & 0,165 & 0,655 & 0,707 & 0,911 & 0,807 \\
\hline PRO_03 & 0,148 & 0,058 & 0,208 & 0,180 & 0,628 & 0,739 & 0,914 & 0,754 \\
\hline PRO_04 & 0,083 & 0,062 & 0,197 & 0,155 & 0,655 & 0,695 & 0,922 & 0,774 \\
\hline PRO_05 & 0,076 & 0,052 & 0,197 & 0,180 & 0,641 & 0,694 & 0,924 & 0,761 \\
\hline CUS_01 & 0,112 & 0,014 & 0,175 & 0,143 & 0,579 & 0,715 & 0,676 & 0,854 \\
\hline CUS_02 & 0,087 & 0,036 & 0,214 & 0,165 & 0,583 & 0,617 & 0,643 & 0,854 \\
\hline CUS_03 & 0,078 & 0,008 & 0,182 & 0,173 & 0,668 & 0,689 & 0,775 & 0,909 \\
\hline CUS_04 & 0,084 & 0,036 & 0,159 & 0,149 & 0,649 & 0,696 & 0,823 & 0,894 \\
\hline CUS_05 & 0,110 & 0,028 & 0,164 & 0,141 & 0,646 & 0,676 & 0,840 & 0,874 \\
\hline
\end{tabular}

Fonte: Software SmartPLS ${ }^{\circledR}$, v. 3.3.3 (RINGLE; WENDE; BECKER, 2015).

Os próximos testes realizados na primeira etapa da avaliação da mensuração do modelo, são o Teste de Fornell e Larcker e o HTMT (Heterotrait-Monotrait Ratio).

Conforme Fornell e Larcker (1981) essa análise compara as correlações entre as VL's (rij para $i \neq j$ ), nesse sentido, o modelo aponta que devem ser menores do que a raiz quadrada da variância média extraída, com objetivo de assegurar que uma dimensão é independente da outra. Verifica-se na Tabela 
4 que os valores da diagonal principal são maiores que os demais $\left(\sqrt{A V E^{\prime} s}>r_{i j}\right)$ logo a validade discriminante é estabelecida no nível de construção do modelo Fornell e Larcker (1981).

Tabela 4 - Critérios de Fornell-Larker e HTMT

\begin{tabular}{|c|c|c|c|c|c|c|c|c|c|}
\hline \multirow{2}{*}{ Dimensões } & \multirow[b]{2}{*}{ VME } & \multicolumn{8}{|c|}{ Matriz de Correlação de Pearson } \\
\hline & & AQUI & ASS & EXP & ABE & SUS & PRO & CUS & TRA \\
\hline AQU & 0,778 & 1,000 & & & & & & & \\
\hline ASS & 0,801 & 0,557 & 1,000 & & & & & & \\
\hline EXP & 0,870 & 0,346 & 0,371 & 1,000 & & & & & \\
\hline $\mathrm{ABE}$ & 0,825 & 0,151 & 0,069 & 0,276 & 1,000 & & & & \\
\hline SUS & 0,920 & 0,160 & 0,040 & 0,204 & 0,675 & 1,000 & & & \\
\hline PRO & 0,915 & 0,113 & 0,054 & 0,201 & 0,704 & 0,773 & 1,000 & & \\
\hline CUS & 0,877 & 0,107 & 0,028 & 0,206 & 0,712 & 0,773 & 0,852 & 1,000 & \\
\hline TRA & 0,846 & 0,414 & 0,514 & 0,636 & 0,239 & 0,185 & 0,184 & 0,177 & 1,000 \\
\hline
\end{tabular}

\section{LS (HTMT) $97,5 \%$}

\begin{tabular}{llllllll}
\hline AQU & & & & & & & \\
ASS & 0,837 & & & & & & \\
EXP & 0,536 & 0,503 & & & & \\
ABE & 0,298 & 0,187 & 0,430 & & & & \\
SUS & 0,306 & 0,124 & 0,336 & 0,817 & & & \\
PRO & 0,238 & 0,132 & 0,331 & 0,835 & 0,860 & & \\
CUS & 0,236 & 0,118 & 0,331 & 0,861 & 0,871 & 0,841 & \\
TRA & 0,622 & 0,652 & 0,803 & 0,379 & 0,306 & 0,301 & 0,297 \\
\hline
\end{tabular}

Fonte: Software SmartPLS ${ }^{\circledR}$, v. 3.3.3 (RINGLE; WENDE; BECKER, 2015).

Na Tabela 4 tem-se o critério de HTMT, demonstrando que os resultados atendem a exigência do critério, ou seja, os limites superiores, determinados pelo método de boostrapping, utilizando 5.000 subamostras, obtiveram valores menores que 1,00. O modelo então processado resulta um diagrama de caminho, ou seja, a definição de cada indicador (VO) e o tipo de relação com cada dimensão (VL), que serviram de base para a construção do modelo de mensuração conforme demonstra a Tabela 4.

A figura 2 apresenta o modelo de caminhos com suas respectivas hipóteses.

Figura 2 - Modelo de caminho inicial 


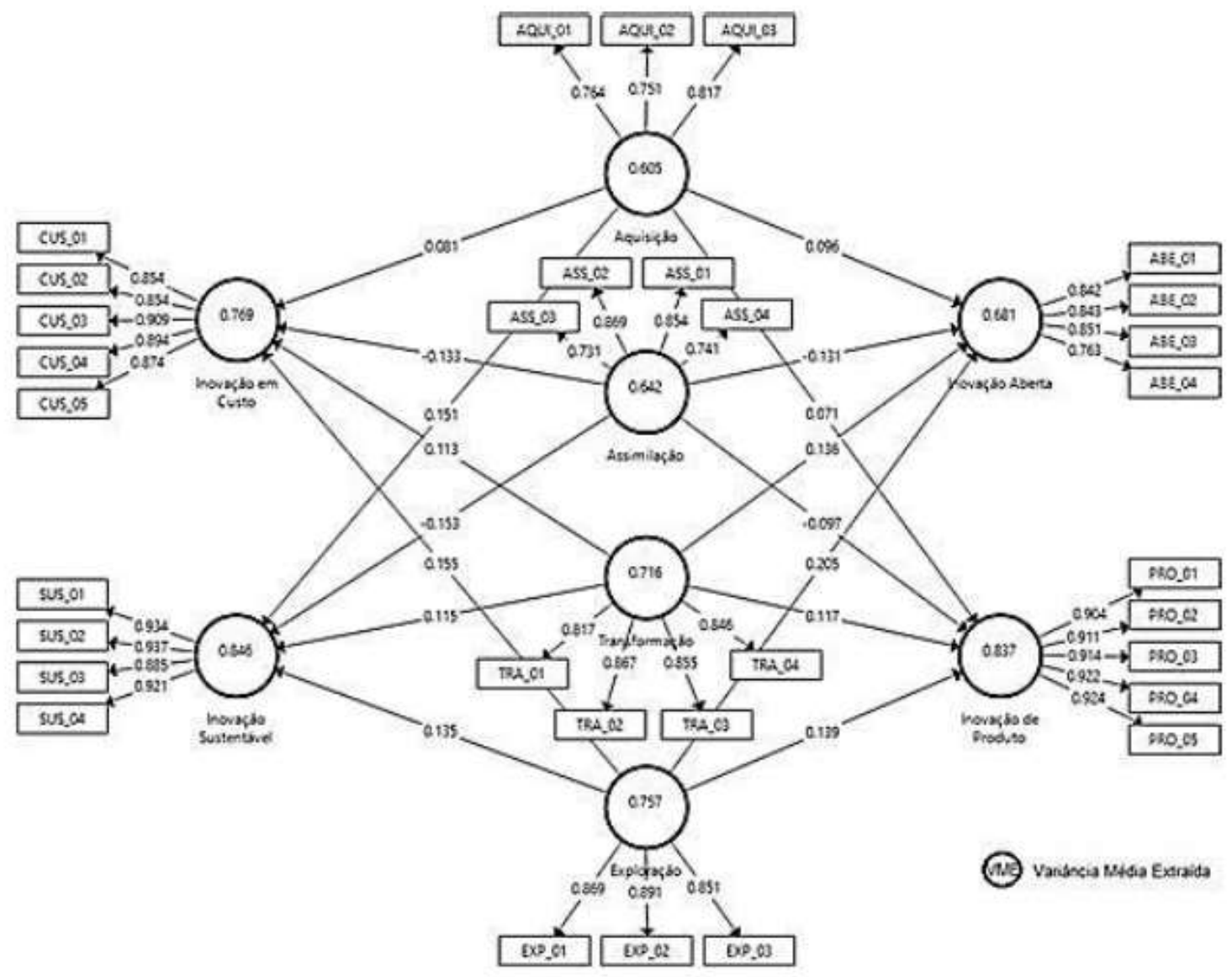

Fonte: Software SmartPLS ${ }^{\circledR}$, v. 3.3.3 (RINGLE; WENDE; BECKER, 2015).

Após avaliação do modelo de mensuração, o modelo poderá ser dito confiável e válido. A próxima etapa buscou avaliar o modelo estrutural e comprovar suas hipóteses. Nesse sentido, Hair Jr. et al. (2017) afirmam que a avaliação do modelo estrutural é realizado pela análise de colinearidade (Variance Inflation Factor - VIF); nível de significância do R2; tamanho do efeito f2; avaliação da significância e relevância dos betas do modelo estrutural (teste t de Student); e por fim, pela avaliação da relevância preditiva Q2. Dessa maneira, na Tabela 5, a VIF indica se há um potencial problema de colinearidade no modelo caso os valores sejam superiores a 5 (HAIR Jr. Et al., 2017).

Tabela 5 - Análise de multicolineariedade- Valores de VIF para as dimensões do modelo CAI-IF

\begin{tabular}{lcccc}
\hline \multirow{2}{*}{ Dimensões Exógenas } & \multicolumn{4}{c}{ Dimensões Endógenas (Inovação) } \\
\cline { 2 - 5 } & Aberta & Sustentável & Produto & Custo \\
\hline Aquisição & 1,513 & 1,513 & 1,513 & 1,513 \\
Assimilação & 1,687 & 1,687 & 1,687 & 1,687 \\
Exploração & 1,702 & 1,702 & 1,702 & 1,702 \\
Transformação & 1,993 & 1,993 & 1,993 & 1,993 \\
\hline
\end{tabular}

Fonte: Software SmartPLS ${ }^{\circledR}$, v. 3.3.3 (RINGLE; WENDE; BECKER, 2015). 
Observa-se no modelo que todos os valores de VIF são menores que 5, atendendo aos pressupostos não há fortes relações entre as dimensões, portanto não há problemas de colinearidade.

A Tabela 6 apresenta as significâncias do coeficiente de determinação (R2) que explica em graus a influência da variável independente em uma variável dependente, acompanhado pelos valores do tamanho do efeito $\left(f^{2}\right)$, obtidos pelo método de boostrapping.

Tabela 6 - Coeficiente de explicação $\mathrm{R}^{2}$ e os efeitos $f^{2}$ para o modelo de mensuração

\begin{tabular}{lcccc}
\hline \multirow{2}{*}{ Dimensões Exógenas } & \multicolumn{3}{c}{ Dimensões Endógenas (Inovação) } \\
\cline { 2 - 5 } & Aberta & Sustentável & Produto & Custo \\
\hline Aquisição & $0,007(0,382)$ & $0,016(0,248)$ & $0,004(0,631)$ & $0,005(0,527)$ \\
Assimilação & $0,011(0,179)$ & $0,015(0,233)$ & $0,006(0,539)$ & $0,011(0,315)$ \\
Exploração & $0,027(0,106)$ & $0,012(0,317)$ & $0,012(0,318)$ & $0,015(0,242)$ \\
Transformação & $0,010(0,295)$ & $0,007(0,384)$ & $0,007(0,390)$ & $0,007(0,405)$ \\
\hline \multicolumn{1}{c}{$\mathrm{R}^{2}$} & $0,095(0,001)$ & $0,067(0,006)$ & $0,052(0,016)$ & $0,057(0,007)$ \\
\hline
\end{tabular}

Fonte: Software SmartPLS ${ }^{\circledR}$, v. 3.3.3 (RINGLE; WENDE; BECKER, 2015).

O coeficiente de determinação (R2) compreende valores entre 0 e 1. Nesse sentido, Cohen (1988) descreve as relações como forte $(R 2>0,19)$, moderadas $(0,075<R 2 \leq 0,19)$ e fracas $(0,02 \leq R 2 \leq 0,075)$ avaliando a porção da variabilidade das dimensões preditoras (endógenas). Dessa forma, as dimensões aberta, sustentável, de produto e em custo da inovação frugal (variáveis endógenas), não apresentam resultados significativos, apenas a inovação aberta apresenta uma relação moderada sobre as dimensões da capacidade absortiva individual (variável exógena) com R2 de 0,095, enquanto as variáveis exógenas inovação sustentável, inovação de produto e inovação em custos apresentaram fracas relações sobre as varáveis endógenas os R2 respectivamente $(0,067,0,052$ e 0,057).

Desta forma, no modelo proposto a inovação aberta é a variável mais explicada pelas dimensões da capacidade absortiva individual, sendo assim, a inovação aberta é explicada pelo modelo em 0,09\%, enquanto a inovação sustentável é explicada com $0,07 \%$, inovação em custo com $0,06 \%$ e, inovação em produto explicada em $0,05 \%$.

Quanto às estimativas dos coeficientes de regressão e as correlações nos seus devidos caminhos os betas de regressão nos mostram sua significância, ou seja, a quantidade em graus de liberdade, algumas relações obtiveram betas não significativos, ou seja, não houve uma relação entre as dimensões, são elas: aquisição com inovação aberta, com inovação em custo e com inovação e com inovação em produto. Desta forma, as análises demonstraram que a dimensão assimilação não obteve 
relação com a inovação de produto, já a dimensão transformação não obteve relação com a inovação em custo, inovação sustentável e inovação de produto.

Quanto aos valores $f^{2}$ que avalia a utilidade de cada dimensão para o ajuste do modelo, que segundo Cohen (1988) esses valores são classificados em $f 2>0,225$ (grande efeito), 0,075 $<f 2 \leq 0,225$ (médio efeito); e $0,02 \leq f 2 \leq 0,075$ (pequeno efeito).

Após o modelo ajustado, foi realizada a avaliação da qualidade de ajuste do modelo por intermédio das análises dos coeficientes, interpretados como os betas (b's) da regressão com os resultados de $f 2$ descritos na Tabela 6, influenciando na confirmação das hipóteses propostas no modelo, onde a relação das dimensões $A Q U I$ e OI $(0,007)$, entre $A Q U I$ e OS $(0,016)$, entre $A Q U I$ e OP $(0,004)$ e $A Q U I$ e OC $(0,005)$, indicando desta forma um pequeno efeito sobre a relação da dimensão aquisição com as dimensões da inovação frugal.

As dimensões entre ASS e OI $(0,011)$, entre ASS E OS $(0,015$, entre AS e OP(0,006) e entre ASS e OC $(0,011)$ indicam um pequeno efeito sobre a relação da dimensão assimilação com as dimensões da inovação frugal. A dimensão exploração também apresenta um pequeno efeito sobre todas as dimensões da inovação frugal: $\operatorname{EXP}$ e OI $(0,027), \operatorname{EXP}$ e OS $(0,012), \operatorname{EXP}$ e OP $(0,012)$ e $\operatorname{EXP}$ e OC $(0,015)$ e por fim, a dimensão transformação apresenta igualmente as demais dimensões da capacidade absortiva individual um pequeno efeito sobre todas as dimensões da inovação frugal:

TRA e OI $(0,010)$, TRA e OS $(0,007)$, TRA e OP(0,007) e TRA e OC $(0,007)$. Conforme apontamentos de Cohen (1988), pode-se inferir que o modelo apresenta em geral um pequeno $f^{2}$ (tamanho de efeito).

Após a avaliação da qualidade do ajuste do modelo, parte-se para a interpretação dos coeficientes de caminho, esses coeficientes através do teste $t$, que avalia as relações entre as dimensões do modelo. Os coeficientes de caminho conforme Hair et al. (2014) são medidas que representam as relações hipotéticas entre as dimensões do modelo estrutural (variáveis exógenas $\rightarrow$ variáveis endógenas), comprovando ou não as hipóteses propostas. A Tabela 7 apresenta a validação dos coeficientes estruturais e suas respectivas hipóteses. 
Tabela 7 - Validação dos coeficientes estruturais e suas respectivas hipóteses

\begin{tabular}{|c|c|c|c|c|c|c|c|}
\hline Dim. Exógenas & $\rightarrow$ & Dim. Endógenas & $\beta$ 's & D. P. & $\begin{array}{c}\text { Estat. T } \\
(\mid \beta / \text { D. P. } \mid)\end{array}$ & p-valor & Situação \\
\hline \multirow{4}{*}{ Aquisiçãa } & $\rightarrow$ & Inovação Aberta & 0,096 & 0,055 & 1,757 & 0,079 & Rejeita \\
\hline & $\rightarrow$ & Inovação Sustentável & 0,151 & 0,064 & 2,367 & 0,018 & Aceita \\
\hline & $\rightarrow$ & Inovação de Produto & 0,071 & 0,062 & 1,146 & 0,252 & Rejeita \\
\hline & $\rightarrow$ & Inovação em Custo & 0,081 & 0,057 & 1,414 & 0,157 & Rejeita \\
\hline \multirow{4}{*}{ Assimilação } & $\rightarrow$ & Inovação Aberta & $-0,131$ & 0,055 & 2,366 & 0,018 & Aceita \\
\hline & $\rightarrow$ & Inovação Sustentável & $-0,153$ & 0,073 & 2,112 & 0,035 & Aceita \\
\hline & $\rightarrow$ & Inovação de Produto & $-0,097$ & 0,072 & 1,347 & 0,178 & Rejeita \\
\hline & $\rightarrow$ & Inovação em Custo & $-0,133$ & 0,069 & 1,942 & 0,052 & Aceita \\
\hline \multirow{4}{*}{ Transformação } & $\rightarrow$ & Inovação Aberta & 0,136 & 0,065 & 2,100 & 0,036 & Aceita \\
\hline & $\rightarrow$ & Inovação Sustentável & 0,115 & 0,065 & 1,769 & 0,077 & Rejeita \\
\hline & $\rightarrow$ & Inovação de Produto & 0,117 & 0,064 & 1,822 & 0,068 & Rejeita \\
\hline & $\rightarrow$ & Inovação em Custo & 0,113 & 0,064 & 1,756 & 0,079 & Rejeita \\
\hline \multirow{4}{*}{ Exploração } & $\rightarrow$ & Inovação Aberta & 0,205 & 0,060 & 3,428 & 0,001 & Aceita \\
\hline & $\rightarrow$ & Inovação Sustentável & 0,135 & 0,064 & 2,119 & 0,034 & Aceita \\
\hline & $\rightarrow$ & Inovação de Produto & 0,139 & 0,064 & 2,161 & 0,031 & Aceita \\
\hline & $\rightarrow$ & Inovação em Custo & 0,155 & 0,063 & 2,473 & 0,013 & Aceita \\
\hline
\end{tabular}

Fonte: Software SmartPLS ${ }^{\circledR}$, v. 3.3.3 (RINGLE; WENDE; BECKER, 2015).

O resultado demonstra que das dezesseis hipóteses 09 foram aceitas $(p<0,05)$ e 07 foram rejeitadas $(p>0,05)$. As análises confirmaram a relação direta e positiva entre a variável exógena exploração com todas as dimensões endógenas da inovação frugal:

H1m: a Capacidade de Exploração do Conhecimento é preditora da Inovação em Custo;

H1n: a Capacidade de Exploração do Conhecimento é preditora da Inovação Sustentável;

H1o: a Capacidade de Exploração do Conhecimento é preditora da Inovação de Produto;

H1p: a Capacidade de Exploração do Conhecimento é preditora da Inovação Aberta.

A variável exógena aquisição é apenas preditora da inovação sustentável (H1b: A Capacidade de Aquisição do Conhecimento está relacionada com a Inovação Sustentável), as demais hipóteses relacionando a variável exógena aquisição com inovação aberta, inovação de produto e inovação em custo foram rejeitadas.

A variável exógena assimilação apenas não é preditora da inovação de produto (H1g: A Capacidade de Assimilação do Conhecimento está relacionada com a Inovação de Produto) onde a hipótese foi rejeitada. As demais hipóteses da variável exógena assimilação foram aceitas (H1e: A Capacidade de Assimilação do Conhecimento está relacionada com a Inovação em Custo; H1f: A Capacidade de 
Assimilação do Conhecimento está relacionada com a Inovação Sustentável e H1h: A Capacidade de Assimilação do Conhecimento está relacionada com a Inovação Aberta).

Em relação a variável exógena transformação é apenas preditora da inovação aberta (H1l: A Capacidade de Transformação do Conhecimento está relacionada com a Inovação Aberta) as demais hipóteses da variável exógena transformação com inovação em custo, inovação sustentável e inovação de produto foram rejeitas (H1i: A Capacidade de Transformação do Conhecimento está relacionada com a Inovação em Custo; H1j: A Capacidade de Transformação do Conhecimento está relacionada com a Inovação Sustentável e H1k: A Capacidade de Transformação do Conhecimento está relacionada com a Inovação de Produto).

A seguir, apresenta-se o cálculo do indicador de Stone-Geisser (Q2) pelo método blindfolding, que tem por objetivo avaliar a precisão do modelo ajustado. Os autores Hair Jr. et al., (2017) usam como critério de avaliação, indicando que valores de Q2 devem ser maiores que zero. Os valores de 0,02; 0,15 e 0,35 indicam, respectivamente, a relevância preditiva: pequena, média e grande (Tabela 8).

Tabela 8 - Validade preditiva do modelo CAI-IF

\begin{tabular}{lccc}
\multicolumn{1}{c}{ Dimensões Preditivas } & SQO & SQE & $Q^{2}=1-\frac{\mathrm{SQE}}{\mathrm{SQQ}}$ \\
\hline Inovação Aberta & $1.852,00$ & $1.741,73$ & 0,060 \\
Inovação Sustentável & $1.852,00$ & $1.757,49$ & 0,051 \\
Inovação de Produto & $2.315,00$ & $2.221,98$ & 0,040 \\
Inovação em Custo & $2.315,00$ & $2.220,51$ & 0,041 \\
\hline
\end{tabular}

SQO = Soma dos Quadrados Observados; SQEE = Soma dos Quadrados dos Erros Estimados

Fonte: Software Smart PLS ${ }^{\circledR}$ v. 3.3.3 (Ringle et al., 2015).

Observa-se que todos os resultados indicam a precisão do modelo e apontam todas as dimensões com pequena relevância preditiva, ou seja, dimensões variando de 0,041 a 0,60, ou seja, OI $(Q 2=0,060)$, SI $\left(Q^{2}=0,051\right), \operatorname{PI}\left(Q^{2}=0,040\right)$ e OC $\left(Q^{2}=0,041\right)$. Com isso, finalizadas as etapas de avaliação do modelo, conforme propõe Hair Jr. et al (2014), passa-se para as considerações finais, apontando os principais achados dessa pesquisa. A Figura 3 e a Tabela 9 apresentam os resultados finais do modelo de caminho. 
Figura 3 - Modelo de caminhos das dimensões CAI-IF

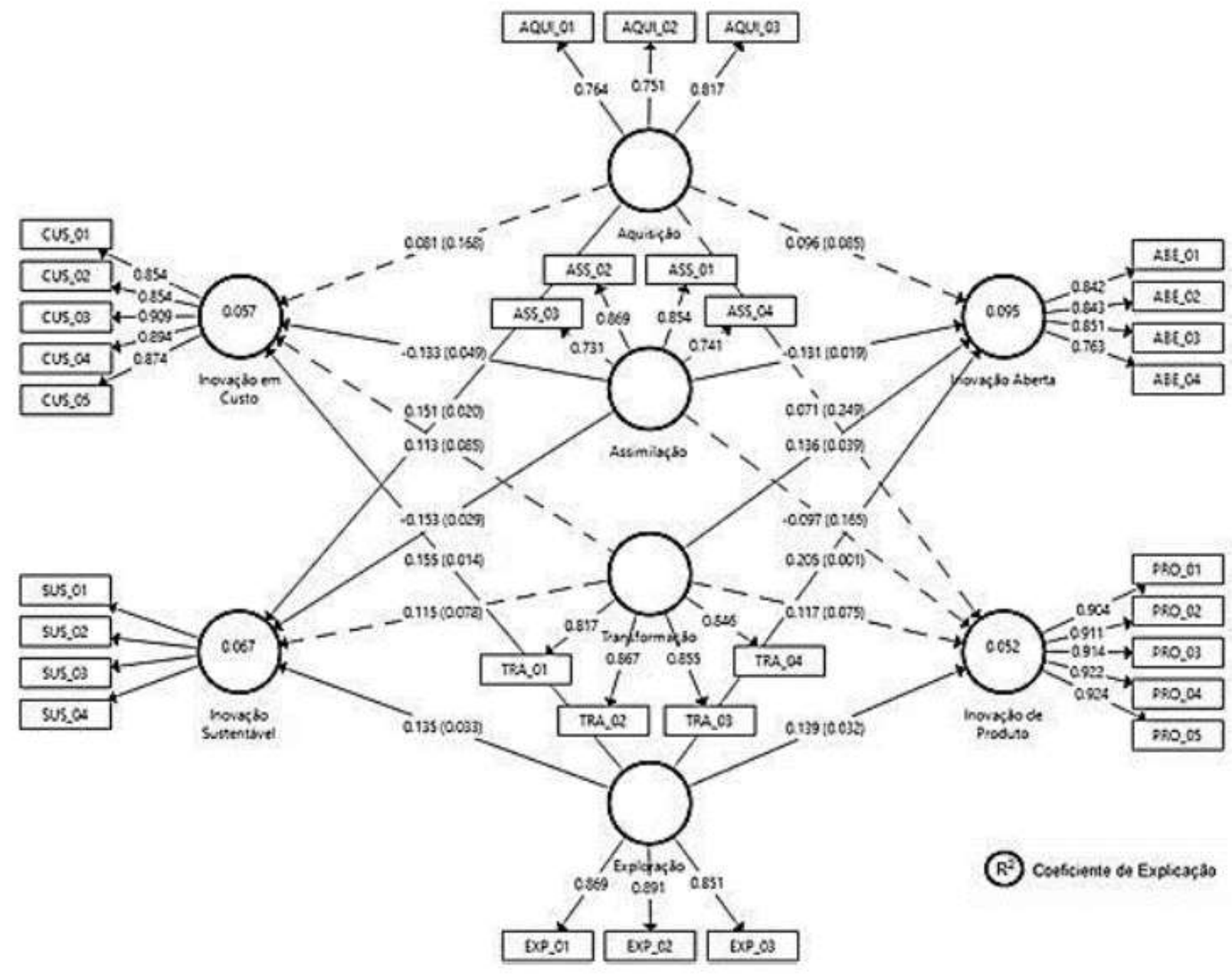

Fonte: Software Smart PLS ${ }^{\circledR}$ v. 3.3.3 (Ringle et al., 2015).

Tabela 9 - Diagrama de caminhos para o modelo final CAI-IF

\begin{tabular}{llclc}
\hline $\begin{array}{l}\text { Dimensões } \\
\text { Endógenas }\end{array}$ & & Dimensões & + & Erro \\
CUS & $=$ & $-0,133 \mathrm{ASS}+0,155 \mathrm{EXP}$ & + & $\varepsilon_{\mathrm{CUS}}$ \\
$\mathrm{SUS}$ & $=$ & $0,151 \mathrm{AQUI}-0,153 \mathrm{ASS}+0,135 \mathrm{EXP}$ & + & $\varepsilon_{\mathrm{SUS}}$ \\
$\mathrm{PRO}$ & $=$ & $0,139 \mathrm{EXP}$ & + & $\varepsilon_{\mathrm{PRO}}$ \\
$\mathrm{ABE}$ & $=$ & $-0,131 \mathrm{ASS}+0,136 \mathrm{TRA}+0,205 \mathrm{EXP}$ & + & $\varepsilon_{\mathrm{ABE}}$ \\
\hline
\end{tabular}

Fonte: Dados da pesquisa com base em Hair Jr., Gabriel e Patel (2014).

\section{CONSIDERAÇÕES FINAIS}

Neste estudo, o objetivo foi explorar a associação entre as dimensões dos construtos CAI e IF em estudantes de pós-graduação. Identificou-se, por meio das análises de correlação, que a Inovação 
Aberta é a dimensão mais explicada pelas dimensões da CAI, que possui mais associações significativas para as dimensões de

CAI. A análise de equações de mínimos quadrados demonstrou que há a dimensão exploração da CAI possui as ligações mias fortes e significativas com todas as dimensões da Inovação Frugal, aceitando todas as hipóteses propostas no modelo referente a associação entre as dimensões EXP com OI, OS, OP e OC.

Na prática, a globalização conforme Zahra e George (2002) é um dos principais motores da inovação aberta (OI), dessa forma, as organizações com parceiros externos são mais ativas em gerar inovação. Sendo assim, no presente estudo capacidade de assimilação, transformação e exploração dos estudantes pode influenciar o desenvolvimento em busca de inovação aberta em 0,09\%, sendo a ligação mais forte descoberta nesse estudo.

Corroborando com outros estudos, é possível afirmar que os estudantes de pós-graduação incorporam o conhecimento adquirido, assimilado e transformado em suas operações e rotinas diárias para a aplicação em produtos, serviços ou processos que estejam relacionados com a inovação aberta e sustentável, de produto e em custo, onde se observou a maior ligação com inovação aberta, com um $T=3,428$, com 0,205 graus.

Para uma visão geral dos caminhos sólidos (significativos) e pontilhados (insignificantes). A dimensão exploração forma um caminho sólido, ou seja, significativo com as 4 dimensões da inovação frugal) inovação aberta, sustentável, de produto e em custo, conforme apresentado na figura 3. Destaca-se que a dimensão, exploração, engloba habilidades de usar de forma eficaz o conhecimento para criar algo novo, conforme pontuam os autores Flatten et al., (2011), Zahra e George (2002) e Yildiz et al. (2019).

Corrobora também com autores que salientam que a exploração depende do uso e implementação do conhecimento, por exemplo, criando assim, competências essenciais para intensificar o conhecimento (COHEN; LEVINTHAL, 1990; LANE et

al., 2006; PREXL, 2020).

As tentativas individuais de assimilar o conhecimento externo permitem a exploração, mas esses esforços requerem a abertura, o compromisso e a motivação para reconhecer o valor do conhecimento para transferi-lo para a base de conhecimento corporativa, e transformá-lo em processos internos ou explorá-lo em novos produtos (PREXL, 2020). 
Nesse sentido, a dimensão transformação forma um caminho sólido e significativo com a Inovação aberta, enquanto a dimensão assimilação forma um caminho sólido e significativo com a inovação aberta e a inovação em custo, corroborando com as descobertas dos estudos de Prexl et al. (2020), corroborando com apontamentos dos autores, quando concluem que tentativas individuais de assimilar o conhecimento externo permitem a exploração, mas esses esforços requerem a abertura, o compromisso e a motivação para reconhecer o valor do conhecimento.

Já a dimensão aquisição forma um caminho sólido e significativo somente com a inovação sustentável. Com isso, conclui-se que as os estudantes de pós-graduação possuem capacidade de exploração de conhecimento ligada de forma direta e positiva com a inovação frugal, ou seja, com suas dimensões: inovação aberta, sustentável, de produtos e em custos. Assim, nessa população analisada a exploração do conhecimento é presente nas práticas diárias dos estudantes, ou seja, explorando em suas pesquisas, na gestão de organizações na qual são proprietários ou colaboradores, ou ainda, em sala de aula, desempenhando o papel de docente. Esta capacidade pode dar origem à criação de produtos frugais, ou melhoria de um produto, serviço, sistema ou processo, com características frugais.

Ainda, o modelo CAI-IF demonstrou ter boas propriedades psicométricas com estudantes de pósgraduação, no entanto, um estudo com indivíduos de nacionalidade, idade e formações diferentes, é importante para confirmar a generalização das escalas CAI-IF.

Diversos trabalhos mostram que a pós-graduação stricto sensu é responsável pelo crescimento da produção científica no Brasil nos últimos 45 anos. Sob essa perspectiva espera-se dos cursos de pósgraduação melhores professores, especialistas e pesquisadores, ou seja, um retorno para a sociedade através da continuidade e melhoria do conhecimento científico, devido aos investimentos de alta qualidade feitos para este tipo de formação (FREITAS; SOUZA, 2018). Os autores defendem que esse conhecimento produzido nos cursos de pós-graduação elenca de forma significativa o coletivo social e econômica.

Conforme Freitas e Souza (2018) a Pós-Graduação stricto sensu no Brasil no campo das ciências humanas e sociais vem se fortalecendo cada vez mais, através da atualização e divulgação do conhecimento, comprometidos com a realidade do país e a produção de conhecimentos nacionais socialmente relevantes. Nesse contexto, ressaltasse a importância de estudos relevantes e atuais pelos cursos de pós-graduação e sua participação em desenvolvimento de P\&D que segundo Cohen et al. (2002) auniversidade contribui com suas pesquisas em diversos setores e tem desempenho decisivo no fomento da inovação em algumas indústrias. 
A capacidade absortiva invividual (CAI) é considerada um dos principais determinantes da criação e do compartilhamento de conhecimento dentro das organizações. A capacidade absortiva se refere ao potencial para adquirir, assimilar, transformar e aplicar conhecimentos ou informações obtidos (EASTERBY-SMITH, 2008).

Os resultados da pesquisa mostraram associação entre as dimensões da capacidade absortiva de conhecimento (CAI) no modelo proposto com capacidade de aquisição como variável exógena e independente se relacionando de forma direta e positiva com as três variáveis endógenas e dependentes (capacidade de assimilação, capacidade de transformação e capacidade de exploração). No estudo de Inovação frugal e suas dimensões: evidências no contexto acadêmico com base na literatura que norteou o delineamento desta pesquisa, a partir dos estudos de quatro autores (ABULRUB; LEE, 2012; CHEN, 2008; AFONSO et al., 2008; GUNDAY et al., 2011), os resultados apresentados trouxeram luz às inferências e aos pressupostos levantados neste estudo e o problema de pesquisa proposto foi respondido, concluindo-se que a IA (Inovação aberta) influência direta e positivamente a inovação sustentável, a inovação de produtos e a inovação em custo, estimando-se que a variação de uma unidade IA implique a variação de $12 \%$ em inovação de produto; a variação de uma unidade inovação aberta implique a variação de $35 \%$ em inovação em custos e a variação de uma unidade em inovação aberta implique a variação de 68\% em inovação sustentável.

Após apresentados os resultados do modelo estrutural e o teste de hipóteses do modelo proposto, confirma-se as quatro relações testadas $(\mathrm{H} 1, \mathrm{H} 2, \mathrm{H} 3, \mathrm{H} 4, \mathrm{H} 5$ e H6). As seis hipóteses são suportadas para o modelo. Todas as hipóteses são significativas para $p<0,05$. Embora somente com base nos dados não seja validar as hipóteses, os modelos de regressão utilizados no presente estudo comprovam através do coeficiente de determinação R2 o grau em que cada uma das variáveis explica o modelo proposto, ou seja, o quanto cada variável contribui para a validação do modelo proposto.

As hipóteses em termos gerais foram validadas, contudo, em uma análise mais profunda percebe-se que o efeito com maior grau de influência é da inovação aberta sobre a inovação sustentável em 68 graus, seguido pela inovação de produtos influenciada de forma direta e positiva pela inovação em custos com 60 graus e ainda em destaque a inovação em custo que é influenciada de forma direta e positiva pela inovação sustentável em 53 graus.

Os resultados deste trabalho empírico podem ser usados por outros investigadores para explorar e testar relações causais das inovações que compõem a inovação frugal em outras populações, ou replicar esse estudo em demais universidades. 
Quanto ao significado e limitações aponta-se o seguinte significado teórico: em primeiro lugar, escolhemos a inovação aberta como uma variável exógena e independente para estudar seu efeito sobre as demais inovações propostas pelo modelo de Silva e Itiel (2018) como antecedentes da inovação frugal.

É uma nova perspectiva de pesquisas sobre a relação da inovação aberta na perspectiva de inovação frugal; em segundo lugar, este estudo confirma que a inovação aberta tem relação mais significativa, direta e positiva com a inovação sustentável em $68 \%$ e a variável dependente e endógena que melhor explica o modelo é a inovação de produtos em $78 \%$. A inovação aberta em diversos estudos tem sido apontada como uma forma eficaz de inovação, e este estudo aceita todas as hipóteses propostas, comprovando a eficácia do modelo proposto.

Os achados corroboram com os autores Enkel \& Sebaux (2014) que afirmam que a estratégia de inovação de uma empresa é caracterizada pelas noções de exploração que resultam que resultam em inovações radicais. Em suma, o estudo descobriu nos estudantes de pós-graduação que a capacidade absortiva individual exploração tem relação direta e positiva sobre todas as dimensões da inovação frugal: inovação aberta, inovação sustentável, inovação de produtos e inovação em custos.

Já, os esforços de capacidade absortiva individual em assimilar o conhecimento externo podem ser denominados como uma encruzilhada entre a capacidade de exploração e a inovação exploradora (TORTORIELLO, 2015). Nesse quesito no presente estudo os estudantes de pós-graduação tem ligação direta e positiva da capacidade de assimilação com a inovação aberta, sustentável e em custo. A OECD (2018) contribui salientando que em um padrão sistêmico e integrado, o conhecimento e a informação tornam-se protagonistas do ciclo de desenvolvimento econômico e na formação de poder e da riqueza das empresas, regiões e nações como estratégia, voltada a vantagem competitiva.

Neste sentido, o modelo estudado, reflete como os estudantes de pós-graduação da UFSM, absorvem o conhecimento e o exploram, ou seja, já colocam em prática. Em vista disso, confirma-se a validação das escalas de CAI e IF para o contexto de estudantes de pós-graduação. Busca-se com esse estudo, inserir a temática na discussão em estudos de Ciências Sociais, em espaços de pesquisa. 


\section{REFERÊNCIAS}

AFONSO, P.; NUNES, M.; PAISANA, A.; BRAGA, A. The influence of time-to-market and target costing in the new product development success. International Journal of Production Economics, v. 115, p. 559-568, 2008.

AGARWAL, N.; BREM, A. The Frugal Innovation Case of Solar-powered Automated Teller Machines (ATMs) of Vortex Engineering in India. Journal of Entrepreneurship and Innovation in Emerging Economies, v.3, n.2, p. 115-126, 2017.

ALBURUB, A. G.; LEE, J. Open innovation management: challenges and prospects. Procedia - Social andBehavioral Sciences, v. 41, p. 130-138, 2012.

ALMULHIM, A. F. O papel das fontes internas e externas de conhecimento sobre a inovação frugal: papel moderador das capacidades de inovação. International Journal of Innovation Science. vol. à frente da impressão, no à frente da impressão. https:

//doi- org.ez47.periodicos.capes.gov.br/10.1108/IJIS-09-2020-0130, 2021.

ATKINSON, R. C.; BLANPIED, W. A. Universidades de pesquisa: núcleo do sistema de ciência e tecnologia dos EUA.Technology in Society, vol. 30n @1, pp.30-48, 2008.

BARROS, J. D`A. A elaboração textual de hipóteses - uma contribuição ao seu exclarecimento no ensino de metodologia. Revista Educação em Questão, Natal, v. 33, n. 19, p. 305-328, 2008.

BRASIL, M. Lei de Diretrizes e Bases da Educação Nacional, no 9394/96, Pub. L. No. 9394/96, 1996.

BHARDWAJ, S. S. - Service quality in Indian higher education: a comparative study of selected state owned and private universities\|, Indian Journal of Marketing, v. 45, n. 4, p. 32-42, 2015.

BRESCIANI, S. A. T. Intenção empreendedora em inovação frugal: validação da Escala EIF. 2020, 287 f.

Tese (doutorado) - Universidade Federal de Santa Maria, Centro de Ciências Sociais e Humanas, Programa de Pós-Graduação em Administração, RS, 2020.

BOGERS , M. , FOSS , N. J.; LYNGSIE , J. The -human side\|l of open innovation: The role of employee diversity in firm-level openness. Research Policy, v. 47, n. 1, p. 218- 231, 2018.

BOUCHERY, Y. Including sustainability criteria into inventory models European.Journal of operational research, vol.22, p.229 -240, 2012.

CAMISÓN, C.; FORÉS, B. Knowledge absorptive capacity: new insights for its conceptualization and measurement.Journal of Business Research, v. 63, n. 7, p. 707- 715, 2010.

CHEN, Y. S. The Drivers of green innovation and green image: green core competence.Journal of Business Ethics, Charlottesville, v. 81, n. 3, p. 531-543, 2008.

CHEN, Y. S.; LAI, S. B.; WEN, S. T. The influence of green innovation performance on corporate advantage in Taiwan.Journal of Business Ethics, v. 67, p. 331-339, 2006. 
CHEN, Y. S.; LIN, M. J. J.; CHANG, C. H. The positive effects of relationship learning and absorptive capacity on innovation performance and competitive advantage in industrial markets. Industrial Marketing Management, v. 38, n. 2, p. 152-158, 2009.

CHIN, W. W. Issues and opinion on structural equation modeling. MIS Quarterly, v. 22, n. 1, p. 716,1998 .

$\mathrm{CHIOU}, \mathrm{Tzu}-Y u n$ et al. The influence of greening the suppliers and green innovation on environmental performance and competitive advantage in Taiwan. Transportation Research Part E: Logistics and

Transportation Review, v. 47, n. 6, p. 822-836, 2011.

COHEN, J. Statistical Power Analysis for the Behavioral Sciences. 2. ed. New York: Psychology Press, 1988.

COHEN, W. M.; LEVINTHAL, D. A. Innovation and Learning: the two faces of R\&D.The Economic Journal, v. 99, p. 569-596, 1989.

. Capacidade de absorção: uma nova perspectiva sobre aprendizagem e inovação. Administrative Science Quarterly, v. 35, n 1, p. 128-152, 1990.

CROSSAN, M. M.; APAYDIN, M. A multi- dimensional framework of organizational innovation:A systematic review of the literature. Journal of Management Studies, v. 47, n. 6, p. 1154-1191,2010.

DA SILVA, E. R.; D‘ARRIGO, F. P.; FURLAN, J.; GANZER, P. P. ; OLEA, P. M. ;LARENTIS, F.; DORION, E. C. H.; NODARI, C. H.; RADAELLI, A. A. P.; PRODANOV, C.C. Capacidade Absortiva Individual: Uma Perspectiva com Alunos de Administração. Revista Espacios, v. 37, n. 1, 2016.

DOST, M.; PAHI, MH; MAGSI, HB; UMRANI, WA. -Effects of knowledge sources on frugal innovation: moderating role of environmental turbulencell, Journal of Knowledge Management, vol. 23No.7, p.1245- 1259, 2019.

DUH, M. Toward more operational dynamic capabilities concept: possible contribution of the dynamic enterprise construct. International Journal of Business and Management, v. 8, n. 9, p. 24, 2013.

EASTERBY-SMITH; M.; GRAÇA, M.; ANTONACOPOULOU, E.; FERDINAND, J. Absorptive Capacity: A Process Perspective. Management Learning, v. 39, n. 5, p. 483-501, 2008.

ECONOMIST, T. The Power of Disrupt: Business Innovations from Emerging Markets Will Change the Rich World Too. The Eonomist, v. 395, p. 16-18, 2010.

ELIA, G.; MARGHERITA, A.; PETTI, C. An operational model to develop technology entrepreneurship

EGO-system, International Journal of Innovation and Technology Management, v. 13 n. 5, p. 164-182, 2016.

ENGEL, K.; SEBAUX, E. Capturing the Power of Frugal Innovation. A.T. Kearney, 2014.

ESCRIBANO, A.; FOSFURI, A.; TRIBÓ, J.A. Managing external knowledge flows: the moderating role of absorptive capacity. Research Policy, v. 38, n. 1, p. 96-105, 2009. 
FLATTEN, T. C.; ENGELEN, A.; ZAHRA, S. A.; BRETTEL, M. A measure of absorptive capacity: Scale development and validation. European Management Journal, v. 29, p. 98-116, 2011.

FORNELL, C.; LARCKER, D. F. Evaluating structural equation models with unobservable variables and measurement error. Journal of Marketing Research. v. 18, n. 1, p. 39-50, 1981.

FREITAS, H.; OLIVEIRA, M.; SACCOL, A. Z.; MOSCAROLA, J. O método dapesquisa Survey. Revista de Administração, São Paulo v. 35, n.3, p. 105- 112, 2000.

FREITAS, M. F. Q. de; SOUZA, J. Pensar a formação e a pesquisa na pós-graduação. Educar em Revista, v. 34, n. 71, p. 9-18, set/out. 2018.

FUCHS, J. P. S., ROSSETTO, C. R.; CARVALHO, C. E. A influência da capacidade absortiva realizada no desempenho da PME Vitivinícola. Empreendedorismo e Inovação, v. 14, n. 37, p. 144- 167, 2016.

GIL, A. Métodos e técnicas de pesquisa social. 5. ed. São Paulo: Atlas, 1999.

GOVINDARAJAN, V.; TRIMBLE, C. Reverse Innovation - Is It In Your Strategic plan? Ontario: Leadership Excellence, 2012.

GUNDAY, G.; ULUSOY, G.; KILIC, K.; ALPKAN, L. Effects of innovation types on firm performance. International Journal of Production Economics, v. 133, p. 662- 676, 2011.

HAIR Jr. J. F.; BLACK, W. C.; BABIN, B. J.; ANDERSON, R. E.; TATHAM, R. L.Análise Multivariada de Dados. 6. ed. Porto Alegre: Bookman, 2009.

HAIR Jr., J. F.; GABRIEL, M. L. D. S.; PATEL, V. K. Modelagem de Equações Estruturais Baseada em Covariância (CB-SEM) com o AMOS: Orientações sobre a sua aplicação como uma Ferramenta de Pesquisa de Marketing. Revista Brasileira de Marketing, v. 13, n. 2, p. 44-55, 2014.

HAIR Jr.; J. F.; HULT, G. T. M.; RINGLE, C.; SARSTEDT, M. A primer on partialleast squares structural equation modeling (PLS-SEM). Los Angeles: Sage publications; 2017.

HARO-DOMINGUEZ, M. C.; ARIAS-ARANDA, D.; LLORENS-MONTES, F. J.;RUIZ-MORENO, A. The impact of absorptive capacity on technological acquisitions engineering consulting companies. Technovation, v. 27, p. 417-425, 2007.

HOOKER, H.; ACHUR, J. First Findings from the UK Innovation Survey 2013. UK Department for Business Innovation and Skills. London, UK, 2014.

HOSSAIN, M.; SIMULA, H.; HALME, M. Can Frugal go global? Diffusion patterns of frugal innovations. Technology in Society, v. 46, p. 132-139, 2016.

HOSSAIN, M. Frugal innovation: a review and research agenda. Journal of Cleaner Production, v. 182, 2018.

JIMÉNEZ, D. J.; COSTA, M. M.; VALLE, R. S. Knowledge management practices for innovation: a multinational corporation's perspective. Journal of Knowledge Management, v. 18, n. 5, p. 905-918, 2014. 
KIM, W. C.; MAUBOURGNE, R. Procedural justice, strategic decision, and the knowledge economy. Strategic Management Journal, v. 19, n. 4, p. 323-338, 1998.

KHORASANIZADEH, H.; HONARPOUR, A.; PARK, M. S. A.; PARKKINEN, J.;PARTHIBA, R.Adoption factors of cleaner production technology in a developing country: energy efficient lighting in Malaysia. Journal of Cleaner Production. v. 131, p. 97-106, 2016.

KUNAMANENI, S. Challenges in Moving from Incremental to Radical Low-Cost Innovation in Emerging and Transition Countries. International Journal of Innovation Management, v. 23, n. 3, p. 1-36, 2018.

KHAN, R. How frugal innovation Promotes Social Sustainability. Sustainability, v. 8, n. 1034, p. 1-29, 2016.

KUTNER, M.; NETER, J.; NACJTSHEIM, C. ;WASSERMAN , W. Applied linear statistical models. Journal Of The Royal Statistical Society Series A General, v.1, n.1, 2004.

LANE, P. J.; KOKA, B. R.; PATHAK, S. The reification of absorptive capacity: A critical review and rejuvenation of the construct. Academy of Management Review. v. 31, n. 4, p. 833- 863, 2006.

LATOUCHE, Serge. Degrowth. Journal of Cleaner Production, 6(18), pp. 519-522, 2010.

LEE, S. C., LIANG, H., \& LIU, C. Y. The effects of absorptive capacity, knowledge sourcing strategy, and alliance forms on firm performance. The Service Industries Journal, v. 30, p. 2421-2440, 2010.

LEYDESDORFF, L.; ETZKOWITZ, H. The Triple Helix as a model for innovation studies. Science and Public Policy, v. 25, n. 3, p. 195-203, 1996.

LI, Y.; ARORA, S.; YOUTIE, J.; SHAPIRA, P. Using web mining to explore Triple Helix influences on growth in small and mid-size firms. Technovatin, In press, 2016.

MACHADO, R. E. Influência do capital humano na capacidade absortiva e na inovação. Porto Alegre, 124f. Tese (Doutorado em Administração) - Universidade Federal do Rio Grande do Sul, 2014.

MANUAL DE OSLO. Diretrizes para Coleta e Interpretação de Dados sobre Inovação. Produção: ARTIIFINEP. Tradução: Flávia Gouveia. 3 ed., 2018.

MIOCEVIC, D.; MORGAN, R.E. Operational capabilities and entrepreneurial opportunities in emerging market firms: explaining exporting SME growth. International Marketing Review, v. 35, n. 2, 2018.

MORTAZAVI, S., LAINE, I.; QUARHIE, A.; VAATANEN, J.; GUPTA, S.

Multinational company and inclusive innovation at the base of the pyramid: a systematic review of the literature. International Business and Emerging Economy Companies, Palgrave Macmillan, Cham, p.1947, 2020.

MOUSTAGHFIR, K.; SCHIUMA, G. Knowledge, learning, and innovation: research and perspectives. Journal of Knowledge Management, v. 17, n. 4, p. 495 - 510, 2013.

MURTIC, S.; OLACA, R.; KOLESKA, I.; KARIC, L.; TODOROVIC, V. Response of cherry tomato seedlings to liquid fertiliser application under water stress. Horticultural Science, Prague, v. 45, n. 1, p. 22-28, 2018. 
OECD. Latin American Economic Outlook 2011: How middle-class is latin America? 2010.

OLIVEIRA, J.; MORAES, K. Produção do conhecimento na universidade pública no brasil: tensões, tendências e desafios. Educação em Revista. Belo Horizonte, v. 32, n. 4, 2016.

O'SHEA, R. P.; ALLEN, T. J.; CHEVALIER, A.; ROCHE, F. Entrepreneurialorientation, technology transfer and spinoff performance of US universities. Research policy, Amsterdam, v. 34, n. 7, p. 994-1009, 2005.

PRABHU, J. Frugal innovation: doing more with less for more, Philosophical Transactions of the Royal Society A, v. 375, n. 2095, p. 375, 2017.

PREXL, K. M.; HUBERT, M.; HUBERT, M.; GONERA, A. Exploring the individual: an empirical investigation of interrelationships between dimensions of absorptive capacity. International Journal of Innovation Management, 2020.

QUANDT, C. O.; BEZERRA, C. A.; FERRARESI, A. A. Dimensions of organizational innovativeness and its impact on innovation performance: proposition and evaluation of a model. Gestão \& Produção, v. 22, n. 4, p. 873-886, 2015.

RADJOU, N.; PRABHU, J. 4 CEOs Who Are Making Frugal Innovation Work. Harvard Business Review, v. 28, p. 1-6, 2014.

RAO, B. C. Advances in science and technology through frugality. IEEE Engineering Management Review, v. 45, n. 1, p. 32-38, 2017.

RAMÃO, G. B. Utilização de informações patentárias na busca de soluções inovadoras para o setor de atendimento hospitalar de emergência. São Paulo, 2017, 100f. Dissertação (Mestrado Profissional em Administração) - Universidade Nove de Julho, 2017.

RINGLE, C. M.; SILVA, D.; BIDO, D. S. Modelagem de equações estruturais utilização do SmartPLS. REMark - Revista Brasileira de Marketing, v. 13, n. 2, p. 56-73, 2014.

RINGLE, C. M.; WENDE, S.; BECKER, J. M. SmartPLS 3. Bönningstedt: SmartPLS, 2015.

ROSSETTO, D. E. Frugal Innovation: a proposal of an instrument to measurement.Tese. ESPM, 2018.

RUMANTI, A. A.; SUNARYO, I.; WIRATMADJA, I. I.; IRIANTO, D. Cleaner production through open innovation in Indonesian batik small and medium enterprises (SME). The TQM Journal , Prelo, 2020.

SAXENA, S. Dialogue between the formal and the informal sector in open innovations at the grassroots' level. Humanomics: The International Journal of Systems and Ethics, v. 31, n. 1, p. 104-117, 2015.

SILVA, I. M. Capacidades Organizacionais para a Inovação Frugal. São Paulo, 2018, 166 f. Tese (Doutorado em Administração) - Universidade de São Paulo, 2018.

SILVA, S. B. S. Inovação frugal à luz dos princípios da Jugaad: Estudo de múltiplos casos em MPEs. São Cristovão, 2018, 163f. Dissertação (Mestrado em Administração) - Universidade Federal de Sergipe, 2018.

SCHUMPETER, J. A. A Teoria do Desenvolvimento Econômico: Uma Investigação sobre Lucros, Capital, Crédito, Juros e o Ciclo de Negócios, Transaction Publishers, Cambridge, 1934. 
SCHUMPETER, J. A. Teoria do desenvolvimento econômico: uma investigação sobre lucros, capital, crédito, juro e o ciclo econômico. Abril Cultural, 1982.

SCHMIDT, T. Absorptive capacity - one size fits all? A firm-level analysis of absorptive capacity for different kinds of knowledge. Managerial and Decision Economics, v. 31, n. 1, p. 1- 18, 2010.

SIMULA, H.; HOSSAIN, M.; HALME, M. Frugal and reverse innovations - Quo Vadis? Current Science, v. 109, n. 5, p. 1567-1572, 2015.

SONI, P.; KRISHNAN, R. T. Frugal innovation: alignin theory, pratice and public policy. Jornal of Indian Business Research, v. 6, n. 1, p. 29-47, 2014.

SPITHOVEN, A., CLARYSSE, B., KNOCKAERT, M. Building absorptive capacity to organize inbound open innovation in traditional industries. Technovation, v. 30, p. 130- 141, 2010.

SULISTYO, H. S. Innovation capability of SMEs through entrepreneurship, marketing capability, relational capital and empowerment. Asia Pacific Management Review, v. 21, n. 4, p. 196-203, 2016.

TATUM, C. T. S. Modelo Frugal à geração de ativos em propriedade intelectual. 2020,194 f. Tese (doutorado) - Universidade Federal de Sergipe (PPGI/UFS), São Cristóvão, SE, 2020.

TEECE, D. J. Explicating dynamic capabilities: the nature and microfoundations of (sustainable) enterprise performance. Strategic Management Journal, v. 28, n. 13, p. 1319-1350, 2007.

TEECE, D. J. A dynamic capabilities-based entrepreneurial theory of the multinational enterprise. Journal of International Business Studies, v. 45, n. 1, p. 8 37, 2014.

TEECE, D. J.; PISANO, G.; SHUEN, A. Firm capabilities, resources, and the concept of strategy. University of California, Berkeley: Center for Research in Management, p. 90-8, 1990.

TEECE, D. J.; PISANO, G.; SHUEN, A.. Dynamic capabilities and strategic management. Strategic Management Journal, v. 18, n. 7, p. 509-533, 1997.

TIWARI, R.; HERSTATT, C. India - A Lead Market for Frugal Innovations? Extending the Lead Market Theory to Emerging Economies. Hamburg: Institute for Technology and Innovation Management, 2012.

TORTORIELLO, M. The Social underpinnings of absorptive capacity: the moderating effects of structural holes on innovation generation based on external knowledge. Journal Strategic Management. v. 36, p. 586- 597, 2015.

VEGA-JURADO, J.; GUTIÉRREZ-GARCIA, A.; FERNÁNDES-DE-LÚCIO, I.Analying the determinants of firm's absorptive capacity: beyond R\&D. R\&D Management, v. 38, n. 4, p. 392-405, 2008.

WANG, W.; FENG, M.; LIU. F. Innovation with IS usage: individual absorptive capacity is a mediator. Industrial Management \& Data Systems, v. 144, n. 8, p. 1110-1130, 2014.

WEISS, M.; CATTANEO, C. Degrowth-Taking Stock and Reviewing an Emerging Academic Paradigm. Ecological Economics, v. 137, p. 220-230, 2017. 
WEYRAUCH, T.; HERSTATT, C. What is frugal innovation? Three defining criteria. Journal of Frugal Innovation, v. 2, n. 1, 2017.

YILDIZ, H. E, MURTIC, A., ZANDER, U. O que promove a capacidade de absorção de nível individual nas multinacionais? Uma Estrutura Ampliada de Motivação- Habilidade-Oportunidade. Management-vIntVer. v. 59, p. 93-129, 2019.

ZAHRA, S. A.; GEORGE, G. Absorptive capacity: A review, reconceptualization, and extension. Academy of Management Review. v. 27, n. 2, p. 185-203, 2002.

ZESCHKY, M.; WIDENMAYER, B.; GASSMANN, O. What is frugal innovation? In the European Academy of Management Proceedings, Valencia-ESP, 2014. 